\title{
The Political Economy of Foreign Aid
}

\author{
by \\ Martin Christoph Steinwand
}

Submitted in Partial Fulfillment

of the

Requirements for the Degree

Doctor of Philosophy

Supervised by

Professor Randall Stone

Department of Political Science

Arts, Sciences and Engineering

School of Arts and Sciences

\author{
University of Rochester \\ Rochester, New York
}


For Alexandra and Victor. 


\section{Curriculum Vitae}

The author was born in Stuttgart, Germany, on February 11, 1975. He attended Humboldt University Berlin from 1995 to 2002, and graduated with a Magister Artium degree in 2002. He attended Brandeis University from 2002 to 2004 and graduated with a Master of Arts degree in 2004. He came to the University of Rochester in 2004 and began graduate studies in Political Science. He received a W. Allen Wallis Fellowship in Political Economy in 2007. He pursued his research in international relations under the direction of Professor Randall Stone and received the Master of Arts degree from the University of Rochester in 2007. 


\section{Acknowledgements}

In the course of writing this dissertation I have incurred numerous debts of gratitude. The members of my committee, Randy Stone (chair), Hein Goe-

mans, and Tasos Kalandrakis, were most generous with their time, and were always ready to offer me thoughtful advice and engage in open-minded discussion. Other members of the faculty were equally helpful with their time and comments, including Mark Fey, Michael Peress, and Curtis Signorino. Special thanks go to my fellow graduate students for their good spirits, solidarity and friendship, in particular the members of my cohort, Daniel Gillion, Fabiana Machado, Navine Murshid, and Yoji Sekiya. I gratefully acknowledge financial support from the Department of Political Science and the W. Allen Wallis Institute of Political Economy. I thank my parents for all their support, financially and otherwise, that they have extended to me in a most gracious and unquestioning manner throughout my academic career. This dissertation would have been impossible without the unwavering and caring support of my wife, Alexandra Hennessy. I am deeply grateful to know her as a friend, colleague, and partner. Finally, I thank my son Victor for being an endless source of joy who rekindled my curiosity for the wonders of the world, political and otherwise. 


\begin{abstract}
This dissertation studies the relationship between foreign aid and civil war in developing countries, as well as collective action problems and coordination among donors in the provision of foreign aid. Chapter 1 presents a formal model that investigates a donor's decision how much bilateral aid to provide to a recipient government that is engaged in rent extraction, but needs to worry about popular opposition. The theoretical analysis demonstrates under which circumstances recipient governments are able to exploit donor preferences for political stability to extract higher rents, and how this increases the risk of political unrest. The statistical analysis produces evidence that higher levels of committed aid decrease the probability of civil war onset, while aid shortfalls increase the risk of conflict. Chapter 2 investigates under which conditions foreign aid is under-provided because of free-riding between donors. I develop a unified game-theoretic and statistical model that treats aid as going towards an impure public good. The statistical analysis provides evidence that donors are more likely to freeride on each others' contributions if recipient countries have lower budget deficits and better political institutions. The third chapter explores patterns of stable and long-lasting relationships between individual donors and recipient countries. I develop a theory that attributes lead donorship to strategic interactions between donors, as well as a new conceptual measure of lead donorship. The statistical analysis provides evidence that strategic interactions play an important role in giving rise to lead donorship.
\end{abstract}




\section{Contents}

1 Foreign Aid Shortfalls and Civil War Onset in Developing

$\begin{array}{ll}\text { Countries } & 1\end{array}$

1.1 Introduction . . . . . . . . . . . . . . . 1

1.2 Aid and Conflict in the Literature . . . . . . . . . . . 4

1.3 A Model of Aid and Civil War Onset . . . . . . . . . . . 9

1.3.1 Sequence of Moves . . . . . . . . . . . . . . 9

1.3 .2 Utilities . . . . . . . . . . . . . . . . 11

1.3.3 Equilibrium Play and Empirical Predictions . . . . . . 14

1.4 Empirical Analysis . . . . . . . . . . . . . . 25

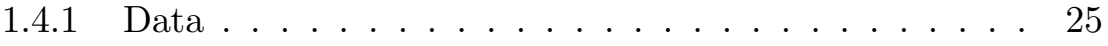

1.4 .2 Results . . . . . . . . . . . . . 27

1.5 Zaire 1977: The Historic Example of 'Shaba I' . . . . . . . . . 37

1.6 Conclusion . . . . . . . . . . . . . . . . . . 40

2 Free-Riding, Recipient Country Properties and The Provision of Foreign Aid $\quad 43$

2.1 Introduction . . . . . . . . . . . . . . . 43 
2.2 Collective Action Problems and Development Aid . . . . . . 48

2.2.1 Theoretical Considerations . . . . . . . . . . 48

2.2.2 Spatial Statistical Methods . . . . . . . . . 56

2.3 A Formal and Statistical Model of Impure Public Goods Provision . . . . . . . . . . . . . . . . 59

2.4 Empirical Analysis . . . . . . . . . . . . . . . . 65

2.4 .1 Data ......................... 65

2.4 Results ................... 68

2.5 Conclusion . . . . . . . . . . . . . . . 80

3 Lead Donorship: Patterns, Preferences, and Competition 82

3.1 Introduction . . . . . . . . . . . . . . . . 82

3.2 Theory. . . . . . . . . . . . . . . . . 85

3.2.1 A Theory of Lead Donorship . . . . . . . . . . . 89

3.2.2 Motivations for Giving Aid . . . . . . . . . . 92

3.2.3 Operationalizing Donor Preferences . . . . . . . . 96

3.3 Empirical Analysis . . . . . . . . . . . . . . . . . . . 101

3.3.1 Patterns of Lead Donorship . . . . . . . . . . . 101

3.3.2 Statistical Setup . . . . . . . . . . . . . 111

3.3.3 Data . . . . . . . . . . . . . . . 118

3.3.4 Results ..................... 125

3.4 Conclusion . . . . . . . . . . . . . . . . . . . 139

$\begin{array}{lr}\text { Bibliography } & 142\end{array}$ 
Appendix to Chapter $1 \ldots \ldots \ldots$. . . . . . . . . 156

Appendix to Chapter $3 \ldots \ldots$. . . . . . . . . . . . 162 


\section{List of Tables}

1.1 Equilibrium Characteristics . . . . . . . . . . . . . . . 14

1.2 Descriptive Statistics . . . . . . . . . . . . . . 28

1.3 Event-History Analysis of Conflict Onset . . . . . . . . . . . 30

2.1 Aid Committed to Individual Countries, US Included, Identical Connectivity Weights . . . . . . . . . 70

2.2 Aid Committed to Individual Countries, no US, Identical Connectivity Weights . . . . . . . . . . 71

2.3 Aid Committed to Individual Countries, US Included, PeriodSpecific Connectivity Weights . . . . . . . . . . 72

2.4 Aid Committed to Individual Countries, no US, Period-Specific Connectivity Weights . . . . . . . . . . . . 73

3.1 Largest Donor, $\geq 50 \%$ of Time . . . . . . . . . . . 103

3.2 Largest or Second Largest Donor, $\geq 50 \%$ of Time . . . . . . 106

3.3 Recipient Countries with Eight or More Different Top Contributors . . . . . . . . . . . . . . . 109

3.4 Remaining Countries with $\leq 7$ Top Contributors . . . . . . 110 
3.5 Aid Channeled Through Government Agencies . . . . . . . 121

3.6 Lead Donorship \& Committed Allocation . . . . . . . . . . . 126

3.7 Effect on Probability of Lead Donor . . . . . . . . . . . 130

3.8 Lead Donorship, Accuracy of Prediction . . . . . . . . . . . 131

3.9 List of CRS Codes, Private Good Aid . . . . . . . . . . 162 


\section{List of Figures}

1.1 Sequence of Moves . . . . . . . . . . . . . . . . . . . 10

1.2 Equilibrium Taxation, Mean Valuation Stability, Fighting Costs 17

1.3 Equilibrium Aid Shortfall . . . . . . . . . . . . . . . . 20

1.4 Probability of Conflict . . . . . . . . . . . . . . 21

1.5 Aid Shortfall and Probability of Conflict . . . . . . . . . . . 22

1.6 Cost of Fighting and Probability of Conflict . . . . . . . . . . 24

1.7 Probability of Conflict, Aid Shortfall, Moderate Tax Rates . . 32

1.8 Probability of Conflict, Aid Shortfall, Extreme Tax Rates . . 34

1.9 Committed Aid, Aid Shortfalls . . . . . . . . . . . . 36

1.10 Probability of Conflict, Effects of Aid . . . . . . . . 37

2.1 Free-Riding Loss, Macroeconomic Policy . . . . . . . . . . . . 77

2.2 Free-Riding Loss, Institutional Quality . . . . . . . . . . . . 79

3.1 Oil Imports, Lead Donorship . . . . . . . . . . . . . . 128

3.2 Exports from Donor, Lead Donorship . . . . . . . . . . . 129 


\section{Chapter 1}

\section{Foreign Aid Shortfalls and Civil War Onset in Developing Countries}

\section{$1.1 \quad$ Introduction}

International aid plays a crucial role in the economy and political lives of very poor recipient nations. ${ }^{1}$ At the same time, we have strong reasons to believe that civil conflict and war in those countries have economic roots. Cross-regional quantitative studies show economic development reduces the likelihood of conflict (Collier and Hoeffler, 1998; Fearon and Laitin, 2003) and furthers the chances of democratic stability (Przeworski et al., 2000). Accounts of rebel activity in conflicts that center around the extraction and

\footnotetext{
${ }^{1}$ To illustrate the severity of aid dependency, consider the substantial portion that aid contributed to the gross national income of big sub-Saharan countries such as Nigeria $(7.4 \%)$, and Ghana $(10.6 \%)$ in 2005 . In very poor countries and those with recent internal conflict this contribution can reach up to one third of GNI. Examples include the Democratic Republic of Congo and Guinea-Bissau (OECD DAC, 2007a).
} 
smuggling of diamonds (Libera, Sierra Leone) or illicit drugs (Columbia, Afghanistan) also suggest the importance of economic incentives (Collier and Hoeffler, 2000).

Given these connections between aid and economics on one hand, and economics and civil war on the other, it comes as a surprise that existing works fail to establish a robust empirical relationship between aid and civil war onset. I argue that this null-finding is spurious, and results from incorrectly specifying the theoretical relationship between aid and civil war.

In section 3 of this chapter I develop a formal model that predicts that large shortfalls in aid increase the risk of civil war. The theory takes at its starting point the empirical observation that aid disbursements are notoriously hard to predict. Donors frequently distribute less than they have committed to give. While recipient governments try to internalize this uncertainty, sometimes disbursements will be lower than expected.

In order to understand the effects of aid shortfalls, we need to make assumptions about why donors provide aid and how it is used by recipient governments. Taking a pessimistic standpoint, I will assume donors give aid not because they care about development but because they seek to maintain political stability. Historically, motives for this behavior have been the need for reliable allies in the Cold War, as well as hedging against migratory pressures that can result from civil war.

Governments in poor countries are often narrowly self-interested in rent seeking. This seems particularly true for sub-Saharan Africa. In such a political environment, aid is either misappropriated outright or employed to further other rent extraction possibilities. Rent extraction causes grievances, 
and makes it more desirable for potential rebels to wrest territorial control from the government. Political stability rests on a mixture of government suppression and relief of the humanitarian consequences of misrule. International aid supports both policies. Since it is fungible, even aid specifically designed to relieve human suffering frees government resources for the use of force.

Donors prefer aid recipient governments to refrain from destabilizing rent extraction, but they are unable to commit to withholding aid once destabilization occurs. After the fact, they rather pay the bill for providing stability than see civil war break out. Donors thus face a 'Samaritan's Dilemma' in which they effectively subsidize the rent extraction schemes of recipient governments. Rebellion results from unexpected shortfalls in aid, which leaves the government with insufficient means to suppress the unrest caused by its extraction policies.

In the remainder of the chapter, I first discuss why existing works fail to provide a viable theoretical mechanism to connect aid and civil war onset. I then present a formal model and derive testable hypotheses. Next, I discuss the data and operationalization issues and present empirical results. I then present a brief historic example illustrating the plausibility of the causal mechanism. The conclusion summarizes the theoretical and empirical findings, and discusses implications for public policy and future research. 


\subsection{Aid and Conflict in the Literature}

During the Cold War, political stability of recipient countries was a traditional part of diplomatic considerations driving decisions of international donors. With the end of the Cold War, endemic political instability in many developing countries has led donor governments to emphasize conflict prevention and post-conflict assistance. ${ }^{2}$ This went hand in hand with a recognition that civil war and political violence form major obstacles to economic development (Collier et al., 2003). Conflict prevention therefore squares well with a recently revived interest in targeting aid more effectively to support economic reform and growth. ${ }^{3}$

Unlike recent scholarly efforts to test the effectiveness of aid in furthering economic development (Burnside and Dollar, 2000), the role of aid in increasing political stability and preventing violent civil conflict has received little academic attention. This is an important shortcoming since aid plays a crucial role in the political lives of very poor recipient nations, and political instability and civil conflict in those countries are closely tied to economic factors.

What then is the connection between aid and civil strife? The literature identifies two main mechanisms. The first attributes rebellion and civil

\footnotetext{
${ }^{2}$ Hoebink and Stokke (2007) discuss policy changes, Lancaster (2000) analyzes discourse.

${ }^{3}$ This could explain why donors continue to support countries that serially violate political and personal freedoms such as Zimbabwe under President Mugabe. Britain as main donor increased its aid to Zimbabwe from $\$ 16.4$ million in 2000 , the starting year of the devastating violent expropriations of white farmers, to $\$ 67.8$ million in 2003 (OECD, 2008b, 2005 dollars). While the British government took pains to ensure this money went to alleviate the humanitarian consequences of the resulting economic crash, the policy arguably helped to keep economically motivated unrest in check that otherwise might have led to violent protests.
} 
war to the desire to capture the government's revenue stream that is often misused for private gain. Aid is an important part of this revenue stream. Thus aid makes rebellion more attractive (Grossman, 1991, 1992) and sustains non-democratic governments that rely on the threat of violence to stay in power (Bueno de Mesquita and Smith, 2007). Unfortunately, this perspective does not allow us to understand why suppressive measures fail to deter rebellion. It also ignores threats to political stability from within the political elite.

The reason for this explanatory deficiency is that aid makes being in office more attractive, but it ostensibly also supplies the means to ensure the grip on power. Why can't governments simply use some of the proceeds of foreign aid to suppress rebellion, or even to buy off potential rebels? In order to establish a causal connection between foreign aid and civil war onset, we need to understand why governments sometimes fail to implement suppressive measures and redistributive policies that are sufficient to deter rebellion.

Existing answers to this question remain incomplete. Acemoglu and Robinson (2005) extensively explore the problems non-democratic governments face in committing to long-lived distributional policies. Like Grossman, the authors assume domestic power struggles are essentially stochastic, and there is uncertainty about the relative military capabilities of rebels and the government (Grossman, 1999). Unfortunately, we learn little about the substantive sources of this uncertainty. In my theory, commitment is not at the center of interest. Instead I argue that uncertainty arises because recipient governments are not sure how much donors are willing to give to prevent the breakdown of political stability. 
The second mechanism in the literature that connects aid and political conflict assumes that rebels do not aim to overthrow the government. Instead, their intention is to exert territorial control over easily exploitable sources of revenue such as diamond mines or narcotic crops (Collier and Hoeffler, 1998; Collier, 2001; Collier et al., 2004). In this context, aid serves to increase the costs of rebellion. Aid frees up government resources that can be channeled into the military. With increased government fighting power, rebellion becomes a more costly business proposition. Without doubt, this argument aptly characterizes the political economy of a number of longrunning conflicts with entrenched insurgent groups that finance themselves through illicit drug (e.g. Columbia, Peru) or diamond trade (e.g. Angola, Sierra Leone).

But this theory also fails to explain conflict onset. From the perspective of military efficiency, it should be easier to suppress rebellion when it forms than to dislodge rebels from a piece of territory they control. The loss of territorial control also implies the government loses income. Again the issue is one of efficiency. Why did the government not use the revenue to police unrest or quiet potential rebels through redistribution?

In summary, both rent-extraction and war-as-business-model explanations fall short of identifying viable causal mechanisms through which aid affects civil war onset. It is therefore not surprising that existing empirical tests that build on these theories don't produce evidence for a causal relationship between foreign aid and the onset of civil war. For example, Collier and Hoeffler (2002) show that levels of aid do not have a direct effect on the probability of civil war when controlling for other economic and demo- 
graphic variables. ${ }^{4}$ Arcand and Chauvet (2001) reproduce this non-finding with a variety of additional control variables. ${ }^{5}$

I follow the theoretical outlook of Collier and Hoeffler, and conceptualize civil war as a contest for the exploitation of a geographically bound economic resource. Unlike those authors, I argue that by itself this approach does not imply anything about the geographic scale of the conflict. Some resources, such as raw diamonds, might only exist in small areas and can be exploited under local political control. Others require substantive infrastructure investments or encompass most or all of the agricultural base of the economy. Examples include oil production in Nigeria and cocoa farming in Côte d'Ivoire. By their nature, contestation for these resources involves a struggle for government power.

I disagree with Grossman's claim that rebels seek government power to benefit from aid. While this represents a theoretically feasible causal mechanism, to account for such wealth effects would unnecessarily distract from the study of how aid influences struggles for domestic resources. In reality, victorious rebel movements seldom gain control over past aid revenue that was embezzled by the disposed government. Often times, these funds are already in a numbered account outside the country. In addition, the donor

\footnotetext{
${ }^{4}$ The authors claim that aid has an indirect effect of decreasing conflict through fostering growth. However, they fail to establish the existence of this effect empirically.

${ }^{5}$ The authors find slightly improved coefficient estimates when they include residuals from a first stage prediction of aid levels as independent variables. This measure of unexplained variation in aid provision seems to increase the likelihood of conflict, while the effect of aid levels remains inconclusive (a first order and a square term of the variable have opposite signs). However, all estimates remain below commonly accepted levels of statistical significance, and the use of residuals can lead to biased inferences (Clarke and Stone, forthcoming 2008). On the theoretical front, they improve on Grossman (1999) by asserting that aid introduces uncertainty about the value of office holding.
} 
community frequently punishes successful rebels by withholding aid. This is particularly true after uprisings lead by the military. Both observations suggests that rebels don't stand to gain from aid payments in the short run.

My theory adds to the literature on civil war a fundamental insight from the bargaining theory of international war. War is costly, thus it needs to be explained in terms of bargaining inefficiencies (Fearon, 1995). These inefficiencies arise because the conflicting parties are incapable of finding a peaceful division of the issues at stake, though both would benefit from avoiding the costs of fighting. Similar to Arcand and Chauvet (2001), I argue that foreign aid is a critical source of such inefficiencies. In particular, I argue that unexpected shortfalls of aid adversely affect the government's ability to both uphold its deterrence posture regarding potential challenges to its territorial control, and maintain redistributive policies aimed at preventing unrest. $^{6}$ Furthermore, aid can unexpectedly fall short because recipient governments are not sure how much donors are willing to give to ensure political stability. This assumption is plausible for two reasons. First, donors have incentives to misrepresent how much they value stability in order to avoid moral hazard on part of the recipient government. Second, governments in developing countries typically don't have the intelligence gathering capacity to procure this information independently.

In the next section I will present my theory in detail. For the sake of theoretical clarity, I present the argument in the form of a formal model.

\footnotetext{
${ }^{6}$ In contrast, Arcand and Chauvet adopt Grossman's framework of civil war and attribute aid with introducing uncertainty to the value of holding office.
} 


\subsection{A Model of Aid and Civil War Onset}

The game has four players, nature $N$, the donor $D$, the government $G$, and a rebel group $R$. Since I am interested in bilateral aid, the donor is a state and not a multilateral agency. I assume rebels face no collective action problem. In fact, the term rebels is just a convenient shorthand for the occupants of a territory from which the government extracts revenue if it maintains territorial control, and I will refer to rebels, population and occupants interchangeably. If the occupants choose to fight the government and win, they stand to keep the full revenue from the territory. The game is a sequential-move game with incomplete information.

\subsubsection{Sequence of Moves}

The sequence of play is represented in figure 1.1. Before the players get to move, nature draws the donor's payoff for stability in the recipient country, $\phi$, from a probability distribution with p.d.f. $f_{\phi}(\phi)$ and mean $E(\phi)=\mu$. The only restriction we need to put on $f_{\phi}(\phi)$ is that its support lies on the positive real numbers, $\operatorname{supp}\left(f_{\phi}(\phi)\right)=\mathbb{R}_{+}$. The shape of $f_{\phi}(\phi)$ is common knowledge, but the realization of $\phi$ is $D$ 's private information. In particular, the government does not know with certainty how much the donor values stability. ${ }^{7}$

The government moves next and chooses a marginal tax rate $t$. It does not collect taxes immediately, but only after it has ensured territorial control. Let's preview the strategic problem the government faces in choosing

\footnotetext{
${ }^{7}$ It is inconsequential if the rebels know $\phi$ since they condition their choice only on observed behavior of the other players.
} 
$t$. Higher taxes will make rebellion more attractive, as the population gains more by evading taxes if it successfully resists the government. To keep the peace, higher taxes thus need to be accompanied by more spending on deterring rebellion. I normalize the government revenue that is available prior to the collection of taxes to 0 . Any money spent on preventing rebellion therefore must be financed through international aid. ${ }^{8}$ Unfortunately the government is not certain how much aid the donor is willing to provide to ensure rebellion is averted.

Figure 1.1: Sequence of Moves

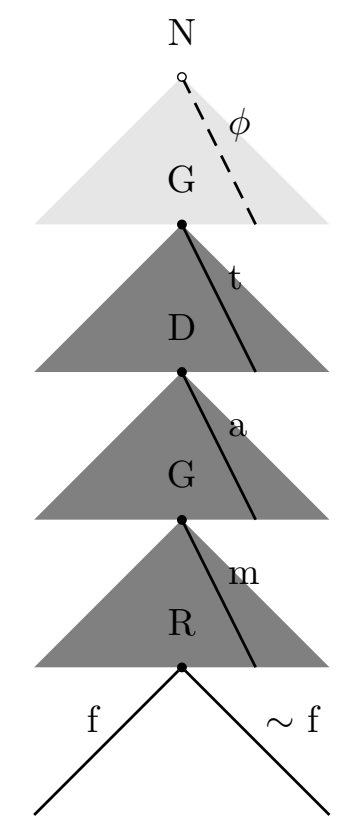

Next, the donor decides how much aid, $a$, to give and disburses the funds

\footnotetext{
${ }^{8}$ This normalization is without loss of generality.
} 
to the government. As discussed above, I assume that donors only consider whether aid helps to further political stability when making their decision. Consequently, I normalize all aid payments made for different reasons to 0 .

After the government receives aid (if any), it decides how much to spend on deterring rebellion, $m$. Finally, the rebels decide whether they are better off fighting the government, $f$, or not fighting and paying taxes for sure, $\sim f$. The game ends with the government collecting taxes if it maintains control of the territory. If the rebels fight and win, they receive the full revenue from the territory minus the costs of fighting.

\subsubsection{Utilities}

Payoffs are given by the following equations:

$$
\begin{aligned}
& U_{G}(t, m)= \begin{cases}{[1-p(m)] t+a-m} & \text { if } r=f, \\
t+a-m & \text { if } r=\sim f,\end{cases} \\
& U_{D}(a)= \begin{cases}-a & \text { if } r=f, \\
\phi-a & \text { if } r=\sim f,\end{cases} \\
& U_{R}(r)= \begin{cases}p(m)+(1-p(m))(1-t)-c & \text { if } r=f, \\
1-t & \text { if } r=\sim f .\end{cases}
\end{aligned}
$$

Consider the government's utility first. If the rebels don't fight, $G$ will receive income from taxes $t$. The value of the taxed product is normalized to $1 . G$ also keeps any received aid minus its deterrence expenditures. If 
the rebels fight the government can only ensure receiving $t$ if it successfully defeats the rebels. I model the outcome of the conflict as costly lottery. The probability of rebel victory $p(m)$ is a function of deterrence expenditure. The more the government spends on the military and humanitarian relief, the less likely the rebels are to prevail, though deterrence spending has decreasing returns in lowering $p(m)$. Expressed more formally, I assume that $p \in[0,1], p^{\prime}(m)<0, p^{\prime \prime}(m) \geq 0$.

The government's utility encapsulates the assumption that it can commit to tax rate $t$, and can't extract everything $(t=1)$ after it ensures territorial control. This assumption reflects the 'stickiness' of the institutions on which the government needs to rely for tax collection purposes. ${ }^{9}$ Poor countries that lack a formal bureaucracy build such institutions using patronage and ethnic networks (Kasara, 2007). Those institutional arrangements take time to build and cannot be changed instantaneously. Even where weak formal bureaucracies exist, they are ill-equipped to implement sudden policy changes.

Second, the donor values political stability, measured by parameter $\phi, \phi \geq$ 0 , and incurs costs from providing aid $a, a \geq 0$. It is obvious that the donor only wants to provide aid if the government can keep the rebels from fighting.

Third, the rebels need to weigh the utility of fighting against not fighting. If they don't fight, they receive income from the territory, normalized to 1 , minus taxes $t$. If they decide to fight, they will win full territorial control with probability $p(m)$. If they win, the population consumes the entire

\footnotetext{
${ }^{9}$ On a technical level, this assumption does away with the need to endogenously model commitment. Modeling commitment would typically require a dynamic setting, obstructing the analysis' focus on the role of incomplete information.
} 
revenue of 1 , minus the costs of fighting, $c$. If they lose, they have to pay taxes $t$, but still incur the costs of fighting $c$.

Before we can look at equilibrium behavior of the players, we need to define strategies. The solution concept we employ below to derive an equilibrium is Perfect Bayesian Equilibrium. Accordingly, a player's strategy is a complete plan of action for all possible paths of play, given her beliefs about payoffs. ${ }^{10}$

First, nature draws $\phi$ from the probability distribution described by $f_{\phi}(\phi)$ and $E(\phi)=\mu$, fixing the game. Recall that only the donor observes the drawing. The government $G$ moves twice. Its first strategy is $s_{G 1}$ : $\emptyset \longrightarrow T$. Note that the government makes its decision about how to set the tax rate based on its best guess regarding the true value of $\phi$. The donor $D$ faces no uncertainty. Its strategy is $s_{D}(t): T \longrightarrow A, A=\mathbb{R}_{+}$. In words, the donor conditions its decision how much aid to give on the tax rate $t$ set by the government. The government's second strategy depends on $D$ 's observable actions, i.e. how much aid it received, and its own choice of tax rate $t$. It therefore is $s_{G 2}(t, a): T \times A \longrightarrow M$. It is important to note that deterrence spending $m$ is constrained by the size of aid $a$, i.e. $M=[0, a]$. Finally, the rebels' strategy is $s_{R}(t, a, m): T \times A \times M \longrightarrow\{f, \sim f\}$. That is, the rebels decide whether to fight or not on the basis of the tax rate, the amount of aid provided to the government and how much the government spent on deterrence. With all constituent parts of the game in place, we can now characterize how the actors will behave in equilibrium.

\footnotetext{
${ }^{10}$ Since there is no information transmission in the game, we do not have to be concerned about information updating.
} 


\subsubsection{Equilibrium Play and Empirical Predictions}

The solution concept appropriate for this sequential move game with incomplete information is Perfect Bayesian Equilibrium. Since there is no signalling, the solution can be found through simple backwards induction. The game has a unique equilibrium. It is characterized by a vector of optimal strategies $\left(S_{G 1}^{*}, S_{D}^{*}, S_{G 2}^{*}, S_{R}^{*}\right)$ that yields optimal choices $\left(t^{*}, a^{*}, m^{*}, r^{*}\right)$. Table 1.1 summarizes equilibrium characteristics for all possible parameter configurations. $^{11}$

Table 1.1: Equilibrium Characteristics

\begin{tabular}{lll} 
& $\begin{array}{l}\text { Deterministic } \\
\text { Peace }\end{array}$ & $\begin{array}{l}\text { Probabilistic } \\
\text { Peace }\end{array}$ \\
\hline Government, $t:$ & $\underline{t}$ or 1 & $\hat{t}, \bar{t}$, or 1 \\
Donor, $a:$ & 0 & $\underline{m}(\hat{t}), \underline{m}(\bar{t})$, or $\underline{m}(1)$ \\
Government, $m:$ & 0 & $\underline{m}(\hat{t}), \underline{m}(\bar{t})$, or $\underline{\underline{m}}(1)$ \\
Rebels, $r:$ & $\sim f$ & $\sim f$ \\
\hline & Probabilistic & Deterministic \\
& War & War \\
\hline Government, $t$ & $\hat{t}, \bar{t}$, or 1 & 1 \\
Donor, $a:$ & 0 & 0 \\
Government, $m:$ & 0 & 0 \\
Rebels, $r:$ & $f$ & $f$
\end{tabular}

The table represents equilibrium strategies for all players, for each of the four possible paths of play. Since the equilibrium is unique, each path is only reached under different parameter configurations. In addition, the parameterization also determines which equilibrium strategy players choose

\footnotetext{
${ }^{11}$ I provide a proof of uniqueness and exhaustiveness of the equilibrium characteristics in the appendix.
} 
on a given path of play. To clarify notation, for the government $\hat{t}$ is the interior solution to its maximization problem. This is an equilibrium strategy for both paths of play leading to probabilistic war and peace. For other parameterizations of the game, the government plays $\bar{t}$ on these paths of play. This quantity represents the highest value for which the government can commit to use aid to suppress rebellion, instead of being tempted to keep the aid for consumption and risk civil war.

Quantity $\underline{m}$ represents the lowest amount of aid necessary to keep the peace, given the unrest caused by the government's extraction policy. Aid is only provided on the path of play leading to probabilistic peace.

Finally, $\underline{t}$ represents the highest tax rate that keeps the population indifferent from rebellion, if the government spends no money on deterrence. The quantity is one of the government's equilibrium strategies on the path of play leading to deterministic peace. For other parameterizations, $\underline{t}$ is greater than the natural upper bound of taxation, leading to an equilibrium strategy of 1 .

Let's first look at the two extreme cases, deterministic war and peace. In the deterministic war scenario, the rebels fight irrespective of the choices that other players make. The government therefore does not need to restrain itself, and sets the marginal tax rate as high as it can, i.e. $t^{*}=1$. The donor has no means to bring about stability, and therefore gives no aid. This in turn implies that the government has no money to spend on deterrence. This scenario is extreme and unrealistic. It also violates the widely held belief that political conflict is probabilistic in nature.

Deterministic war occurs only if the government stands to gain more 
from fighting with a small chance to gain control over the entire economic output, than setting a moderate tax rate that will keep the peace. This can only occur when the rebels' chances of winning are large relative to their costs of fighting; a scenario that arises when the government does not spend money on deterrence. ${ }^{12}$ However, this hypothetical case is not very plausible since intuition tells us that low costs of rebellion should be associated with a high probability of prevailing against the government. Figure 1.2 illustrates the limited range for which deterministic war occurs. The graph shows equilibrium play $t^{*}$ as a function of the donor's average valuation of stability $\mu$, and the population's cost of fighting $c$. The function that determines the probability of rebel victory is fixed as $p(m)=0.8 /(1+m) .{ }^{13}$ Deterministic war accounts for the discontinuous jump to $t^{*}=1$ for $c<1.6$.

It should be noted that for low values of $c$ the donor never provides aid to ensure stability, even if it highly values this outcome. This is because the government faces a moral hazard problem of its own. The costs of deterring rebellion are high when the rebels have low costs of fighting, which implies aid flows would have to be high as well. In this situation, the government cannot commit to spend the aid it receives on deterrence, since it would prefer to pocket the money and let the rebels fight. Foreseeing this, the donor does not give aid. We call the level of taxation that is sufficiently low relative to $c$ at which the government can credibly commit to spend aid on

\footnotetext{
${ }^{12}$ In technical terms, deterministic war only occurs if $\underline{t}<p(0)$, where $\underline{\mathrm{t}}=\mathrm{c} / \mathrm{p}(0)$, i.e. if $c<p(0)^{2}$.

${ }^{13}$ I also assume that $\phi \sim \Gamma(k, \mu / k)$, with $k=4$. Note that the equilibrium characterization does not depend on this functional form assumption nor on the assumption about $p(m)$.
} 
Figure 1.2: Equilibrium Taxation, Mean Valuation Stability, Fighting Costs

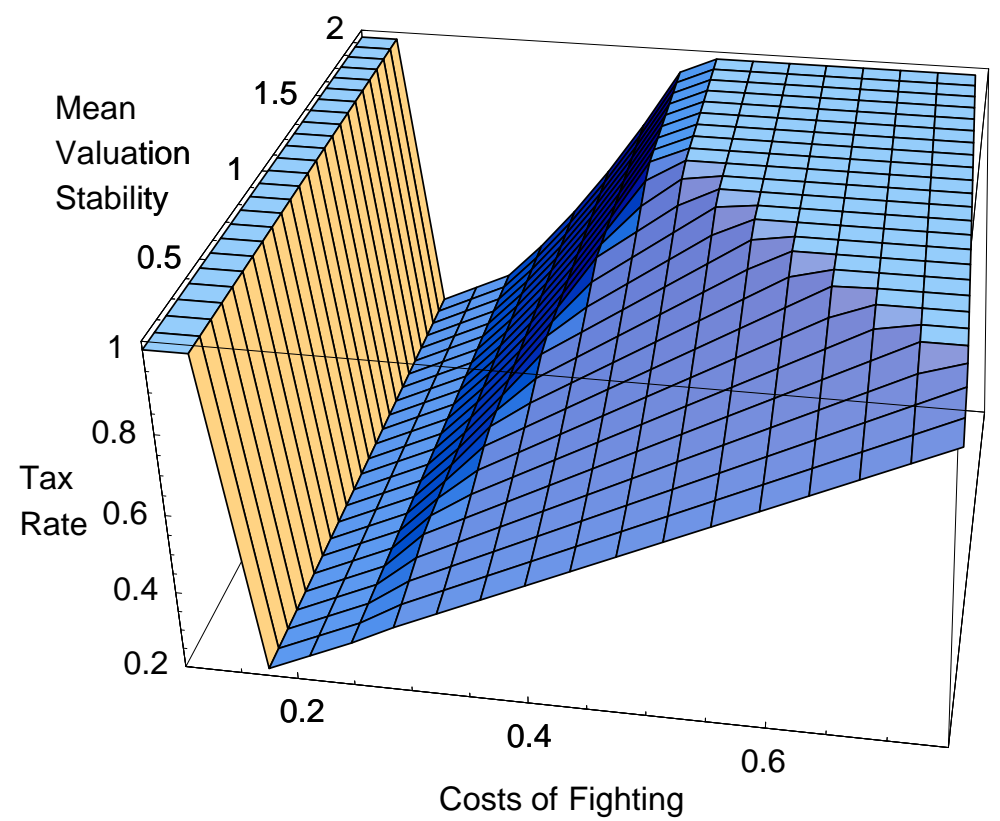

deterrence $\bar{t}$. It forms $G$ 's 'peace constraint'. ${ }^{14}$

Under deterministic peace conditions, the rebels always choose not to fight. Since peace always prevails the donor does not have to spend money on the preservation of stability, and accordingly gives no aid. Deterministic peace breaks further down into three scenarios. In the first, the government still faces some threat of rebellion and therefore can't fully extract the economic surplus. It sets the tax rate to an upper bound $\underline{t}<1$ that keeps the rebels from fighting. When the rebels face higher costs of fighting, $\underline{t}$ increases accordingly. We can see this relationship in figure 1.2 as straight

\footnotetext{
${ }^{14}$ The derivation of $\bar{t}$ can be found in the appendix.
} 
line. When holding the donor's average valuation of stability $\mu$ fixed at $0, t^{*}$ rises in linear fashion from 0.2 to 1 as the rebel's cost of fighting $c$ increase from 0.16 to 0.8 .

In the second scenario, deterministic peace occurs independent of the donor's valuation of stability. In the graph, this region forms a plane adjacent to the discontinuity associated with deterministic war and extends from $c \geq 1.6$ to about $c=2.5$. In this region, the rebels' costs of fighting are high enough to support a peaceful outcome. Yet, the government can't exploit the donor's preference for stability because tax rates that satisfy its peace constraint $\bar{t}$ are less than what it can charge without risking war, i.e. $\bar{t}<\underline{t}$.

Finally, in the third scenario deterministic peace results because the rebels' cost of fighting become prohibitively large. In this situation, the government can extract all economic surplus. Accordingly, it sets the tax rate to 1 , without fearing that such policies might create a political backlash. In figure 1.2 this region lies at values of $c \geq 0.8$.

Equilibrium behavior is more interesting for the middle range of values of rebels' cost of fighting $c$ that support probabilistic peace and war. Let us first look at the effects of the donor's preference for stability. As just discussed, if the donor does not care about stability $(\mu=0)$, the government is limited to extract just enough to keep the rebels from fighting (i.e. $\underline{t}$ ). This changes for greater values of $\mu$, with which the donor is increasingly likely to value stability. The government can exploit this desire for stability. Through the tax rate it controls indirectly how much it needs to spend on deterrence to keep the peace. When it maximizes its revenue, it needs to balance higher 
income through taxation against an increase in the risk that the donor is not sufficiently motivated to pick up the deterrence bill. The tax rate that solves this maximization problem is called $\hat{t}$. It increases monotonically with $\mu$ until it hits its natural bound 1 or the government's peace constraint $\bar{t}$. In figure 1.2, the area where equilibrium tax rates increase alongside $\mu$ is the triangle in the front right part of the graph. The boundary of the triangle that runs alongside the $c$ axis from $c=0.16$ to $c=0.8$ is the line on which peace is a deterministic outcome. The constraints $\bar{t}$ and 1 form the other two boundaries.

Of central interest is the relationship between aid and the associated probability of conflict. On a conceptual note, the probability of conflict is the probability that the donor's true valuation of stability $\phi$ is less than its cost of paying for peace, or more formally $\operatorname{Pr}\left(\phi<\underline{m}\left(t^{*}\right)\right) .{ }^{15}$ If the realization of $\phi$ in fact is less than $\underline{m}(t)$, the donor does not provide any aid. Otherwise, it provides $a^{*}=\underline{m}\left(t^{*}\right)$. Accordingly, the equilibrium aid level $a^{*}$ is equal to the shortfall in aid that the government faces if $\phi$ is too small.

Figures 1.3 and 1.4 show comparative statics for equilibrium aid levels $a^{*}$ and the probability of conflict. Unsurprisingly, equilibrium aid $a^{*}$ is 0 for the lower and upper ranges of rebels' cost of fighting $c$ where war and peace are deterministic. In the middle range of $c$, where the government exploits the donor's preference for stability, equilibrium aid $a^{*}$ increases monotonically with the donor's expected valuation of stability $\mu$ until the tax rate $t^{*}$ reaches either $\bar{t}$ or 1 . The probability of conflict follows a similar pattern. It increases

\footnotetext{
${ }^{15}$ The quantity $\underline{m}\left(t^{*}\right)$ is the amount of deterrence spending that keeps the rebels indifferent between fighting and peace. It is formally defined in the appendix.
} 
Figure 1.3: Equilibrium Aid Shortfall

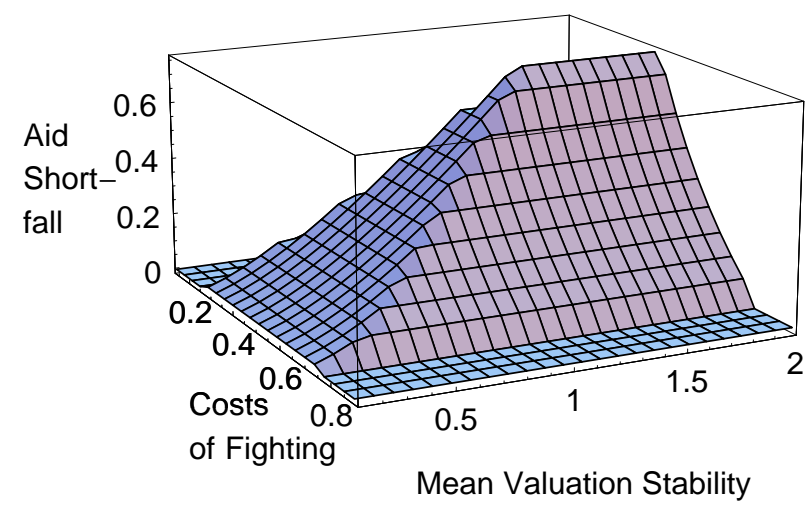

alongside equilibrium aid $a^{*}$ and tax rate $t^{*}$ as the donor's mean valuation of stability $\mu$ grows from 0 . In contrast to aid however, once $t^{*}$ attains either of its bounds the probability of conflict starts to decrease again. This happens because equilibrium aid $a^{*}$ does not grow beyond an upper bound that corresponds to the maximum feasible value of $t^{*}$. As the donor's expected valuation of aid grows while $a^{*}$ stays the same, it becomes less and less likely that the donor's true valuation of stability $\phi$ is less than $a^{*}$.

Up to the point where equilibrium aid $a^{*}$ hits its upper bound it shares a monotonic relationship with the probability of conflict. Figure 1.5 illustrates this point. For a large range of parameter values for which the equilibrium tax rate $t^{*}$ is in a middle range, the probability of conflict increases alongside equilibrium aid (we will discuss the role of $t^{*}$ in more detail below). Since equilibrium aid $a^{*}$ corresponds to the size of the shortfall in aid if the donor's valuation of stability $\phi$ is too small, the model predicts a monotonically increasing relationship between aid shortfalls and the probability of 
Figure 1.4: Probability of Conflict

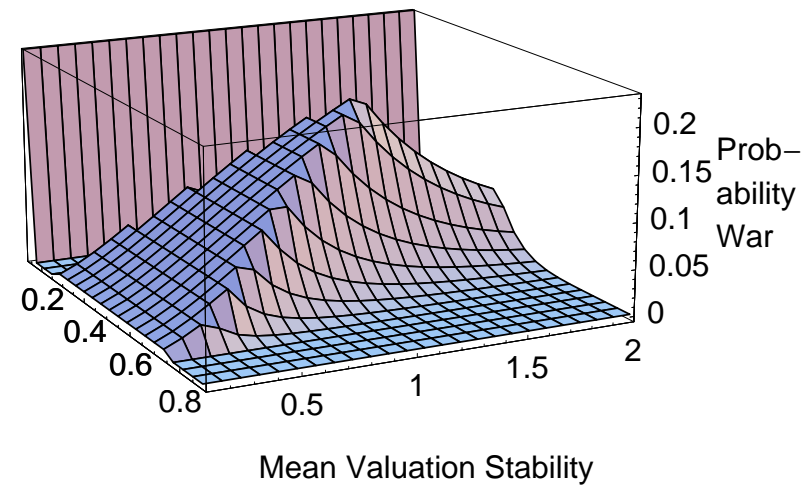

conflict. This leads to our first testable hypothesis:

Hypothesis 1 Greater aid shortfalls increase the probability of civil war in recipient countries.

As I will discuss in more detail in the next section, I use as empirical measure of aid shortfalls the difference between committed and disbursed aid. While the model predicts that in the case of conflict aid drops all the way to zero, this rarely happens in the real world. We can account for this discrepancy with the normalization to 0 in the model of all aid payments unrelated to the donor's desire for stability. This matches the observation in the real world that donors who try to punish recipient governments do not cut back on programs with direct humanitarian impact.

Another insight from the model is that the relationship between aid shortfalls and the probability of conflict heavily depends on location in the parameter space. While deterministic war and peace seem not to correspond to real political behavior, we cannot rely on theoretical arguments alone. 
Figure 1.5: Aid Shortfall and Probability of Conflict

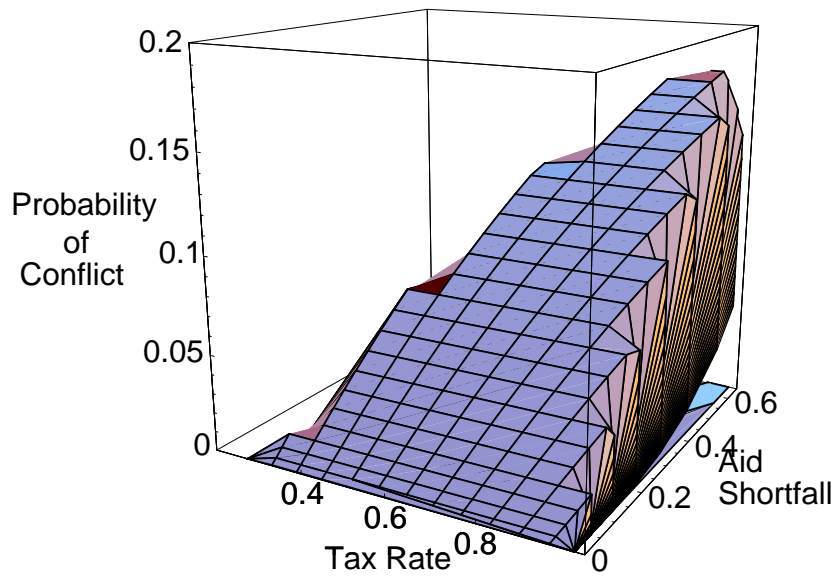

One possibility to handle this problem is to derive a statistical estimator directly from the structure of the game (see for example Signorino, 1999; Lewis and Schultz, 2003). This is difficult to implement in our setting, since all actors but one have continuous choice spaces, and finding covariates that measure donor preferences for stability is conceptually problematic.

I therefore deal with the problem in a different way. The model itself offers clear observable indicators of when we wander off into undesirable parts of the parameter space. Since we are interested in a test of the monotonic relationship between aid shortfalls and the probability of conflict, we need to rule out parts of the parameter space where this relationship does not hold. 
Returning to figure 1.5, we see that for parameter configuration associated with equilibrium tax rates close to 0 and 1 there is no relationship between aid shortfalls and the probability of conflict. The figure furthermore reveals that the positive monotonic relationship breaks down when aid shortfalls grow too big. The exact range of where the relationship holds is a function of the observed tax rate. This gives us our second testable hypothesis:

Hypothesis 2 The positive relationship between aid shortfalls and the probability of conflict onset is strongest for a middle range of observed tax rates, and breaks down for extreme tax rates.

In the statistical analysis, I use several empirical measures to determine what constitutes a middle range of tax rates which I describe in detail below.

Finally, we face the question what our model tells us about factors other than aid that affect the probability of civil war. Existing empirical studies on the causes of civil war have emphasized the role of geographic remoteness and GDP per capita (Fearon and Laitin, 2003), and ethnic fractionalization (Sambanis, 2001). In the context of our model, we can conceptualize all of these measures as affecting the costs of rebellion. Geographic remoteness directly bears on the ability of the government to project military force and lowers costs of rebellion. Higher GDP increases the opportunity costs the average individual faces when he or she fights, and makes rebellion more costly. Finally, ethnic fractionalization affects collective action costs, where small ethnic groups should find it easier to organize than large homogenous populations. What does our model reveal about the relationship between the costs of fighting and the probability of civil war? 
Figure 1.6: Cost of Fighting and Probability of Conflict

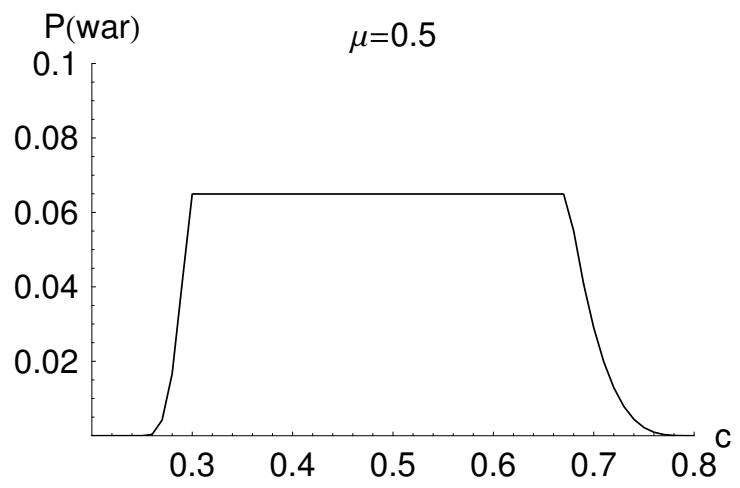

Figure 1.6 shows that this relationship is highly non-linear. Disregarding extreme values of taxation $t^{*}$ (which correspond to $c \lesssim 0.3$ and $c \gtrsim 0.68$ ) the relationship is actually flat. This is both good and bad news. On the positive side, we see that there is no need to condition our test for the effect of aid shortfalls on the probability of conflict onset further. The test already picks the middle range of $c$, and in this range $c$ does not by itself influence the probability of conflict onset. On the negative side, our theory does not agree with existing empirical findings. We follow common practice and include the respective variables into our statistical analysis as controls, but we do not have theoretically informed expectations about their effects.

To sum up, the formal analysis sheds light on the political economy of rent extraction, aid payments, and civil war onset. It shows that if the population's costs of fighting lie in a broad middle range, and the average donor weakly to moderately values stability, civil war occurs with positive probability. In this range, higher average donor valuations of stability lead 
to more rent extraction, more political unrest, more need for aid, and consequently to a higher risk of aid shortfalls and civil war. As a result, the relationship between the size of aid shortfalls and the probability of civil war is strictly monotonic and increasing. The model furthermore shows that this relationship should be strongest for a middle range of observed tax rates, and breaks down for extremely high or low tax rates. We now turn to the statistical analysis.

\subsection{Empirical Analysis}

\subsubsection{Data}

The statistical analysis uses data covering 28 sub-Saharan countries for the years 1972-1989. The time range of the data is largely determined by the availability of data on tax rates, as discussed in detail below.

The dependent variable is civil war onset. I am using an event-history setup with discrete time. This approach essentially models the time until an event of interest occurs. In our case, this is the onset of civil war. The setup requires that we discard observations with continuing war. This makes sense in the framework of our theory since the mechanism that leads to conflict initiation tells little about the course and length of actual fighting. The same argument informs my choice of the dependent variable, which I take from the Armed Conflict Dataset (ACD, Gleditsch et al., 2002). The ACD defines conflicts as years with a minimum of 25 deaths resulting from clashes between the government and an organized political group. This criterion is different from the 1000 battle deaths that the Correlates of War (COW) civil 
war dataset uses. The lower threshold captures most conflict initiations, and does not systematically select only cases that escalate so much that they produce a casualty count of 1000 .

The first main independent variable directly measures the level of rent extraction. It is the real marginal tax rate on cash crops. The measure captures the ratio between producer and world market prices, and adjusts this for marketing and transportation costs (Jaeger, 1992). This data seems uniquely suited to tap into a central mechanism of economic rent extraction for the largely agriculture based economies of sub-Saharan Africa. Unfortunately, its limited availability dictates the narrow time frame for the entire data set.

The second central independent variable captures unexpected aid shortfalls. I use the OECD's International Development Statistics (OECD DAC, 2007b) to calculate a three-year sliding mean of aggregate committed bilateral aid per capita in constant 2005 US dollars, and subtract disbursements in each year. The reason for this is that the OECD attributes aid commitments fully to the year in which they are made, even if the donor plans to disburse them over a number of years. Thus, even donors who fully follow up on their commitments might pledge more in some years than they disburse. The sliding mean smoothes out the effects of multi-year commitments. The three year time window is to some degree an arbitrary choice. Three years don't use up too much degrees of freedom (sliding means lead to loss of observations for the beginning years of the data) but provide meaningful smoothing. The estimation results presented below are not sensitive to longer sliding means. 
The analysis also includes control variables for GDP, mountain coverage and ethnic fractionalization. As discussed above, we don't have theoretically informed predictions about their effects. However, it is common practice to include variables that other studies have identified as relevant in the regression specification. I take all control variables from the seminal piece by Fearon and Laitin (2003). The next section reports estimation results.

\subsubsection{Results}

To obtain a sense of the data, consider the descriptive statistics in table 1.2. ${ }^{16}$ It shows means of all independent variables, broken down for observations with and without conflict onset. The average aid gap is about $\$ 4$ per capita larger for observations with conflict onset than for those without, as the theory leads us to expect. Aid commitments are on average higher for observations without conflict onset, but tax rates are surprisingly lower for those with conflict onset. Among the control variables, GDP per capita and ethnic fractionalization behave in accordance with existing empirical results. Conflict onset is associated with lower GDP and more ethnic fractionalization. Mountain cover is on average lower in conflict countries, contrary to what previous results tell us. We should not ascribe too much importance to these simple comparisons of means, but it is encouraging that the key variable behaves as expected.

The table also lists other characteristics of the data. The data comprise 514 observations and 20 episodes of conflict onset. As described in the previous section, the predicted relationship between aid shortfalls and conflict

\footnotetext{
${ }^{16}$ All time-varying independent variables are lagged by on year.
} 
Table 1.2: Descriptive Statistics

\begin{tabular}{lll} 
& Conflict Onset & \\
Independent Var. & no & yes \\
\hline Tax Rate, \% & 36.3 & 18.0 \\
Committed Aid, \$ p.c. & 43.7 & 35.6 \\
Aid Gap, \$ p.c. & 7.45 & 11.6 \\
GDP, \$ p.c. & 968 & 845 \\
Mountain cover, \% & 10.5 & 7.86 \\
Ethnic fract., \% & 68.7 & 73.5 \\
\hline n & 514 & \\
\# Conflict Onsets & 20 & \\
Mid Range Tax Rates & {$[12.4,70.2]$} & \\
\hline
\end{tabular}

onset only should be strongest for a middle range of observed tax rates, and break down for extreme tax rates. I account for this in two ways.

First, I calculate an interval of moderate tax rates based on the empirical dispersion of the tax variable. The interval encompasses all observations within the 5th and 95th percentile of the tax rate variable, corresponding to the values $[8.00 \%, 78.0 \%] .{ }^{17}$ This choice is somewhat arbitrary, but the estimation results are robust to other specification of the interval. The moderate tax range (MTR) dummy variable is coded to 1 for observations inside this range and 0 for those outside. In the statistical analysis, I interact this dummy with the aid shortfall variable, expecting that aid shortfalls only increase the probability of conflict for moderate tax rates.

Second, in another version of the statistical model I estimate a 2nd order polynomial of the tax rate variable (of the form $\beta_{1} t+\beta_{2} t^{2}$ ). I interact the

\footnotetext{
${ }^{17}$ For this calculation I ignore negative values of the tax rate variable. Negative real tax rates represent a government subsidy. Subsidies are outside the purview of the theoretical model.
} 
estimate of this polynomial with the aid shortfall variable. The expectations are that the polynomial takes the form of an inverted $\mathrm{u}$-shape, and that aid shortfalls have a stronger effect on the probability of civil war for middle ranges of this inverted $u$.

The results from the multivariate analysis are reported in table 1.3. The estimated models are discrete time event-history models with complementary log-log link function. ${ }^{18}$ The first model does not account for aid shortfalls. I call it 'naive' to mark the difference to the other versions, which incorporate the insights generated by the theoretical analysis.

Let us start with a brief look at the 'naive' model. Only taxation has a statistically significant influence on conflict. Higher tax rates reduce the likelihood of conflict onset. The control variables do not confirm to the empirical findings in the literature. However, the key insight of the model is that it reproduces the non-finding of previous studies since there is no relationship between aid levels and civil war onset. A likelihood ratio test suggests that the full model specification with tax polynomial better summarizes the data $(p=.0588) .{ }^{19}$

A first look at the full models shows that aid commitments have a pacifying effect that is statistical significant at low levels, in both specifications. We will discuss this interesting result in more detail below. The interaction terms has a positive sign in the moderate tax range model, and a negative

\footnotetext{
${ }^{18}$ While logit and probit link functions are more commonly used, the cloglog eventhistory model is the discrete time equivalent of the continuous time Cox proportional hazard model (Alt et al., 2001).

${ }^{19}$ Note that the naive model is not nested within the full model with MTR dummy. A likelihood ratio test is therefore not appropriate to compare the two models.
} 
Table 1.3: Event-History Analysis of Conflict Onset

\begin{tabular}{lllllll}
\hline & & & $\begin{array}{l}\text { moderate } \\
\text { tax range }\end{array}$ & \multicolumn{3}{c}{$\begin{array}{l}\text { tax } \\
\text { polynomial }\end{array}$} \\
\hline Aid Shortfall & & & 19.3 & $(46.5)$ & 46.4 & $(33.5)$ \\
Tax Rate & $-0.959^{* *}$ & $(0.475)$ & & & $-1.93^{* *}$ & $(0.872)$ \\
Tax Rate & & & & -0.842 & $(0.803)$ \\
$\left(b_{1}\right.$ Tax $\left.+b_{2} \operatorname{Tax}^{2}\right) *$ & & & & & -34.9 & $(23.6)$ \\
Aid Shortfall & & & & & & \\
MTR & & & $-1.61^{* *}$ & $(0.546)$ & & \\
MTR * Shortfall & & & 66.3 & $(45.6)$ & & \\
Committed Aid & -9.33 & $(10.7)$ & $-21.4^{*}$ & $(13.0)$ & $-22.8^{*}$ & $(13.6)$ \\
GDP p.c. & -0.872 & $(0.740)$ & -0.702 & $(0.672)$ & -1.03 & $(0.748)$ \\
Mountain Cover & -0.0188 & $(0.0179)$ & -0.00349 & $(0.019)$ & -0.0127 & $(0.0186)$ \\
Ethnic Frac. & -0.637 & $(1.08)$ & 0.0655 & $(1.08)$ & -0.357 & $(1.13)$ \\
\hline
\end{tabular}

${ }^{*} p \leq 0.1,{ }^{* *} p \leq 0.05$. Model with cloglog link. All independent variables lagged by one time period. Baseline hazard $t+t^{2}+t^{3}$ (Carter and Signorino, 2007) not reported. 
sign in the tax polynomial model. Both signs are as expected. ${ }^{20}$ However, we are dealing with a non-linear model. Since we are interested in the marginal effect of aid shortfalls, the coefficient estimates and standard errors for the variable and the interaction terms do not have a useful interpretation. We can gauge the direction, size and statistical significance of this effect from figure 1.7 .

The two graphs show predicted probabilities of conflict onset as function of aid shortfalls. The left graph is based on the moderate tax rate model, with medium tax range dummy set to 1 . The right graph uses the tax polynomial model, holding the tax rate at its mean (35.7\%). In both graphs, other variables are kept at their respective means, while the amount of committed aid is allowed to vary alongside the aid shortfall. The graphs therefore show the effect of a complete loss of committed aid. I vary the aid shortfall variable from 0 to its empirical mean $(\$ 7.59)$ plus one standard deviation (\$10.05). In addition, I set the time baseline to 15 years since the last conflict (or entry into the dataset through left-censoring) to ensure the prediction does not capture effects of frequently recurring conflicts. I show simulated $95 \%$ confidence bands based on the variance-covariance matrix of the statistical model. ${ }^{21}$.

Recall that hypothesis 1 predicts that the probability of conflict onset increases with the size of aid shortfalls. This hypothesis finds support in the data. Looking at the tax rate polynomial model, moving from no aid

\footnotetext{
${ }^{20}$ Since both coefficient estimates of the tax polynomial have negative signs, the interaction term has a positive effect.

${ }^{21}$ These are also known as Clarify type confidence bands, after the statistical software introduced by King et al. (2000). Clarify was not used in the analysis presented here. All estimations were performed in $\mathrm{R}$
} 
Figure 1.7: Probability of Conflict, Aid Shortfall, Moderate Tax Rates
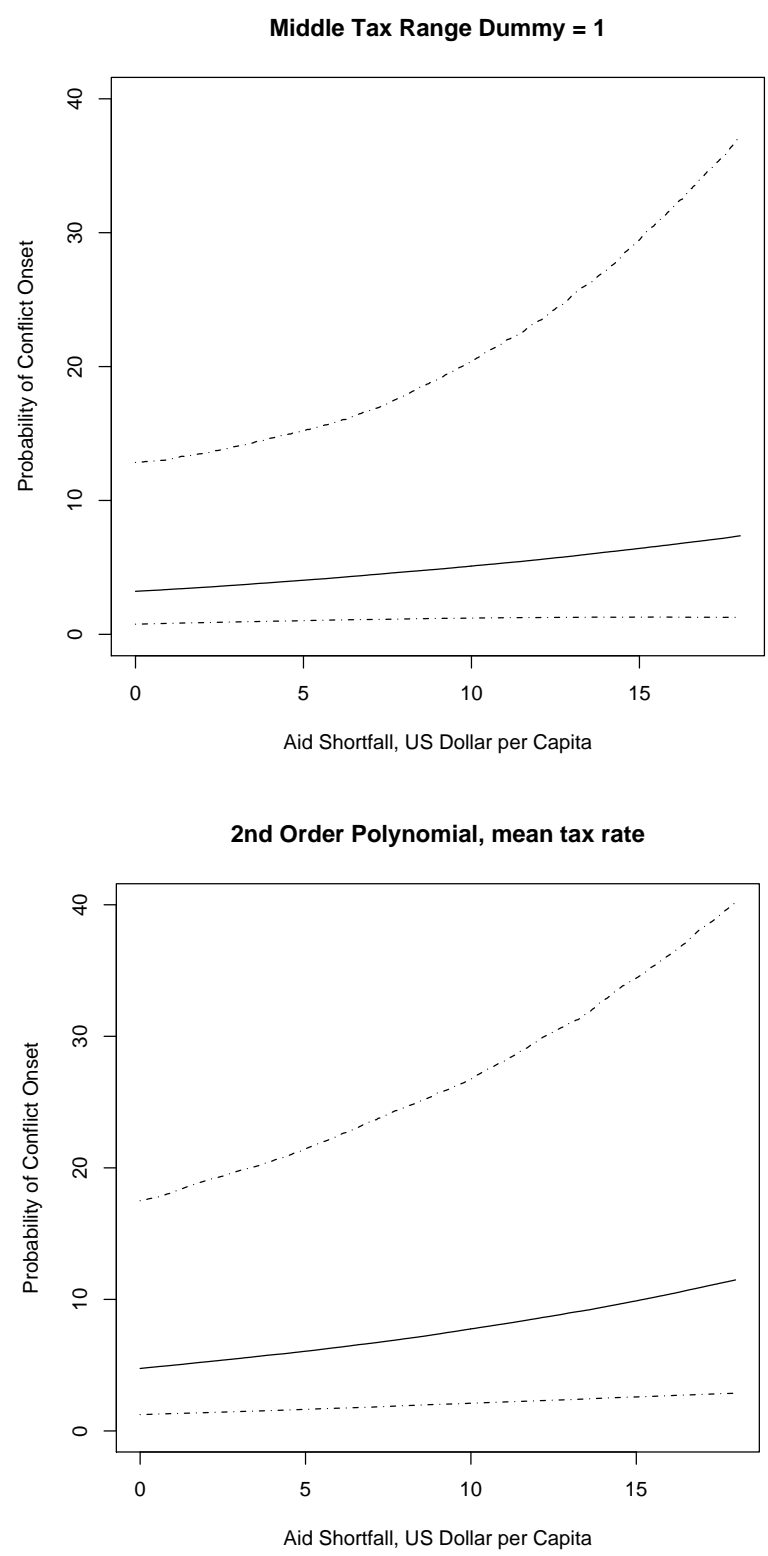
shortfall to its mean increases the probability of conflict onset from $4.7 \%$ to about $6.9 \%$. When we add one standard deviation we arrive at a probability of $11.2 \%$, adding up to a total increase in the likelihood of conflict onset of $6.5 \%$. Since civil war is a low likelihood event, these are substantively meaningful numbers. The effect size is somewhat attenuated in the moderate tax range model. In both models, the effect of aid shortfalls is statistical significant at the $0.05 \%$ level. The $95 \%$ confidence band stays about $1 \%$ above zero, and the upper and lower boundaries of the band increase throughout, more markedly so in the tax polynomial model. We therefore can reject the null hypothesis that the marginal effect of aid shortfalls on the probability of civil war onset is zero or negative.

Hypothesis 2 predicts that the positive relationship between aid shortfalls and the probability of civil war is strongest for a middle range of taxation, and breaks down for extreme tax rates. Consider figure 1.8 to evaluate this prediction. The left graph shows the relationship between aid shortfalls and the probability of conflict onset for the moderate tax range outside the middle tax range interval, i.e. for very high and very low tax rates. We not only find no positive relationship, but in fact increasing aid shortfalls are associated with a decreasing probability of conflict. This effect is statistically significant.

The graph on the right-hand side shows estimates for the tax polynomial model, setting the tax rate to the highest rate occurring in the data, $91 \%$. We still have a positive relationship between aid shortfalls and the probability of conflict onset. However, the effect size is reduced by half compared to its value at the mean tax rate. What is more, the effect is statistically not 
Figure 1.8: Probability of Conflict, Aid Shortfall, Extreme Tax Rates

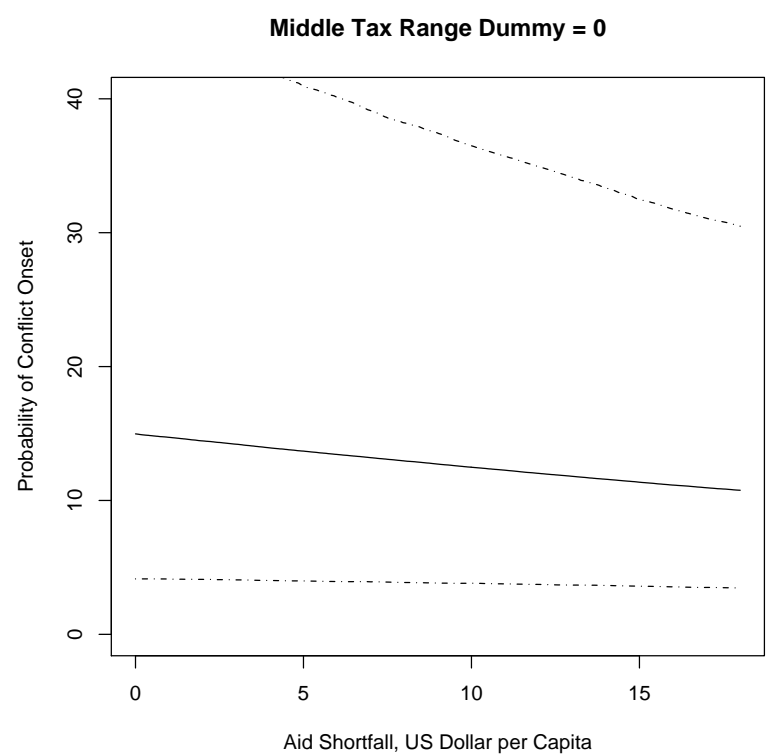

2nd Order Polynomial, tax rate $=91 \%$ (Guinea 1985)

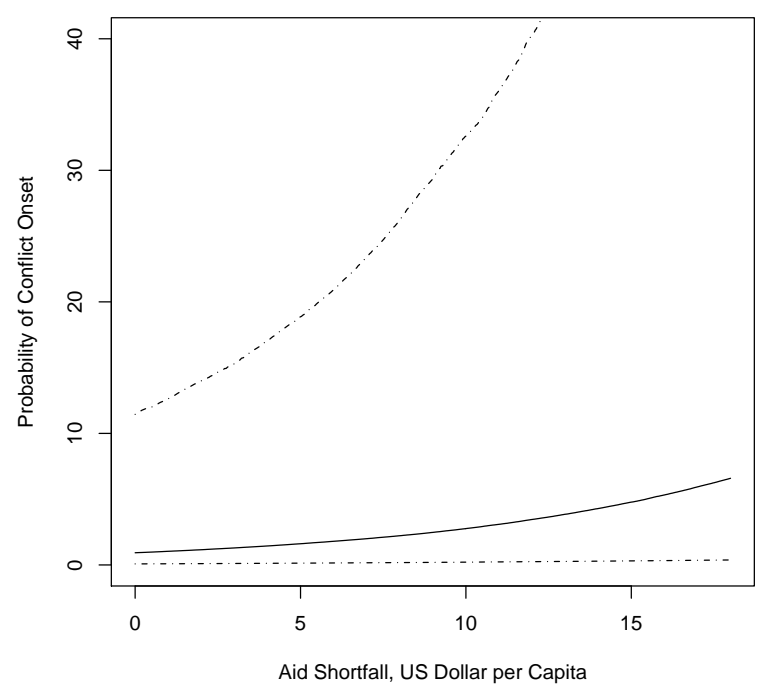


distinguishable from zero, as the lower confidence band is essentially flat. We therefore can conclude that hypothesis 2 finds support in the data.

Let us turn to the finding that increased aid levels reduce the probability of conflict onset once we control for the detrimental effects of aid shortfalls. This result raises the question what empirical relationship committed aid levels and shortfalls have in the data. If shortfalls increase with commitment levels, we have additional evidence that previous studies have failed to identify positive effects of aid because they omitted controls for shortfalls. A scatter plot shows a positive relationship between the two variables (figure 1.9). A simple bivariate regression indicates that each pledged dollar is associated with an additional shortfall of 11 cents. $^{22}$

This empirical association between commitments and shortfalls has important consequences for the probability of conflict. Consider figure 1.10. The solid line shows the baseline probability of conflict without any aid commitments or shortfalls, when holding all other variables at their respective means. If we now add the mean value of aid commitments, but keep shortfalls at zero, the probability of conflict drops dramatically by more than half (lower dashed line). Once we account for the predicted value of aid shortfalls, this gain is cut in half (upper dashed line). The predicted probability of civil war now stays within $2 \%$ of the baseline without aid effects. This proximity explains why previous statistical models were not able to identify the pacifying effect of aid commitments. Substantively, the finding demonstrates that donors' inability to stick to their promises on average erases half of the pacifying effects of aid.

\footnotetext{
${ }^{22}$ The intercept is 3.08 , the slope is 0.106 .
} 
Figure 1.9: Committed Aid, Aid Shortfalls

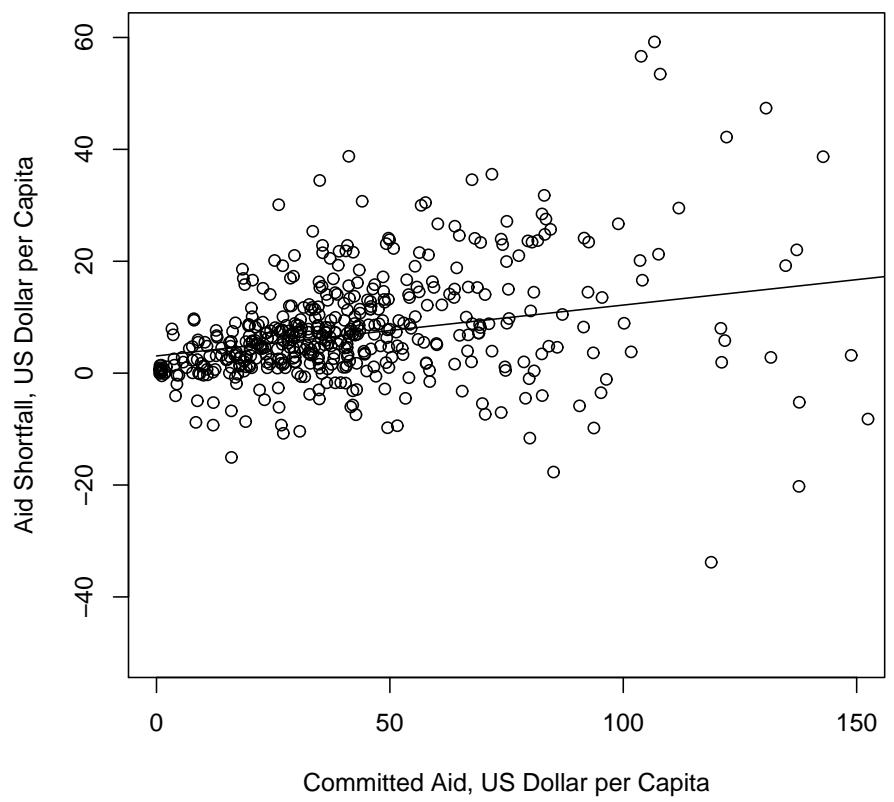

Overall, the statistical analysis provides strong evidence that aid shortfalls affect civil war onsets as our theory predicts. For a middle range of tax regimes, larger aid shortfalls increase the probability of conflict onset. Outside of this range they do not. As a corollary to this finding, we also uncovered that higher levels of aid have a pacifying effect. However, this effect is masked by the negative influence of shortfalls and only appears once we control for these. It remains to note that none of the control variables is statistically significant. In the next section, I present a brief case study. It is intended to probe whether the causal mechanism connecting aid shortfalls 
Figure 1.10: Probability of Conflict, Effects of Aid

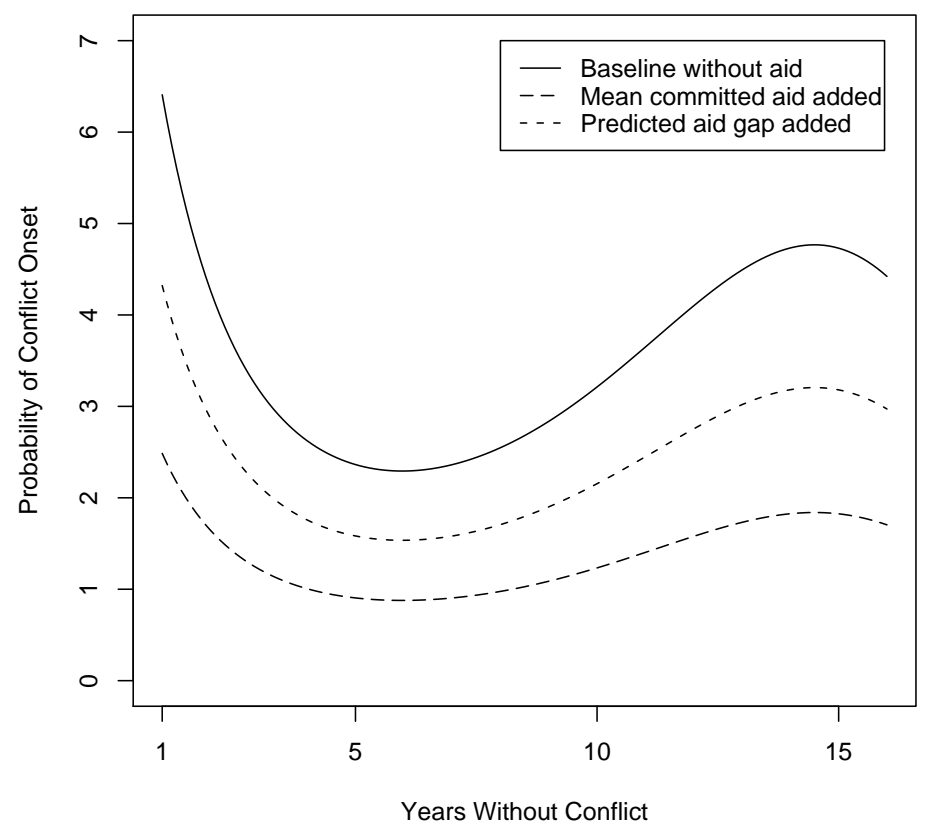

and civil war onset operates in the real world as theorized.

\subsection{Zaire 1977: The Historic Example of 'Shaba I'}

On March 8, 1977, 2000 fighters of the Front de la Libération Nationale Congolese (FLNC) invaded the mineral rich Shaba (Katanga) region in south-eastern Zaire from neighboring Angola. The FLNC fighters made fast inroads and quickly gained control of sizeable portions of the territory. The Zairian forces crumbled in the face of the onslaught, and only military 
supplies from the US, France, and Belgium, as well as pilots and 1500 combat troops from Egypt and Morocco saved the day for the Mobutu regime. After regaining control, Mobutu subjected Shaba's populations to reprisals that drove ten-thousands of refugees into neighboring Angola (Kelly, 1993).

This episode, known as 'Shaba I', raises a number of important questions about the role foreign aid played in the outbreak of hostilities. Mobutu's Zaire was one of the main beneficiaries of Western generosity in supplying African allies with foreign aid during the Cold War. In the 5 years preceding the raid, international bilateral donors pumped on average $\$ 420$ million per year (2005 prices) in official development aid (ODA) into Zaire (OECD DAC, 2007b). For obvious reasons, the numbers are less clear for military aid, but the amounts were substantive. Yet despite this generous support, the Zairian military failed to be a match for the FLNC rebels.

Why did the Mobutu regime not have the military capability to deter rebellion in the economically vital Shaba region? After all, the region had been a focal point of violence after Congo gained independence from Belgium. Mobutu himself crushed a secession attempt. Clearly, ensuring territorial integrity of Shaba must have been a high priority of the regime.

Another important question is why donors continued to provide millions to a government that had a hard earned reputation for embezzlement of state revenues. While donors without doubt were paying for political allegiance in the Cold War, their joint intervention after the rebellion indicates their concern for Zaire's stability. Why did all the millions not buy stability prior to the rebellion?

And finally, why did the rebels choose to attack when they did? After 
all, the West's support for Mobutu was not a secret. He was also reputed as a ruthless dictator. Together these factors should have made rebellion very unlikely to succeed, and thus deterred any attempts.

The example of Shaba I fits the theory laid out in the formal model well. Mobutu's ability to embezzle state-owned economic assets rested on the threat of military suppression of domestic unrest. Western donors, while possibly finding Mobutu's methods distasteful, ultimately were interested in maintaining domestic stability in a perceived key ally in the Cold War on the African continent. This explains why they were willing to foot the bill for keeping the regime in power.

The theory leads us to expect that conflict results from aid shortfalls that occur because the donor is insufficiently motivated to bear the costs of providing for stability. Indeed, the Shaba offensive occurred within 9 months after a severe shortfall in American funding. This funding cut resulted from the Tunney Amendment, which passed early in 1976, and was finalized in the Clark Amendment in June 1976. Though Congress had been briefed on the escalating clandestine CIA involvement in the Angolan civil war pursued by President Ford, its Democratic leadership abruptly distanced itself once this policy was revealed to the public late in 1975 (Mount and Gauthier, 2006). The amendment effectively and immediately barred the US government from direct or indirect support of the pro-western FNLA/UNITA forces in the Angolan civil war (Kelly, 1993). This had two effects. It strengthened the FLNC rebels who were stationed in Angola and were supported by the communist MPLA. This directly hurt Mobutu's military position relative to the FLNC. In addition, Mobutu had served as main conduit to channel 
money between the CIA and UNITA/FNLA, and he likely was allowed to keep a share of the money which he now lost. The FNLC rebels exploited this temporary weakness and started the invasion in March 1977. We can therefore explain the timing of the offensive directly as result of the unexpected shortfall in American funding.

\subsection{Conclusion}

In this chapter I develop and test a novel theory that relates shortfalls in international aid to an increased risk of civil war onset. The theory shows how governments that receive aid can exploit donor preferences for political stability. This happens when they implement exploitative tax regimes, knowing that donors will give aid to counteract the destabilizing political consequences of such policies. Since stability consequentially rests on donor support, unexpected aid shortfalls lead to political crisis. I test this prediction on data of 28 sub-Saharan countries from the years 1972 to 1989 . The analysis shows that shortfalls in bilateral foreign aid substantively increase the probability of civil war onset. I also find that higher aid levels lower the likelihood of conflict, but only once we control for the negative effects of aid shortfalls.

These findings are, to my knowledge, the first that identify a significant empirical relationship between foreign aid and civil war onset. They have potentially important implications for aid policy and future research. Previous works have focused on the question whether aid creates additional incentives to hold office, or whether it strengthens the hand of the gov- 
ernment in dealing with rebellion. The evidence presented in this chapter suggests that more aid indeed helps to preserve the peace.

However, donors who value stability need to realize that they might encourage recipient governments to make bad policy choices. What is more, if they try to conceal how much they value stability they increase the uncertainty that surrounds their aid programs, which in turn can serve as cause of destabilization. In order to benefit from the pacifying effects of more aid, donors should change the practices they use in making aid allocation decisions.

Two imperatives should be heeded. First, there is a need to overcome the moral hazard of rewarding destabilizing policies. This could be achieved through institutional innovations that guarantee aid is provided only to countries that demonstrate they are willing to forgo such policies. The recent creation of the Millennium Challenge Corporation (MCC) by the US administration is an example for such an attempt. The MCC has an institutionally fixed mandate to support only countries that already have demonstrated their use of good policies. Whether the MCC can extract itself from political influence and successfully practice this form of ex-post conditionality remains to be seen. Other thinkable schemes could involve the creation of a multi-lateral institution that is tasked to dispense aid in a similar fashion, and that potentially would be more insulated against political inference by donor governments.

The second imperative is that donors need to strive to make aid allocations more reliable and predictable. While this is not a new insight in the context of ensuring the success of development projects, aid shortfalls 
also have a negative effect on political stability. Aid agencies in donor countries with parliamentarian systems should find it generally easier to build long-term aid plans and adhere to them, since funding is ensured by a parliamentary majority. In a Congressional system like the American, there are obvious institutional limits to the centralization of the aid process. The creation of predictable aid plans therefore might require investment in political majorities rather than changes to institutional designs.

The finding that aid shortfalls increase the likelihood of conflict is novel. With the limited geographic and temporal scope of the data in this study in mind, future research has the task to establish the validity of this relationship for other regions of the world and more current data.

Shortfalls are not the only imperfections that plague foreign aid. This study has established that aid reduces the likelihood of civil war. Since political stability is a global public good from the perspective of interested donors, these donors face incentives to free ride on the aid provided by others. If we take the interconnection between aid and political conflict seriously, a logical next step is to explore to what extent collective action problems among donors are responsible for political instability in developing countries. 


\section{Chapter 2}

\section{Free-Riding, Recipient Country Properties and The Provision of Foreign Aid}

\section{$2.1 \quad$ Introduction}

In the second half of the 20th century, foreign aid has become a core component of international relations between the industrialized countries of the West and developing nations of the South. While aid traditionally has been used to foster diplomatic goals and provide shadow subsidies to domestic export industries, there is plenty of evidence that donors also seek to foster economic development and growth in recipient countries. Donor governments have created specialized aid agencies, sometimes at cabinet level, that solely focus on development questions and attract and generate expert knowledge on the subject. Swift reactions to natural disasters and other humanitarian relief situations also show that the tragic human consequences of underdevelopment matter to donors.

At the same time, Western donors have time and again missed self-set 
goals. Sub-Saharan Africa remains mired in poverty. More importantly, donor governments have recurrently promised and failed to adhere to the UN target of giving 0.7 percent of GDP to poorer countries. What accounts for this under-provision of aid, and who is affected by it most? Critics have often pointed out that self-serving goals of donors tend to undermine the developmental aspects of aid, particularly in the context of the global confrontation between West and East during the Cold War. While there is much merit to this argument, it cannot explain why donors have failed to give enough aid. After all, if aid can help them secure valuable private benefits, why should they be stingy with it?

A prominent answer to the question why aid is under-provided flows from the observation that development constitutes a public good. It is a well-known that this can lead to collective action problems, and in particular under-provision because of free-riding among contributors. Altruistic humanitarian concerns of donors give rise to public good characteristics of development, as there is no rivalry of consumption or means of excluding any bystander from enjoying the humanitarian benefits of poverty reduction.

This insight has generated valuable research on how aid is delivered. For example, local institutions structure how infrastructure and other aid projects are implemented, which is critical for success or failure (Ostrom et al., 1993). Another line of research has looked at how decision making processes of donor aid agencies affect aid allocations (Martens, 2005; Gibson et al., 2005, chap. 7).

While this institutionalist focus makes sense from an immediate policy perspective, we know surprisingly little to what extent and under which con- 
ditions free-riding behavior actually affects the provision of aid. For better designed aid allocation policies we need to know which recipient countries are subject to under-provision of aid. From a theoretical perspective, it is not clear whether a narrow focus on local and bureaucratic institutions is sufficient to analyze strategic interactions between donor governments. Not withstanding the bureaucratic processes that give rise to aid policy, donor governments find themselves embedded in an international system in which only weak institutional arrangements constrain their actions. In this chapter, I therefore study the strategic interactions between donor governments, and the circumstances under which those lead to the under-provision of aid.

To this end, we need an empirical method that can quantify when and how much collective action problems matter in the provision of aid. This method needs to be capable of both, differentiating aid with regard to its private vs. public goods content, and accounting for the effects of strategic interactions between donors. In order to develop such a method, I turn to recent statistical advances in the geographic sciences and its applications in the analysis of the effect of environmental regulations (see for example Murdoch et al., 1997, 2003).

I derive the strategic equivalent of a spatial autoregressive (SAR) model (Anselin, 1988), also known as spatial-lag model, directly from a gametheoretic model of impure public goods provision. Unlike its SAR relative, the strategic autoregressive (STAR) model moves beyond geographic space as determinant of interconnectedness between actors (Beck et al., 2006). The connectivity weights capture the public goods content of aid, and determine the degree to which donor actions are strategically interconnected. 
To determine the public goods content of aid we need to consider that donor governments sometimes structure aid in ways that directly benefit themselves or their constituents. A suitable measure of this is the tying status of aid. Recipient governments typically need to spend the part of aid that is tied in ways that benefit the donor country. Examples include nobidding requirements on public contracts that must go towards companies from the donor country, and aid that takes the form of export credits. ${ }^{1}$ Thus, tied aid generates a clearly defined private good enjoyed by the donor. In contrast, a low tying ratio of aid indicates a higher public goods content, as the donor gives up control over how the money is spent.

I draw on the current debate on how macro-economic policy and government institutions affect the effectiveness of aid to generate hypotheses about recipient country properties and donor free-riding behavior. Burnside and Dollar (2000) claim that aid promotes economic growth only in recipient countries with good macro-economic policies. To the extent that the developmental benefits of growth are non-rivalrous and non-exclusionary for donors, growth constitutes a public good. As a logical consequence, the provision of aid should only suffer from free-riding problems that arise out of the public goods nature of growth if it is effective in promoting growth. The perverse implication of this is that we should expect countries with good macro-economic policies to suffer more from free-riding between donors than those with bad policies.

A similar argument applies to the role of political institutions. A long-

\footnotetext{
${ }^{1}$ Aid tying should not be confused with conditionality. Conditionality aims to influence recipient government policy. Tying in contrast narrowly dictates how a recipient country can spend aid, wherein the donor country usually benefits economically.
} 
running debate relates economic performance to institutional quality, in particular to property rights, and bureaucratic effectiveness (for example Knack and Keefer, 1995; Acemoglu et al., 2001). Accordingly, aid should be more effective in promoting growth in the presence of conducive political institutions (Bräutigam and Knack, 2004). As before, political institutions therefore are tied to how much effect aid has on growth. We therefore should expect donors to face more incentives to free-ride on each others' efforts if they give aid to countries with better political institutions.

Finally, there is much anecdotal evidence that donors during the Cold War used development aid to secure geo-political objectives. In the 1990s, many Western donors pledged to pay more attention to aid effectiveness and 'good governance' of recipient countries (Hook and Zhang, 1998; Hjertholm and White, 2000). Geo-political objectives inherently constitute a private good for the donor who pursues them, while genuine developmental goals have collective good characteristics. If the outlook of aid provision shifted in a fundamental fashion from self-seeking to more public goods oriented after the Cold War, we should expect aid provision to have been subject to more free-riding problems in the 1990s than before.

In the next section, I develop these hypotheses in more detail, and discuss how my approach fits in with existing work on spatial statistical methods in political science. I then present the STAR model in detail. Next, I proceed to test the hypotheses by applying the STAR model to data on bilateral Official Development Aid (ODA) commitments, and recipient country and donor characteristics between 22 OECD donors and 66 recipient countries for the years 1974 to 1997. I conclude with an outlook on future work. 


\subsection{Collective Action Problems and Development} Aid

\subsubsection{Theoretical Considerations}

As mentioned in the introduction, the study of collective action problems in the area of development has been strongly influenced by the new economics of institutions. The principal protagonist of this line of research has been Elinor Ostrom. While much of her work has focused on Common Pool Resources and how local institutions structure the provision of public goods on the ground, her coauthored book The Samaritan's Dilemma (Gibson et al., 2005) provides an overview of how asymmetric information, principal agent problems and other structural factors constrain the choices of aid providers and recipient governments. Yet the book does not systematically explore the implications of strategic interactions between donors. While the authors mention that recipient countries could try to play-off altruistically motivated donors against each other, they discount this possibility (p. 75). I argue that this reasoning ignores the real possibility that even altruistically motivated donors have incentives to free-ride on each others' aid contributions.

These incentives stem from the scarcity of resources allocated to development aid. Simply put, giving aid is costly. While it seems plausible that bureaucratic self-interest drives aid agencies to expand their activities and push for larger aid commitments (Vaubel, 1986), there is ample evidence that aid agency actions are constrained by actors higher up in the government hierarchy, or by inter-agency rivalry. In the US context for example, 
larger outlines of aid policy are frequently drawn by cabinet level decisions, and executed through agencies other than USAID. Aid has long been an important tool in the arsenal of the State Department (Lancaster, 2007, p. 101, author's interview with former US foreign policy official). Other recent examples include the creation of the Millenium Challenge Cooperation, and the increasing share of aid provided through the Ministry of Defense. The existence of parallel channels for aid provision ensures competition for tight budget resources.

In Japan and Germany, various aspects of aid provision are permanently delegated to different agencies (Lancaster, 2007, p. 113 f., 187 f.), which in turn also ensures that these agencies compete for resources (author's interview with former German aid ministry official). Finally, aid agencies are perennially at a disadvantage when competing against other, particularly domestic, demands on government resources. Aid recipient governments have little political influence, while domestic constituency groups are relatively powerful. Given these organizational checks, and the overall political logic of aid provision, it seems safe to argue that aid is given as a scarce resource, with donor governments caring about the costs of aid provision.

Another line of research questions how the proliferation of donor organizations affects the ability of recipient governments to implement programs (Knack and Rahman, 2007). Here, the focus is again on local government institutions. Donor coordination, or the lack thereof, is analyzed as a means to reduce transaction costs of aid program implementation. In contrast, I am interested not in the transaction costs of aid programs, but in free-riding incentives that arise out of the public goods nature of such programs. 
To my knowledge, there exists only one article that explicitly addresses the question of strategic interactions between donors in the allocation of development aid. Mascarenhas and Sandler (2006) present reduced form donor reaction functions for the provision of development aid under a public goods and a cooperative Lindahl scenario. They estimate which better fits the empirical record of total annual bilateral and multilateral aid commitments of 15 OECD donors from 1970 to 2001. They find that aid is given in a non-cooperative fashion, i.e. is subject to free-riding behavior, and that there is no evidence for cooperation.

My study improves on this earlier work in several ways, and addresses additional important questions. Instead of assuming that all aid commitments are going towards the provision of public goods, I conceptually differentiate between aid that goes towards private consumption of the donor, and aid directed towards public goods provision. My method allows to empirically differentiate between these two types of aid. As measure of public goods content I propose the tying-ratio of aid. ${ }^{2}$ In addition, I am not so much interested in the question whether aid is subject to free-riding problems, but under which circumstances this is the case. To this end, I develop a methodology that allows us to evaluate which recipient country characteristics are salient for strategic interactions between donors. In addition, my approach offers a number of methodological improvements, which I will discuss below.

What are the circumstances under which donors have incentives to free-

\footnotetext{
${ }^{2}$ The methodological framework presented below can be extended to accommodate estimating the public goods content of aid statistically, using for example OLS. In an ongoing project, I address the methodological challenges that arise from the additional statistical uncertainty this introduces into the analysis.
} 
ride? First, aid has to go towards the provision of a public good. Second, it has to be effective in generating this good. To address the first issue, I explicitly model the provision of aid as an impure public goods problem. That is, only some part of aid goes towards the provision of a public good, while some goes towards the donor's private consumption.

As measure of the public goods content of aid I use the tying ratio of aid. Tied aid needs to be spent with companies from the donor country. Aid tying clearly generates private benefits for the donor. It is not a perfect measure, however, since tied aid can also be used to finance projects that have public good properties. ${ }^{3}$ Donors clearly have less control over untied aid, which makes it more likely that it goes towards projects with public good characteristics. Nonetheless, untied aid can also generate private benefits for the donor, for example if it serves as side-payment that secures other goods such as access to raw materials or strategic allegiance. ${ }^{4}$ These shortcomings not withstanding, there is a consensus that aid tying practices are an impediment to effective development policy (Jepma, 1991; World Bank, 1998). As a practical matter, tying ratios are readily available from the OECD Creditor Reporting System (OECD, 2008b). ${ }^{5}$

The second issue that affects the free-riding behavior of donors is aid effectiveness. If aid programs that are geared towards providing public goods don't succeed, why do donors continue to provide the money? A frequently given answer points to the role of altruism. Gibson et al. (2005) for exam-

\footnotetext{
${ }^{3}$ As example, consider an infrastructure project that is bound to be executed by companies of the donor country.

${ }^{4}$ Examples include the recent entry of China as major donor to Africa, and US support for countries such as Zaire and Chile during the Cold War.

${ }^{5}$ The exception being US data, discussed in more detail below.
} 
ple argue that altruism is pervasive in the aid arena, and that it gives rise to ineffective aid policies associated with the Samaritan's Dilemma. Since altruistic donors obtain private consumption value from the act of helping, even if aid misses its stated goals, it follows that ineffective aid is not subject to collective action problems. In contrast, if aid succeeds in generating public goods, donors face incentives to free-ride on each others' contributions. This insight creates a logical link between aid effectiveness and the free-riding behavior of donors. In the following, we will use results from existing research about recipient country characteristics associated with aid effectiveness to derive hypotheses about the circumstances under which we should expect free-riding in the provision of aid.

We will first look at the relationship between macro-economic policies, aid, and economic growth. Few pieces of scholarly work have incited such an intensive aid policy debate as Burnside and Dollar's (B\&D, 2000) finding that aid has a positive effect on economic growth, but only in the presence of good macro-economic policies. Their piece has been harshly criticized on substantive and methodological grounds. This is not the place to rehash these arguments. ${ }^{6}$ Instead, I will focus on the implications of good macroeconomic policies for free-riding in the provision of aid.

Fostering economic growth is a core goal of development aid. At the same time, economic growth in developing countries is, at least partly, a public good. Though it is perceivable that individual donors try to shield others from benefiting from growth through political arrangements such as

\footnotetext{
${ }^{6}$ An overview over the empirical aid effects literature and and a meta-study of the available evidence can be found in Doucouliagos and Paldam (2008).
} 
preferential trade agreements, growth has benefits to donors that are nonexcludable and enjoy non-rivalry in consumption. These include increased political stability and reduction of human misery. Also, with free access to the markets of developing countries, growth presents investment opportunities for all comers.

The public goods character of growth implies that aid that effectively fosters growth produces incentives for donors to free-ride. Following B\&D's logic that good macro-economic policies increase the effectiveness of aid, we should expect aid that goes to countries with better macro-economic policies to be subject to greater free-riding pressures. We restate this relationship in form of a hypothesis.

\section{Hypothesis 1: Good macro-economic policies of aid recipient countries are associated with greater free-riding among donors.}

The normative implication of this hypothesis is that the most deserving countries, those with the greatest ability to make good use of aid, will be relatively undersupplied with aid.

Another widely discussed claim about the preconditions for aid effectiveness is the role of political institutions or 'good governance'. In the early 1990s, good governance had become a buzz word in the aid community, as donors were forced to recast their aid policies in the wake of the end of the Cold War. World Bank officials contrasted the ongoing economic misery of Sub-Saharan African with the early successes of the East Asian miracle, and attributed the difference to the latter's better governance institutions 
(Thorbecke, 2000, p. 40). The intellectual underpinnings of this approach came from empirical work that linked economic performance to newly available times-series data from institutional and policy indicators of developing countries (for example Knack and Keefer, 1995). More recent proponents of the argument follow the new institutionalist focus in economics. They link growth performance to endogenous (Acemoglu and Robinson, 2000, 2005; Bueno de Mesquita et al., 2003) and exogenous factors of institutional development (Acemoglu et al., 2001, 2002). From this perspective, good political institutions are a pre-condition for aid successfully fostering economic growth.

Building on this claim, our argument about political institutions and collective action problems in the provision of aid follows the same logic as in the case of macro-economic policies. If aid is only effective in fostering growth in the presence of good political institutions, free-riding among donors should follow the same pattern. This is because effective aid is given out of public good concerns, but ineffective aid is not (i.e. it satisfies private needs of donors). Accordingly, our second hypothesis reads as follows.

Hypothesis 2: Good political institutions in aid recipient countries are associated with greater free-riding among donors.

The normative implications are the same as before. The most promising recipients in terms of their ability to successfully use aid to improve growth face an undersupply of aid due to free-riding among donors. 
The next theoretical consideration addresses the fact that aid policies change over time. We alluded before to the need of donors to recast their rationale for giving aid after the end of the Cold War. Ample anecdotal evidence shows that during the Cold War bilateral donors often targeted development aid to obtain economic and geo-political advantages. Countries that changed fronts could expect handsome payoffs in terms of development aid, ${ }^{7}$ and those who stayed put were sometimes able to extract high rewards. ${ }^{8}$ The use of aid for garnering influence resembles a political auction mechanism, in which favors go to the highest bidder. In the Cold War scenario, collusion between donors could help them to transfer some of the rents from the aid provision from recipient governments to themselves (Grossman and Helpman, 1994). While I address this possibility in chapter 1, the relationship between donors under this scenario maintains fundamentally competitive, and unaffected from free-riding problems.

After the end of the Cold War in the early 1990s, donors started to put more emphasis on the developmental aspect of aid. Successful development leads to higher economic growth rates, but also to improvements of other social indicators. Hypotheses 1 and 2 already tap into the relationship between aid effectiveness, recipient country characteristics, and growth. In addition, if donor preferences did really shift in the 1990s towards developmental concerns, we would expect a stronger concern for the provision of a variety of local public goods, such as schools and secure food supplies. As a consequence, aid in the 1990s should have been subject to stronger

\footnotetext{
${ }^{7}$ Examples include Ethiopia and Egypt.

${ }^{8}$ Witness the lavish US support for Mobutu's Zaire during the 1970s and 80s.
} 
free-riding incentives than during the Cold War. This insight generates our third testable hypothesis.

Hypothesis 3: Aid provision during the 1990s was associated with greater free-riding among donors than during the Cold War.

In the next section, we situate the method developed in this chapter in the current literature on spatial statistics.

\subsubsection{Spatial Statistical Methods}

Spatial statistical methods have recently received much attention in political science. A number of pieces discuss estimation procedures (Ward and Gleditsch, 2002; Franzese and Hays, 2007b), ${ }^{9}$ and there is a growing number of applications in substantively motivated empirical analysis. ${ }^{10}$ These methods are attractive since they allow us to account for spatial dependency of observational units. If ignored, the result can be biased statistical inferences. Moreover, political units never act in geographic, social or economic isolation, and thus dependencies along these dimensions will be ubiquitous in observational data.

Political scientists to date have not paid much attention to the kind of theoretical insights needed to inform proper specification of spatial statis-

\footnotetext{
${ }^{9}$ These draw on the fundamental works by Anselin and others (Besag, 1975; Anselin, 1988; Huffer and $\mathrm{Wu}, 1998)$. There exist similar useful methodological reviews in the geographic sciences (Brueckner, 2003; Páez and Scott, 2004) and economics (Anselin, 2002)

${ }^{10}$ Franzese and Hays give an overview for comparative politics (Franzese and Hays, 2008). Examples in international relations include (Gleditsch, 2002; Buhaug and Rød, 2006).
} 
tical models. The issue arises from defining how observational units are interconnected. Both spatial lag models (with spatially interconnected observations of the dependent variable) and spatial error models (with spatially interconnected errors) require the analyst to precisely define the degree of interconnection, which is technically captured in a spatial weight or connectivity matrix. ${ }^{11}$ How should this be done? Typical applications in the social sciences use geographic space as proxies of interconnectedness (Conley and Ligon, 2002; Buhaug and Rød, 2006). While this makes sense where interactions are influenced by actual geographic space, ${ }^{12}$ political and economic relationships are influenced by numerous other ties, such as trade (Beck et al., 2006), money flows or capital ownership.

I harness the methodological apparatus developed in these earlier works to statistically model free-riding behavior. Franzese and Hays have pointed to the role of spill-ins and externalities as key characteristics of interdependent behavior (Franzese and Hays, 2008). In economics, the statistical analysis of strategic interactions in the form of spill-overs has received much attention (for an overview see Brueckner, 2003). A prominent application is the analysis of environmental pollution. Murdoch et al. $(1997,2003)$ for example model a country's choice of how much air pollutants to emit as conditional on literal spill-ins of those pollutants by other countries.

I use a more abstract notion of inter-connectivity. I derive a statistical estimator of a donor's choice how much aid to provide directly from an

\footnotetext{
${ }^{11}$ Recent research in semi-parametric estimation methods somewhat ameliorates this problem as it allows for measurement error of spatial relationships (Conley and Molinari, 2007). However, the method still relies on theoretically informed conceptualizations of space.

${ }^{12}$ Examples include military encounters and transportation costs of traded goods.
} 
impure public goods game. In contrast to a pure public goods game, the impure version allows me to distinguish between the parts of aid that go towards the creation of a public good, and those that go towards the donor's private consumption. This approach ensures a tight link between theory and empirical model, while accommodating important conceptual details that characterize aid provision in the real world. Accordingly, the parameters of the resulting strategic auto-regressive model have an interpretation that flows directly from the theoretical setup.

Much political science data is in time-series cross-section format, and analysts might want to make statements about dynamic processes. Unfortunately, a well-known result from game theory is that in repeated games almost any outcome can be sustained in equilibrium. ${ }^{13}$ To deal with this problem and make the analysis mathematically tractable, modelers of stochastic dynamic games typically restrict the analysis to Markov stratgies (Fudenberg and Tirole, 1991). Yet even after this simplification the methodological challenges in deriving a structural estimator from a stochastic dynamic game remain formidable. I follow a second approach and present a single-shot game that formally ignores temporal dynamics. ${ }^{14}$ To test my hypotheses, I fit the model to cross-section time series data in which individual panels span four year periods. ${ }^{15}$ Conceptually, this approach can be interpreted as if the players were engaged in a repeated stage game, but without con-

\footnotetext{
${ }^{13}$ This is known as the 'folk theorem'.

${ }^{14}$ Recent advances in spatial statistics allow for the incorporation of dynamic elements into the statistical analysis, for example in the form of serial correlation of error terms (Anselin et al., 2008), or temporal-spatial lags of the left-hand-side variable (Giacomini and Granger, 2004). However, this is not equivalent to a dynamic choice environment in which rational actors condition their behavior on past and anticipated future actions.

${ }^{15}$ The data are discussed in detail in the next section.
} 
sidering the history of moves. Alternatively, the game can be interpreted as limiting equilibrium of a long running repeated stage game. I derive and discuss the model in detail in the next section.

\subsection{A Formal and Statistical Model of Impure Pub- lic Goods Provision}

My exposition of the public goods game is based on a textbook example (Varian, 1992, p. 420). I expand this model to accommodate the impurity of the public good.

The model represents a single-shot simultaneous move game with complete information. The players are $n$ international aid donors, each denoted $i=1 \ldots n$. A donors's utility is given by

$$
U_{i}=\lambda f\left(b_{i} a_{i}+\sum_{j \neq i} b_{j} a_{j}\right)+f\left(m_{i}-b_{i} a_{i}\right)
$$

where $a_{i}$ is the aid provided by player $i$, and $m_{i}$ is her endowment. The function $f(x)$ that maps consumption into utility levels is strictly increasing and concave, i.e. $f^{\prime}(x)>0$ and $f^{\prime \prime}(x) \leq 0, \forall x$. It is assumed to have identical functional form for both public and private goods. However, the parameter $\lambda \geq 0$ scales how much utility player $i$ derives from private versus public goods consumption, and thus allows for sufficient flexibility. At this stage, the precise functional form $f(x)$ is not relevant. However, to ensure existence of a closed-form equilibrium solution we will impose more structure below. 
The weights $b_{i} \in[0,1]$ capture the extent to which individual payments contribute to the public good. In the context of aid provisions, tying aid to specific projects or imports from one donor country constitutes private consumption for the donor and reduces the public good input enjoyed by all players.

The donor needs to compare the utility of providing aid against how much to spend on private consumption. Her benefit from aid provision in turn is a function of the weighted sum of her own and all other aid contributions, $b_{i} a_{i}+\sum_{j \neq i} b_{j} a_{j}$. The donor directly consumes what is left over from the endowment after giving aid plus the private good component of aid, $m_{i}-a_{i}+\left(1-b_{1}\right) a_{i}=m_{i}-b_{1} a_{i}$.

In equilibrium, each donor chooses an aid level $a_{i}^{*}$ that maximizes (2.1), subject to budget and non-negativity constraints that can be summarized as $0 \leq a_{i}^{*} \leq m_{i}$. Assuming an interior solution, the first-order condition to this problem is, for all $i$,

$$
\frac{\lambda f^{\prime}\left(b_{i} a_{i}+\sum_{j \neq i} b_{j} a_{j}\right)}{f^{\prime}\left(m_{i}-b_{i} a_{i}\right)}=1 .
$$

This first order condition has a well-known economic interpretation. The left-hand side represents $i$ 's marginal rate of substitution between public good and private consumption, while the right-hand side is $i$ 's marginal cost of providing the public good. Solving (2.2) for $a_{i}$ gives the best response function $a_{i}^{*}\left(a_{-i}\right)$. This step requires fixing a functional form $f(x)$ that satisfies the constraints given above. A simple utility function that does so is 
$f(x)=\ln (x+1)$, with $f^{\prime}=1 /(x+1) .{ }^{16}$ Substituting into (2.2), we can now solve for $a_{i}$ :

$$
\begin{aligned}
\lambda \frac{1}{b_{i} a_{i}+\sum_{j \neq i} b_{j} a_{j}+1} & =\frac{1}{m_{i}-b_{i} a_{i}+1} \\
a_{i} & =-\frac{1}{\lambda+1} \sum_{j \neq i} \frac{b_{j}}{b_{i}} a_{j}+\frac{\lambda}{\lambda+1} \frac{m_{i}}{b_{i}}+\frac{\lambda-1}{b_{i}(\lambda+1)} .
\end{aligned}
$$

Reparameterizing $\rho=\frac{1}{\lambda+1}$ we have the best response function

$$
a_{i}^{*}\left(a_{-i}\right)=-\rho \sum_{j \neq i} \frac{b_{j}}{b_{i}} a_{j}+(1-\rho) \frac{m_{i}}{b_{i}}+\frac{1-2 \rho}{b_{i}} .
$$

We thus see that player $i$ 's equilibrium spending $a_{i}^{*}$ decreases with aid $a_{j}$ given by other players $j$, weighted by a ratio of the respective public good weight $b_{j}$ and $i$ 's own weight $b_{i}$. In addition, $a_{i}^{*}$ increases with $i$ 's endowment $m_{i}$, again weighted by a ratio involving her weight $b_{i}$. The last term adjusts the level of equilibrium spending as a decreasing function of the free-riding parameter $\rho$, weighted by $b_{i}$.

The solution to the game consists of $n$ equations according to (2.5). It can be conveniently summarized in matrix notation as

$$
\mathbf{A}=-\rho \mathbf{W A}+(1-\rho) \mathbf{M}+(1-2 \rho) \mathbf{L},
$$

where $\mathbf{A}$ is a $n \times 1$ column vector of optimal responses $a_{1}^{*}, \ldots, a_{n}^{*}, \rho$ and $1-\rho$

\footnotetext{
${ }^{16}$ The choice of functional form at this point is somewhat arbitrary. A more flexible form such as $f(x)=x^{\alpha}, \alpha \in[0,1]$ might be more desirable in some applied setting. This way the auxiliary parameter $\alpha$ can be estimated as well. However, this requires numerical solving of the likelihood function at each reiteration of the MLE optimization procedure, adding considerable computational difficulty. For the sake of clarity of exposition, we choose the simplest functional form available.
} 
are scalars as defined above, and $\mathbf{M}$ and $\mathbf{L}$ are $n \times 1$ column vectors. $\mathbf{M}$ contains weighted endowments $m_{1} / b_{1}, \ldots, m_{n} / b_{n}$, and $\mathbf{L}$ contains elements $1 / b_{1}, \ldots, 1 / b_{n} . \mathbf{W}$ is a $n \times n$ weight matrix of the form

$$
\boldsymbol{W}=\left[\begin{array}{cccc}
0 & \frac{b_{2}}{b_{1}} & \cdots & \frac{b_{n}}{b_{1}} \\
\frac{b_{1}}{b_{2}} & 0 & \cdots & \frac{b_{n}}{b_{2}} \\
\vdots & \vdots & \vdots & \vdots \\
\frac{b_{1}}{b_{n}} & \frac{b_{2}}{b_{n}} & \cdots & 0
\end{array}\right]
$$

To reemphasize, the off-diagonal elements of $\boldsymbol{W}$ are formed by the ratio of public good weights $b_{j} / b_{i}$ which is directly derived from the best response function (2.5). Also note in the special case of pure public goods provision all weights $b_{i}$ are set to 1 .

To ensure the game has a unique equilibrium we need to consider uniqueness of the solution to the system of equations (2.6). Fortunately, the system is linear in $a_{i}$ with coefficient matrix $\mathbf{I}+\rho \mathbf{W}$, where $\mathbf{I}$ is the $n \times n$ identity matrix. Thus there exists a unique solution if and only if $\mathbf{I}+\rho \mathbf{W}$ has full $\operatorname{rank}^{17}$

In order to derive a statistical estimator from the game we need to make assumptions about sources of uncertainty. This is necessary since the game itself is deterministic, i.e can't be fitted to data containing stochastic noise. A key step in structural estimation of games is therefore the inclusion of a stochastic component (Signorino, 1999). The literature identifies three principal sources of uncertainty: incomplete information on part of the players,

\footnotetext{
${ }^{17}$ Interestingly, this condition also guarantees identification of the SAR model (Anselin, 1988).
} 
erroneous decisions on parts of players (agent error), and measurement error on part of the analyst (regressor error) (Signorino, 2003).

For purposes of deriving the strategic equivalent of a SAR model from (2.6), agent and regressor error are equivalent. ${ }^{18}$ Both result in a statistical model of the form

$$
\mathbf{Y}=-\rho \mathbf{W} \mathbf{Y}+(1-\rho) \mathbf{X} \boldsymbol{\beta}+(1-2 \rho) \mathbf{L}+\mathbf{e} .
$$

The model now features the disturbance term $\mathbf{e}$, an $n \times 1$ column vector of i.i.d. normal stochastic disturbances $\varepsilon_{i}$ with common variance $\sigma^{2}$ and mean $\mu=0 .{ }^{19}$ The endowment term $\boldsymbol{M}$ is parameterized with covariates $\mathbf{X} \boldsymbol{\beta}$, where $\mathbf{X}$ is an $n \times k$ matrix with elements $x_{i, j} / b_{i}$. This allows the researcher to include variables that affect overall levels of aid, while preserving the structure derived from the game. The vector of dependent variables is named $\mathbf{Y}=\mathbf{A}$, following convention.

What is the substantive interpretation of the estimate for $\rho$ ? In applications of the SAR model in the geographic sciences, $\rho$ captures the strength of the spatial association between observations. In the STAR setup, space is replaced through strategic interconnectedness. A positive estimate for $\rho$ is evidence that donors display free-riding behavior (since the parameter enters the model with negative sign), as they give less aid as others give more. In contrast, a negative sign indicates strategic complementarities.

\footnotetext{
${ }^{18}$ This is because players only move once. Since they also move simultaneously the players do not have more information than the analyst.

${ }^{19}$ The only way to incorporate incomplete information is adding uncertainty about the size of endowments $m_{i}$. This would make player $i$ 's best response a function of $n-1$ errors $\varepsilon_{j}, j \neq i$.
} 
Also, the magnitude of $\rho$ has a direct interpretation that derives from the structure of the underlying theoretical model. Recall that $\rho=\frac{1}{\lambda+1}$, and that $\lambda$ weighs the utility that country $i$ derives from public good consumption relative to private consumption (see equation 2.1). Accordingly, values of $\rho>.5$ indicate that $i$ values public good consumption less than private consumption. For $\rho<.5, i$ prefers public good over private consumption, and for $\rho=.5 i$ 's tastes are weighted equally.

Unlike in traditional SAR models, in the STAR model, the parameter $\rho$ plays an additional role in the STAR model. It weighs the effect of the covariates $\mathbf{X} \boldsymbol{\beta}$ on $\mathbf{Y}$ by $1-\rho$. With increasing size of $\rho$, i.e. stronger free riding behavior, $1-\rho$ decreases, and the size of the endowment has a smaller effect on the donor's aid allocation decision.

In the form expressed in equation (2.8), the model does not allow yet for incorporation of recipient country properties. To achieve this, I introduce two changes. First, I move to a panel data setup. This allows us to include several cross sections of each donor-recipient country pair in the analysis. As previously discussed, I treat each cross section as independent realization of the stage game described above. Thus, to be notational correct, we would have to add a time index to equations (2.1) through (2.5). However, the choice problem these equations describe remains the same. When we introduce the stochastic element, we assume independence of errors, as before. $^{20}$

The second change is that I re-parameterize the coefficient $\rho$ with a

\footnotetext{
${ }^{20}$ This now has the additional implication of assuming serial independence of error terms.
} 
second set of covariates, $\mathbf{X}_{2} \gamma$. Following notational convention for timespace recursive models (Anselin et al., 2008), the resulting stacked system of equations has the form

$$
\mathbf{Y}=-\left(\boldsymbol{X}_{2} \gamma\right)\left(\boldsymbol{I}_{T} \otimes \boldsymbol{W}_{N}\right) \mathbf{Y}+\left(1-\boldsymbol{X}_{2} \gamma\right) \mathbf{X}_{1} \boldsymbol{\beta}+\left(1-2 \boldsymbol{X}_{2} \gamma\right) \mathbf{L}+\mathbf{e}
$$

where $\boldsymbol{I}_{T} \otimes \boldsymbol{W}_{N}$ is a block-diagonal weight matrix. The block-diagonal weight matrix has $N \times T$ cross-sectional weight matrices $\boldsymbol{W}$ on its diagonal that are defined as before. $N$ is the number of cross sections, and $T$ is the number of time periods. All off-diagonal elements are 0.

In the following section, I estimate equation (2.9) using maximum likelihood. The log-likelihood function takes the form:

$$
\begin{aligned}
\ln L= & \ln |\boldsymbol{I}-\rho \boldsymbol{W}|+n \ln \frac{1}{s} \\
& -\frac{1}{2 s^{2}}\left((\boldsymbol{I}-\boldsymbol{W}) \boldsymbol{Y}-\left(1-\boldsymbol{X}_{2} b_{2}\right) \boldsymbol{X}_{1} b_{1}+\left(1-2 \boldsymbol{X}_{2} b_{2}\right) \boldsymbol{L}\right)^{T} \\
& \left((\boldsymbol{I}-\boldsymbol{W}) \boldsymbol{Y}-\left(1-X_{2} b_{2}\right) \boldsymbol{X}_{1} b_{1}+\left(1-2 X_{2} b_{2}\right) \boldsymbol{L} .\right)
\end{aligned}
$$

I first discuss the data and then present results of the empirical tests of my hypotheses.

\subsection{Empirical Analysis}

\subsubsection{Data}

I use data from a variety of sources. For aid data, I rely on the OECD's Creditor Reporting System (2006). The dependent variable is bilateral aid 
committed by 16 Western donor countries to 66 recipient countries, measured in constant 2005 US dollars. ${ }^{21}$ The data is organized in donor-recipient dyads for 6 time periods that cover the years 1974 to 1997. Each time period spans four years. All variables including the aid variable are averaged over each time period.

It is standard practice in the economic growth literature to use longerrunning time averages in a panel setup. I follow in this regard Burnside and Dollar (2000). For our purposes, the approach offers a number of advantages. From a conceptual perspective, each time period represent an independent realization of the stage game. Typical aid programs run for about four years, thus the choice of four year periods reflects to some extent the reality of the aid allocation process. From a methodological point of view, taking means over longer time periods alleviates the problem of serial correlation. This is desirable since our model assumes independence of errors.

For recipient country characteristics $\boldsymbol{X}_{2} \gamma$, I rely on Easterly et al. (2004). The authors seek to establish whether the results of Burnside and Dollar (2000) hold up in a larger sample. To this end, they collect additional data and extend the temporal scope and country coverage of B\&D's original data set. I do not utilize the macro-economic policy index calculated by B\&D, but rather include its component variables into the analysis. Those variables are the government budget balance, expressed as percentage of GDP, a measure of inflation, and a dummy for trade openness following Sachs and Warner (1995). The authors' measure of quality of political institutions is based

\footnotetext{
${ }^{21}$ The donor countries are Australia, Austria, Belgium, Canada, Denmark, Finland, France, Germany, Italy, Japan, Netherlands, Norway, Sweden, Switzerland, UK, and USA.
} 
on the International Country Risk Guide, and captures security of property rights and efficiency of government bureaucracy. In addition, I create a dummy variable that takes on values of 1 for the two post-Cold War time periods from 1990-1997, and 0 for earlier years.

The variables that estimate the donor's budget, $\boldsymbol{X}_{1} \boldsymbol{\beta}$, are intended to capture the financial strength of the government. They are the government's tax take as percentage of GDP, annual GDP growth, and total level of GDP. I take these variables from the OECD's Country Statistical Profiles (2008a), and the World Bank's World Development Indicators (2009). ${ }^{22}$

Finally, for the public good weights $b_{i}$ I use data from the OECD Creditor Reporting System (CRS, 2006). The relevant measure is the percentage of tied aid over total aid. In the formal model, I treat each donor's division of aid between public goods provision and private consumption (i.e. the $b_{i} \mathrm{~s}$ ) as exogenous and fixed. This makes theoretical sense if we think about the private consumption part of aid as exogenously driven by domestic special interest groups. Empirically, tying rates were relatively stable during the Cold War years, with an average of 52.0 percent for all donors in the sample (except the US). However, they began to decline in the 1990s, to an average of only 22.8 percent.

Accordingly, I use two different specifications of the public good weights. In the first specification, I average tying rates over the entire sample period from 1974 to 1997. In other words, the weight matrix $\boldsymbol{W}$ is identical for all time periods. In the second specification, I allow for two different weight

\footnotetext{
${ }^{22}$ It would be possible to use actual budget data for endowment $m_{i}$. The current approach allows for more flexibility in fitting empirical differences in aid spending levels.
} 
matrices $\boldsymbol{W}$, with the first reflecting average tying rates from 1974 to 1990, and the second those from 1991 to 1997.

Using the CRS data poses an additional challenge. Unfortunately, the US stopped reporting aid tying status to the OECD in the early 1990s. The last reliable data I found are from 1991. The US is the largest aid donor in absolute terms, thus we cannot easily omit it from the sample. To remedy the situation, I choose a very simple imputation strategy. I fit an $\operatorname{ARIMA}(1,1,0)$ model of US tying status to the existing data. ${ }^{23} \mathrm{I}$ then use the model to predict US tying behavior for the years following 1991. Since this strategy is not guaranteed to produce good results, I run the analysis both with and without the US. ${ }^{24}$

\subsubsection{Results}

In the empirical analysis, I first test in isolation whether donor free-riding behavior differs between the Cold War period and the 1990s. I then add recipient country specific macroeconomic policy variables to the analysis, as well as institutional quality variables. Finally, I include GDP per capita as control variable for the recipient country's stage of economic development. Each of these models is run in four versions, with and without the US (relying on imputed US connectivity weights), and with and without distinct weight matrices for the Cold War and the 1990s.

\footnotetext{
${ }^{23}$ As independent variable I use the ratio of non-concessional loans over total economic aid per year.

${ }^{24}$ An additional issue arises from the uncertainty that predicted values introduce into the analysis, as the statistical model treats weights $b_{i}$ as fixed parameters. Conley and Molinari (2007) develop a method for dealing with measurement error in spatial weights, which might be adoptable to this situation.
} 
Results for each of the specifications are reported in tables 2.1 to 2.4. Each table features in its upper half the variables $\boldsymbol{X}_{2} \boldsymbol{b}_{2}$, which measure the degree of free-riding (i.e. the re-parameterized version of $\rho$ ). Positive signs indicate increased free-riding behavior, and negative signs decreased freeriding. The variables in the lower half represent donor budgets $\boldsymbol{X}_{1} \boldsymbol{b}_{1}$ (i.e. the re-parameterized version of endowments $\boldsymbol{M}$ ). The estimates show how the financial strength of individual donor governments affects their average level of aid commitments across recipient countries.

Let us start the discussion of results with a look at hypothesis 1 . This hypothesis extends Burnside and Dollars' findings about the role of macroeconomic policy on aid effectiveness to free-riding among donors. A first glance at signs and significance levels shows that the budget balance in recipient countries is positively associated with increased free-riding across almost all model specifications (exceptions are models 3 in table 2.2 and table 2.4$)^{25}$. Since a better budget balance is indicative of good policy, this result is in line with the expectation set forth in hypothesis 1.

In order to evaluate the substantive effect of the estimates, recall that the covariates $\boldsymbol{X}_{2} \boldsymbol{b}_{2}$ re-parameterize the free-riding parameter $\rho$, i.e. $\rho=\boldsymbol{X}_{2} \boldsymbol{b}_{2}$. Since $\rho$ is theoretically bounded between 0 and 1 , the covariates determine where in this range the estimate falls. The budget balance variable is measured as percentage of GDP. It ranges in the sample from -30.6 percent to 14.7 percent. Taking the largest estimated coefficient for the budget balance from model 2 in table $2.1(0.0746)$, and varying the variable over its entire

\footnotetext{
${ }^{25}$ The loss of significance when controlling for recipient country GDP per capita is not unexpected, since the two variables tend to be highly correlated
} 
Table 2.1: Aid Committed to Individual Countries, US Included, Identical Connectivity Weights

\begin{tabular}{llllllll}
\hline & & 1 & & 2 & & 3 & \\
\hline & $\boldsymbol{X}_{2} \boldsymbol{b}_{2}$ & & & & & & \\
Free & Constant & $-0.0264^{* *}$ & $(0.00154)$ & $-0.0314^{* *}$ & $(0.00213)$ & $-0.0313^{* *}$ & $(0.00214)$ \\
Riding, & Post Cold War & 0.00172 & $(0.00111)$ & 0.000652 & $(0.00119)$ & 0.000648 & $(0.00119)$ \\
Recipient & Budget Balance & & & $0.0746^{* *}$ & $(0.0116)$ & $0.0714^{* *}$ & $(0.0119)$ \\
Properties & Inflation & & & $0.00535^{* *}$ & $(0.00131)$ & $0.00513^{* *}$ & $(0.00132)$ \\
& Sachs-Warner & & & & & & \\
& Openness & & & -0.00185 & $(0.00115)$ & $-0.00209^{*}$ & $(0.00117)$ \\
& Political & & & & & & \\
& Institutions & & & $0.00219^{* *}$ & $(0.000288)$ & $0.00207^{* *}$ & $(0.000303)$ \\
& GDP per capita & & & & & 0.000371 & $(0.000295)$ \\
\hline \multirow{3}{*}{$\begin{array}{l}\text { Donor } \\
\text { Budget }\end{array}$} & $\boldsymbol{X}_{1} \boldsymbol{b}_{1}$ & & & & & \\
& Constant & $-1.00^{* *}$ & $(0.00542)$ & $-1.00^{* *}$ & $(0.00541)$ & $-1.00^{* *}$ & $(0.00542)$ \\
& GDP growth & -0.0658 & $(0.0606)$ & -0.0670 & $(0.0603)$ & -0.0658 & $(0.0603)$ \\
& Taxation & $-0.041^{* *}$ & $(0.0129)$ & $-0.0399^{* *}$ & $(0.0128)$ & $-0.0405^{* *}$ & $(0.0129)$ \\
& GDP & 0.000216 & $(0.000216)$ & 0.000245 & $(0.000215)$ & 0.000234 & $(0.000215)$ \\
\hline
\end{tabular}


Table 2.2: Aid Committed to Individual Countries, no US, Identical Connectivity Weights

\begin{tabular}{llllllll}
\hline & & 1 & & 2 & & 3 & \\
\hline & $\boldsymbol{X}_{2} \boldsymbol{b}_{2}$ & & & & & & \\
Free & Constant & $-0.0256^{* *}$ & $(0.0017)$ & $-0.0252^{* *}$ & $(0.00232)$ & $-0.0242^{* *}$ & $(0.00235)$ \\
Riding, & Post Cold War & $0.00269^{* *}$ & $(0.0011)$ & 0.00163 & $(0.0012)$ & 0.00174 & $(0.00119)$ \\
Recipient & Budget Balance & & & $0.0299^{* *}$ & $(0.0124)$ & 0.0159 & $(0.0127)$ \\
Properties & Inflation & & & $0.00428^{* *}$ & $(0.00139)$ & $0.00332^{* *}$ & $(0.0014)$ \\
& Sachs-Warner & & & & & \\
& Openness & & & 0.000832 & $(0.00123)$ & -0.000288 & $(0.00124)$ \\
& Political & & & & & & \\
& Institutions & & & 0.000142 & $(0.000306)$ & -0.000409 & $(0.000323)$ \\
& GDP per capita & & & & & $0.00156^{* *}$ & $(0.000312)$ \\
\hline \multirow{3}{*}{$\begin{array}{l}\text { Donor } \\
\text { Budget }\end{array}$} & $\boldsymbol{X}_{1} \boldsymbol{b}_{1}$ & & & & & \\
& Constant & $-1.04^{* *}$ & $(0.00472)$ & $-1.04^{* *}$ & $(0.00473)$ & $-1.03^{* *}$ & $(0.00478)$ \\
& GDP growth & -0.00210 & $(0.0508)$ & 0.00263 & $(0.0509)$ & 0.00435 & $(0.051)$ \\
& Taxation & 0.0111 & $(0.0103)$ & 0.0122 & $(0.0103)$ & 0.0115 & $(0.0103)$ \\
& GDP & $0.0166^{* *}$ & $(0.000602)$ & $0.0166^{* *}$ & $(0.000603)$ & $0.0166^{* *}$ & $(0.000603)$ \\
\hline
\end{tabular}


Table 2.3: Aid Committed to Individual Countries, US Included, Period-Specific Connectivity Weights

\begin{tabular}{|c|c|c|c|c|c|c|c|}
\hline & & 1 & & 2 & & 3 & \\
\hline & $\boldsymbol{X}_{2} \boldsymbol{b}_{2}$ & & & & & & \\
\hline Free & Constant & $-0.0259^{* *}$ & $(0.00164)$ & $-0.0297^{* *}$ & $(0.00213)$ & $-0.0294^{* *}$ & $(0.00214)$ \\
\hline Riding, & Post Cold War & 0.000525 & $(0.00116)$ & -0.000421 & $(0.00123)$ & -0.000551 & $(0.00123)$ \\
\hline Recipient & Budget Balance & & & $0.0606^{* *}$ & $(0.0102)$ & $0.0563^{* *}$ & $(0.0104)$ \\
\hline \multirow[t]{7}{*}{ Properties } & Inflation & & & $0.00492^{* *}$ & $(0.00123)$ & $0.00456^{* *}$ & $(0.00124)$ \\
\hline & Sachs-Warner & & & & & & \\
\hline & Openness & & & $-0.002^{*}$ & $(0.00109)$ & $-0.00235^{* *}$ & $(0.0011)$ \\
\hline & Political & & & & & & \\
\hline & Institutions & & & $0.00182^{* *}$ & $(0.000264)$ & $0.00162^{* *}$ & $(0.000277)$ \\
\hline & GDP per capita & & & & & $0.000617^{* *}$ & $(0.000268)$ \\
\hline & $\boldsymbol{X}_{1} \boldsymbol{b}_{1}$ & & & & & & \\
\hline Donor & Constant & $-1.01^{* *}$ & $(0.00478)$ & $-1.01^{* *}$ & $(0.00478)$ & $-1.00^{* *}$ & $(0.00481)$ \\
\hline \multirow[t]{3}{*}{ Budget } & GDP growth & 0.0127 & $(0.0542)$ & 0.0182 & $(0.054)$ & 0.0197 & $(0.0541)$ \\
\hline & Taxation & $-0.0403^{* *}$ & $(0.0108)$ & $-0.0395^{* *}$ & $(0.0108)$ & $-0.0402^{* *}$ & $(0.0108)$ \\
\hline & GDP & $0.000440^{* *}$ & $(0.000206)$ & $0.000458^{* *}$ & $(0.000205)$ & $0.000438^{* *}$ & $(0.000206)$ \\
\hline
\end{tabular}


Table 2.4: Aid Committed to Individual Countries, no US, Period-Specific Connectivity Weights

\begin{tabular}{|c|c|c|c|c|c|c|c|}
\hline & & \multicolumn{2}{|l|}{1} & \multicolumn{2}{|l|}{2} & \multicolumn{2}{|l|}{3} \\
\hline \multirow{10}{*}{$\begin{array}{l}\text { Free } \\
\text { Riding, } \\
\text { Recipient } \\
\text { Properties }\end{array}$} & $\boldsymbol{X}_{2} \boldsymbol{b}_{2}$ & & & & & & \\
\hline & Constant & $-0.0245^{* *}$ & $(0.00176)$ & $-0.0241^{* *}$ & $(0.00222)$ & $-0.0229^{* *}$ & $(0.00225)$ \\
\hline & Post Cold War & 0.000776 & $(0.00113)$ & 0.000154 & $(0.00121)$ & -0.000172 & $(0.00121)$ \\
\hline & Budget Balance & & & $0.0231^{* *}$ & $(0.0101)$ & 0.0146 & $(0.0102)$ \\
\hline & Inflation & & & $0.00363^{* *}$ & $(0.00121)$ & $0.0027^{* *}$ & $(0.00122)$ \\
\hline & Sachs-Warner & & & & & & \\
\hline & Openness & & & -0.000233 & $(0.00108)$ & -0.000936 & $(0.00108)$ \\
\hline & Political & & & & & & \\
\hline & Institutions & & & 0.000172 & $(0.000261)$ & -0.000266 & $(0.000273)$ \\
\hline & GDP per capita & & & & & $0.00133^{* *}$ & $(0.000264)$ \\
\hline & $\boldsymbol{X}_{1} \boldsymbol{b}_{1}$ & & & & & & \\
\hline Donor & Constant & $-1.03^{* *}$ & $(0.00412)$ & $-1.03^{* *}$ & $(0.00414)$ & $-1.03^{* *}$ & $(0.00419)$ \\
\hline Budget & GDP growth & -0.0343 & $(0.0441)$ & -0.0282 & $(0.0442)$ & -0.0262 & $(0.0442)$ \\
\hline & Taxation & 0.00647 & $(0.00872)$ & 0.00747 & $(0.00873)$ & 0.00746 & $(0.00874)$ \\
\hline & GDP & $0.0135^{* *}$ & $(0.00053)$ & $0.0135^{* *}$ & $(0.00053)$ & $0.0135^{* *}$ & $(0.000531)$ \\
\hline
\end{tabular}


range, we find that $\rho$ increases by $(0.147+0.306) * 0.0746=0.0338$. This change is relatively small, representing a shift of 3.38 percentage points of the total range of $\rho$. However, it is not straight forward to quantify how much this change affects actual aid provision.

One way to grasp the substantive consequences of free riding is to calculate how a marginal change of one donor's aid contribution affects the other donors' aid giving decisions. While an analytical solution to this problem exists, it is impractically costly to obtain. ${ }^{26}$ Fortunately, it is easy to compute a numerical example, which I will provide below.

The inflation variable is positively related to free-riding, and it is statistically significant in all model specifications. Since good macroeconomic policies should lead to lower inflation, the finding implies that donors face greater collective action problems when providing aid to countries with bad macroeconomic policy. This contradicts our theoretical expectations. The effect size is slightly smaller than those of the budget balance variable. Inflation in the sample ranges from -3.62 percent to 322 percent. Moving from the lower to the upper end of this range increases $\rho$ by $(3.22+0.0362) * 0.00535=0.0174$, again using model 2 in table 2.1 .

The third macro-economic policy variable is the Sachs-Warner dummy for trade openness. The variable is statistically significant at the 5 percent level in one model specification, and at the 10 percent level in two more

\footnotetext{
${ }^{26}$ The analytical solution for $d$ donors would involve taking the total derivative for $d-1$ best reaction functions (2.5). Calculating each total derivative would require solving a system of equations of $d-1$ equations and $d-1$ unknowns. This procedure would have to be repeated for each of the $d$ donors, making for $d(d-1)$ systems of equations with a total of $\mathrm{d}(\mathrm{d}-1)(\mathrm{d}-1)$ unknowns. With 15 donors, this comes to solving 29 systems of equations with a total of 2940 unknowns.
} 
specifications. In all these cases, the variable has an unexpected negative sign. The contribution of the variable to $\rho$ is one order of magnitude smaller than those of either inflation or the budget balance, with a decrease of 0.00235 for countries with open trade policies (model 3 in table 2.3).

What should we make of the unexpected effects of inflation and trade openness on free-riding among donors? Since all variables are designed to tap into the underlying concept of good macro-economic policy, it comes as no surprise that they are closely interrelated. The correlation between inflation and budget balance is $r=-0.255$, between inflation and trade openness $r=-0.133$, and between budget balance and trade openness $r=$ 0.294. It therefore is possible that the unexpected negative signs are due to multicollinearity. In any event, budget balance has the largest effect on $\rho$, and it confirms hypothesis 1 . Still, we qualify our support for hypothesis 1 by limiting it to this particular measure of government policy.

Let us now look at the effects of political institutions. Better institutions are associated with more free-riding, but this finding is limited to the two specifications that include the US (tables 2.1 and 2.3). In the other two specifications, the variable does not attain statistical significance. The influence of institutional quality is comparable to the macroeconomic policy variables. The variable ranges from 1.58 to 9.50 in the sample. Moving through this range, $\rho$ increases by $(9.50-1.58) * 0.00219=0.0173$. Given the reliance of this finding on the presence of the US in the sample, we label the support of hypothesis 2 in the data as only moderate.

We next turn to hypothesis 3. The hypothesis states that free-riding should have increased after the end of the Cold War, as donors increased 
their taste for development and the associated provision of public goods. This claim only finds very weak support in the data. Only in one specification, without US observations and with identical connectivity weights for all time periods (table 2.2), is the post-Cold War dummy variable positive and statistically significant. However, it loses significance once we include the policy and institutional quality variables. On this weak empirical basis, we cannot reject the possibility that the change of political environment had no quantifiable effect on collective action problems between donors.

Before presenting a numerical example of the size of substantive freeriding effects, we take a quick look at variables $\boldsymbol{X}_{1} b_{1}$, which capture donor endowments. From the three variables I use to capture donor governments' financial capacity, only GDP consistently is statistically significant and behaves as expected. The finding indicates that donors with larger economies give more aid. The GDP growth variable does not attain statistical significance throughout. The taxation variable offers a surprise. Statistically significant only in the presence of the US in the analysis, the variable takes on a negative sign. This means that countries with higher tax takes provide lower amounts of aid. Intuitively, this result is due to the fact that the US is the biggest donor of bilateral aid in absolute terms, but has one of the lowest tax shares of GDP of all donor countries in the sample. ${ }^{27}$

To gauge the size of the effect of macro-economic policy on free-riding, consider figure 2.1. It shows the predicted average annual loss in aid due to free-riding as a function of the recipient country's budget balance. This is

\footnotetext{
${ }^{27}$ The average US tax share is 26.5 percent. Only Greece (21.8 percent), Japan (26.3 percent), and Switzerland (26.4 percent) have lower shares.
} 
Figure 2.1: Free-Riding Loss, Macroeconomic Policy

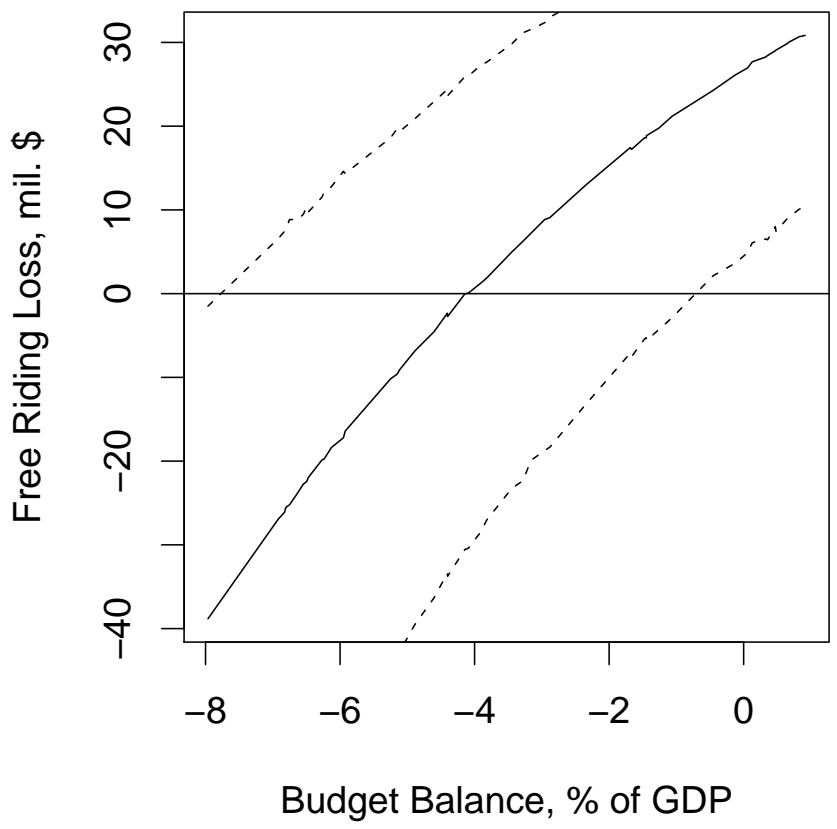

measured against a counterfactual, predicted cumulative annual aid commitments without free-riding. ${ }^{28}$ The calculations are based on model 3 in table 2.1, which provides the strongest case for hypothesis 1 . Predicted values are calculated holding other recipient country characteristics at their respective means, with one exception, and setting the post-Cold War dummy to 1 and the trade openness dummy to 0 . The exception is the political institutional quality variable, which is set to its mean plus one standard deviation. For lower values of this variable, parameter $\rho$ remains below 0 , indicating that

\footnotetext{
${ }^{28}$ To calculate the aid total without free-riding, I set the part of equation (2.9) that models the endogeneity of $\boldsymbol{Y},-\left(\boldsymbol{X}_{2} \gamma\right)\left(\boldsymbol{I}_{T} \otimes \boldsymbol{W}_{N}\right) \mathbf{Y}=0$. The graph includes $95 \%$ Clarifytype confidence bands (King et al., 2000).
} 
donors provide aid in a strategically complementary fashion. This means that collective aid provisions actually are larger because of the contributions of other donors. ${ }^{29}$ Donor endowment variables are kept at their actual values in the sample for the time period from 1994-1997.

The $\mathrm{x}$-axis in figure 2.1 ranges from the mean of the budget balance variable in the sample minus one standard deviation, to the mean plus one standard deviation. The effect of this variation in government policy is quite strong. Each percentage point improvement in the budget balance leads to a predicted loss in average cumulative annual aid payments of about $\$ 10$ million. To put these free-riding losses into perspective, the median of cumulative aid commitments in the sample is $\$ 200$ million.

A similar picture emerges for the quality of political institutions index. Figure 2.2 shows the effect of varying the index from one standard deviation below to one standard deviation above its mean. The profile of regressors for other recipient country characteristics remains as before. The budget balance variable enters at its mean plus one standard deviation. The overall change in free-riding losses over this range of index values is very similar to the one described for the budget balance.

Given that free-riding among donors occurs only with budgetary discipline and good political institutions, how prevalent is the phenomenon? To answer this question, we turn again to a counterfactual. When calculating predicted levels of aid provision both with and without free-riding, we find that only 15 percent of the observations in the sample are affected by

\footnotetext{
${ }^{29}$ In terms of the underlying theoretical model, negative values of $\rho$ are not permitted, and render the model inapplicable. From an empirical perspective however, $\rho$ captures the strength of mutual conditioning of donor choices in both directionsn.
} 
Figure 2.2: Free-Riding Loss, Institutional Quality

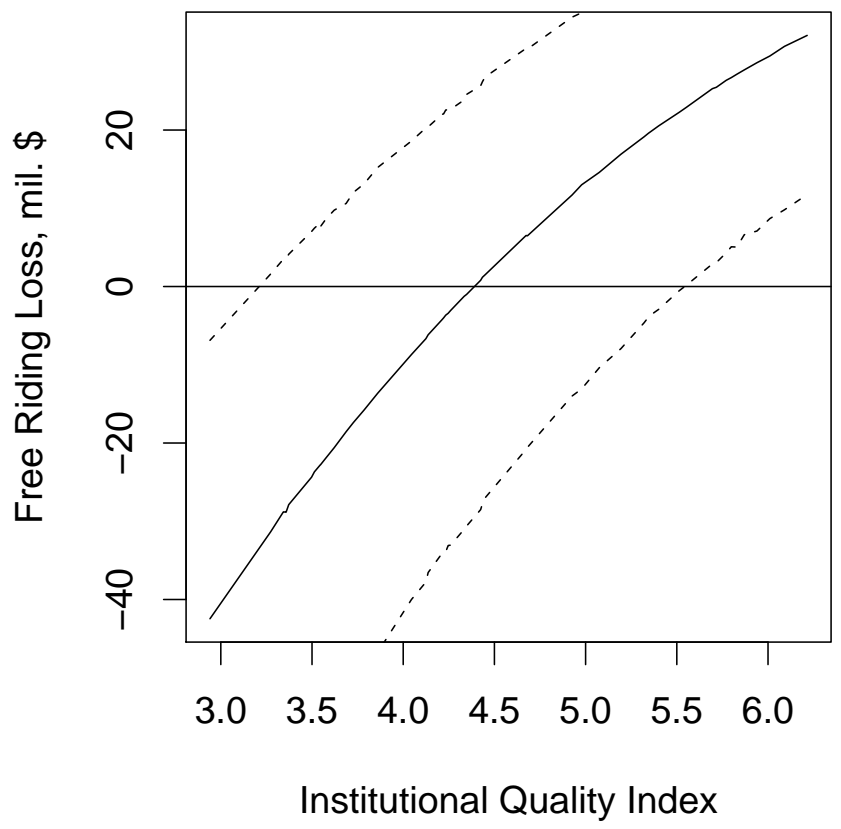

free-riding. The phenomenon is limited to recipient countries with the best economic record. They include for example Mexico from 1993-1997, Ivory Coast from 1986-1989, and South Africa from 1993-1997.

To summarize the empirical analysis, fitting the STAR model to data on aid provision and recipient country characteristics has produced important insights. The empirical evidence strongly supports hypothesis 1, albeit not for all measures of macroeconomic polices. Better budget policy of recipient countries is associated with substantively significant increases in aid losses due to free-riding between donors. However, other indicators of good macroeconomic policy do not display the same effect. In particular, infla- 
tion increases free-riding, opposite to theoretical expectations. There is no consistent empirical support for an effect of trade openness on free-riding.

The analysis produces considerable support for hypothesis 2 . There is evidence that better political institutions increase free-riding among donors. However, this result is not robust against dropping the US from the sample. Finally, we were not able to find evidence for hypothesis 3. Aid provisions in the 1990s appear not to have been subjected to greater free-riding pressures than during the Cold War period.

\subsection{Conclusion}

Western donor countries have frequently failed to meet self-set goals for the provision of development aid. This chapter illuminates some of the circumstances that contribute to the under-provision of aid. A longstanding debate about the effectiveness of aid in promoting growth centers on the role of macroeconomic policies and political institutions. For altruistically motivated donors, development constitutes a public good. I theorize that this leads to free-riding among donors, and that this collective action problem becomes worse as aid becomes more effective. To test this proposition, I develop a unified theoretical and statistical approach. The statistical analysis supports my claims.

The emerging empirical picture shows that recipient country policies and political institutions matter, but that we need to pay attention to detail. There is robust evidence that free-riding among donors worsens with improving budgetary discipline of recipient governments. At the same time, 
free-riding decreases with subsiding inflation, leading to contradicting effects. This anomaly justifies further investigation. Governments typically have no firm control over inflation rates. Also, under some circumstances, higher inflation is associated with liberal macroeconomic reforms, challenging the notion that low inflation rates are synonymous with good macroeconomic policy. Examples of this include liberalization of exchange rate regimes or the controlled devaluation of the national currency, either of which are often part of IMF adjustment programs.

It is also important to recognize that the empirical analysis finds freeriding dynamics only if both, budgetary discipline and good political institutions, are present. This drastically reduces the circumstances under which collective action problems matter for the under-provision of aid. According to the analysis, only about 15 percent of recipient countries in the sample are affected by free-riding dynamics. Since these countries tend to be the ones with the best developmental record, any policy fix that attempts to overcome coordination problems among donors faces an additional burden. As many reactions to Burnside \& Dollar's original finding show, calling for more aid to developing countries that are already relatively well off is normatively contentious. This further highlights the importance of working towards a better and more systematic understanding of how collective action problems hamper the effectiveness of aid programs. 


\section{Chapter 3}

\section{Lead Donorship: Patterns, Preferences, and Competition}

\subsection{Introduction}

Giving aid to poor developing countries is a central foreign policy tool of western nations, and increasingly rising powers such as China. While much research seeks to identify domestic factors in donor and recipient countries that drive aid provisions, we know surprisingly little about a persistent feature of donor-recipient relationships. Individual countries frequently act as lead donor for a given recipient country, sometimes by themselves, sometimes in cooperation with other donors. These lead donor-recipient relationships sometimes last for decades. Their relevance for overall aid policy is reflected in the fact that the international aid community often expects lead donors to shoulder a larger burden than others when dealing with problem states. Examples of this include the US role in Haiti, British leadership in Zimbabwe, and the former role of France in Rwanda. 
Lead donorship differs from other forms of aid provision on two dimensions. First, lead donors have longstanding ties with recipient countries. Second, this relationship is exclusive, i.e. no or few other donors vie for the role as top aid contributor. This is why studying lead donorship is different from work that seeks to identify domestic causes of aid policy. Lead donorship only persists if other donors do not seek the top spot for themselves.

In order to systematically explore the causes of lead donorship, I draw on public goods and oligopoly theory. We can identify two basic mechanisms that would allow a single donor to remain the top contributor to a given country over long periods of time. First, donors could have aligned preferences, or a donor could seek to obtain benefits from giving aid that other donors do not care about. In this situation, lead donorship will naturally arise from a lack of competition. If others do not care, the one donor who cares will automatically become the lead donor. If others share the goal of the lead donor, but this goal has public good properties, higher costs or weaker preferences will prevent them from joining into the lead donor's effort.

The second mechanism operates if donors have opposing preferences. If they use aid to compete for private benefits, we need to explain why an individual donor would be able to secure those goods exclusively for itself over long periods of time. A possible explanation is that donors collude to limit competition among themselves. In an oligopoly, the exclusive nature of the donor recipient country relationship directly results from an explicit or implicit agreement between donors to respect each others' spheres of influence. 
In order to identify which causal pathway best explains the empirical patterns of lead donorship I use the following strategy. To learn more about the phenomenon on a descriptive level, I identify cases of lead donorship drawing on the criteria of long-lasting donor-recipient ties and exclusive donor-recipient relationships.

In the next step, I statistically test whether lead donorship can be explained by the presence of cooperative behavior between donors. This involves two steps. I first need to differentiate between aid with private and public good properties. As lined out above, the logic of strategic interactions between donors is quite different in the two scenarios. Drawing on the existing aid literature, private good aid has the potential to generate private benefits for the donor through facilitating political favors by the recipient government. This type of aid is typically not project bound but either enters the recipient's general budget, or is designated to go towards administrative entities. In contrast, public good aid supports goals that have non-excludable properties. This category includes broader developmental goals such as lower child mortality, increased literacy rates, and the like.

After categorizing private and public good aid, I estimate the probability of whether a recipient country has a lead donor in a given year. I use this estimate in the next step to test whether aid allocation patterns result from cooperative behavior or not. To this end, I fit a modified spatial autoregressive model (SAR) of aid allocations. The SAR setup allows us to explicitly model strategic interconnections in the aid allocations of donors. Specifically, we can incorporate connectivity weights that correspond to lead 
donorship and equal burden sharing, and estimate to what extent aid allocation decisions depend on how much aid other donors give. In this context, the predicted probabilities of lead donorship are used to model which of the two strategic structures is more likely to drive aid allocation decisions. This analysis is performed separately for private and public good aid.

In the following, I first introduce a novel theory of lead donorship, and derive testable hypotheses. I then introduce my measure of lead donorship. The empirical analysis is divided into two parts. The first directly explores the determinants of lead donorship, and the second part tests hypotheses about aid allocation behavior that follow from the theory. I draw on data from the five OECD top donors and 118 aid recipient countries from 1974 to 2006. I find that preference asymmetries and economic interests are a good predictor of lead donorship and that strategic interactions between donors play an important role in how lead donorship arises.

\section{$3.2 \quad$ Theory}

The literature that seeks to explain aid allocation decisions is too large to cover comprehensively. Authors have looked at the role of donor preferences such as geo-political interests (e.g. Alesina and Dollar, 2000; Stone, 2006; Dreher et al., 2008), and economic self-interest (Younas, 2008). Others have researched the effects of recipient country properties such as political and economic institutions (Alesina and Weder, 2002; Bandyopadhyay and Wall, 2007), adherence to human rights norms (Neumayer, 2003), and internal armed conflict (Balla and Reinhardt, 2008). Yet another strand of the lit- 
erature looks at shared properties of donors and recipient countries, such as colonial ties (Alesina and Dollar, 2000).

The goal of this study is not to add another element to the collection of factors that determine the allocation of foreign aid. Instead, it focuses on a recurrent yet under-appreciated pattern of foreign aid practice. Some donors act as top contributors to individual countries over long periods of time. This form of lead donorship is consequential on several dimensions. Exclusive interactions can lead to close ties between aid officials of the donor country and the recipient country bureaucracy, raising the potential for corruption and inefficiencies. ${ }^{1}$ Also, lead donorship generates expectations in the international community with regard to policy leadership towards recipient countries. For example, despite the francophone roots of Haiti, in the late 1980s and 1990s France steered clear of greater involvement in the country's crisis because of long-standing American engagement in the country (Pezzullo, 2006).

The phenomenon of lead donorship has received scant academic attention. An extensive search only produced one piece that explicitly deals with the topic. Lebovic (2005) argues that donors benefit from being the largest aid contributor beyond the payoff associated with a given level of aid. In other words, lead donors receive a bonus for being in the top position. This raises several important questions. If it is lucrative to be the top donor, why do other donors not compete for this position? Under this premise, how can we explain the rise and persistence of long-lasting lead donorship?

\footnotetext{
${ }^{1}$ This criticism has been repeatedly leveled against the French aid efforts in SubSaharan Africa, that are deemed to rely too heavily on personalistic networks stemming from colonial times (Gabas, 2005).
} 
To answer these questions, we need to move beyond the notion that the largest aid provider is automatically a lead donor. Lead donorship can be characterized by two properties. First, it is in essence a longitudinal phenomenon. It is precisely the ongoing and exclusive commitments that some donors have towards select recipient countries that make them worth studying. Germany, for example, has served as top donor to Iran in either the number one or two position for 23 years between 1974 and 2006, starting in 1978 and running all the way to 2006. During this time, Iran underwent the Islamic Revolution, fought a deadly war with Iraq, and was subject to the destabilizing regional effects of the two American-Iraqi wars. In the face of this variety of circumstances, we want to explain the steadfastness of Germany's aid commitments.

A second aspect of lead donorship is the exclusivity of the relationship between a donor and a recipient country. Going back to the previous example, the German commitment to Iran was not only characterized by its longevity, but also by a lack of competition from other donors for Germany's top spot. This forms an important part of the puzzle of lead donorship. If donors use aid to secure private benefits they should face pressures to compete with each other. To the extent that this is true for Germany's engagement in Iran, we need to explain why such competition did not materialize. If, on the other hand, Germany's engagement in Iran mainly produced benefits with public good characteristics, we need to explain why Germany remained a top donor and did not succumb to incentives to free-ride on the efforts of other donors. We will develop a theory of lead donorship that provides plausible explanations for both scenarios below. 
At the other side of the spectrum that defines exclusive donor-recipient country ties lie those countries that attract much support from the international donor community. These recipient countries have a great number of engaged donors which alternate as top aid providers. They frequently receive much attention from the global public as a result of humanitarian needs or political crises. Examples include Rwanda after the 1994 genocide and Zimbabwe during its current decade-long descent into economic dissolution and political violence. Broad support can also result from aspirational motives. Botswana has attracted much support as a role model for political stability and economic progress in Sub-Saharan Africa. Similar support went to South Africa after the fall of Apartheid and Lebanon after the end of its civil war.

The longevity and exclusiveness criteria can overlap if long-standing donor-recipient country ties go hand in hand with broad support from other donor countries. For example, Cambodia's tragic story of internal violence and occupation has garnered sympathy and wide support from the international donor community, with 8 different Western nations taking the top contributor position between 1974 and 2006. Nonetheless, the US has filled a role as largest-or second largest provider of aid during 19 years, both prior to the Vietnamese occupation, and as sponsor of the peace process in the late 1980 s and thereafter.

Below I will use the longevity and exclusiveness dimensions to develop a measure of lead donorship. Before doing so, we need to introduce our theory of lead donorship, and review the motives that drive the aid policies of the five top donors. 


\subsubsection{A Theory of Lead Donorship}

When thinking about long-lasting leadership roles in the provision of public aid, we have to distinguish two principal scenarios. In the first scenario, leaders have aligned incentives, and aid is used to produce public goods. In the second scenario, aid helps to secure benefits that are exclusively enjoyed by the donor.

Let us start with the public goods scenario. It is worth reemphasizing that public goods in the sense used here are not the same as publicly provided goods such as better roads, schools, and the like (though such infrastructure aid may help produce public goods). The public good properties of aid we are interested in arise from the donors' perspective. This means that donors who give aid to foster things like economic development, reduce infant mortality, increase literacy, etc., cannot exclude other donors from enjoying success in these areas. Nor does the value of these development achievements decrease if the number of donors taking an interest in them grows. Together, these two properties are the classic criteria for the existence of a public good.

The insight that international aid given for development purposes forms a public good was first formulated by Olson and Zeckhauser (1966). While their piece is better known for its explanation of asymmetric contributions in military alliances, their causal logic underlies our argument about the source of lead donorship if aid has public good properties. The authors show that if contributors enjoy differences in marginal returns on contribution to a public good, the contributor with the largest marginal returns carries the largest burden. In the context of aid with public good properties this implies that 
the donor with the greatest marginal returns on giving aid will end up as lead donor.

Strictly speaking, differences in marginal returns on aid can result from two different sources. One is variation in the costs of providing aid, the other variation in tastes for development. In practice, this distinction is quite inconsequential. What matters is that donors value helping some developing countries more than others. We have clear anecdotal evidence that this is the case. In former colonial powers, such as Britain and France, there exist lobbies that advocate for an ongoing involvement in former colonies. Another factor are ethnic minorities from the donor country that live in former colonies. For example, Germany's engagement in Namibia since its independence in 1990s seems mostly due to the small German minority living in the country, rather than to the country's brief spell as German colony at the turn of the 19th century.

In a public goods situation with asymmetric marginal returns on the provision of aid, lead donorship essentially arises as a result of free-riding. Free-riding leads to an under-provision of public goods. This is suboptimal from a social welfare perspective. Attempts to overcome collective action problems and coordinate aid programs have been a subject of the aid debate and donor efforts at least since the early 1980s (Aldasoro et al., 2009).

Successful coordination between donors will reduce asymmetries in aid provision. The observable implications of this relationship between asymmetric aid contributions and donor coordination are the following. If a lead donor exists, this is indicative of a relative lack of coordination. We therefore should be able to detect free-riding behavior (i.e. substitution effects) or 
only weak complementarities in aid provision. The absence of a lead donor is indicative for coordination. Therefore, we should see complementarities in aid provision that are significantly stronger than in the lead donorship case.

Next, we consider the situation in which donors use aid to secure private benefits. The notion that donors use aid to attain goals unrelated to development is so old as foreign aid itself. We will review some of the diplomatic and economic uses of aid that the literature has identified below.

A central feature of the private uses of aid is that donors who try to obtain the same sort of benefit should be locked in competition which each other. While scholars of political economy have recognized that in the domestic arena competing interest groups can use money to influence policy outcomes (Grossman and Helpman, 1994), the obvious parallel in the aid realm has been ignored so far. Competition prevents the rise of a lead donor. This is because competing donors have incentives to match the top contributor's aid commitments and thus ensure their share of the pie.

Lead donorship under competition for private benefits therefore can only arise in two ways. First and trivially, if donors do not seek to obtain the same kind of benefits there will be no competition. Second, if donors are able to reduce competition between themselves, they will be collectively better of. They therefore have incentives to try to coordinate their aid allocations. This type of coordination is the equivalent of collusion in oligopoly theory (e.g. Varian, 1992, chapter 16). Lead donorship therefore arises as a result of explicit or implicit collusive agreements to carve up exclusive spheres of influence for individual donors. 
The observable implications of these theoretical considerations are twofold. First, in the absence of lead donorship we have competition between donors. Since competition implies that donors match each others' aid contributions, in this situation we should see complementarities in aid provision. On the other hand, lead donorship is indicative of collusion. In the presence of a lead donor we therefore expect that complementarities in aid provision will decrease or substitution effects arise.

Of central conceptual importance is our ability to distinguish between aid with public goods character and aid allocations that serve to secure private benefits. To help us make this distinction in an informed fashion, and to gather the building blocks for a statistical model of lead donorship, the next section reviews some of the historic driving forces behind aid programs.

\subsubsection{Motivations for Giving Aid}

As we have seen in the previous section, donor preferences play an important role for lead donorship. If preferences and the resulting cost-benefit analysis are asymmetric, donors who give aid to foster development face collective action problems that give rise to lead donorship. Conversely, donors who use aid to secure private influence are locked into competition with each other only if they share preferences for the same goods. Lead donorship then will arise in an attempt to limit this competition.

Given this important role of preferences, if we want to model instances of lead donorship statistically it is necessary to account for similarities and asymmetries in donor preferences. In this section I review what drove the aid programs of the five largest providers of bilateral aid, the US, Japan, 
France, Germany, and the UK. We will take a brief look at each of those donor's aid policies.

After its early years as diplomatic tool in the Cold War, US foreign aid was and continues to be characterized by a duality of diplomatic and development purposes (Lancaster, 2007, p. 79). Carol Lancaster identifies the countries in which American aid has been used for primarily diplomatic purposes as Israel, Egypt, and other countries of the Middle East, Cambodia, the Philippines, and El Salvador, Nicaragua, and Honduras. Motives for support ranged from fundamental strategic goals in the Middle East, over concerns about left-leaning popular movements in Central America, the need to secure support for military bases in South-East Asia, to post-conflict reconstruction in Cambodia, and starting in the 1990s, the former Yugoslavia and again Central America.

The duality of American aid currently finds expression in institutional innovations such as the Millennium Challenge Corporation that aims to strengthen the development aspect of American aid. At the same time, the Pentagon plays an increased role in distributing official American development aid (upwards of 20\%), with an eye to support governments that deny terrorist organizations safe haven (Brown and Patrick, 2007).

While some works argue that the US employs aid to influence voting behavior in the UN general assembly (Dreher et al. 2008, but see Stone 2006), there is relatively little evidence that US aid is geared towards fostering commercial interests. However, American aid tying practices remain opaque, as the US has stopped reporting the relevant numbers in the early 1990s.

Of all five donor countries, French foreign aid policy most directly grew 
out if its colonial experience. There is little dispute that from its inception, French aid was overtly diplomatic in purpose and designed to maintain a political sphere of influence in Sub-Saharan Africa. However, this also resulted in personalistic ties between France and its client states that frequently were used to benefit French industries through non-competitive bidding, and aid-financed development projects (Lancaster, 2007, p. 154). Serious organizational reform was only tried in 1998. However, the new structures appear unsuccessful in isolating diplomatic influence on French aid decisions (Lancaster, 2007, p. 159), a fact that is underlined by the largely unchanged composition of French aid in the post-Cold War period (Quinn and Simon, 2006; Gabas, 2005).

Japanese aid policy has been commonly attributed to commercial motives. Until the 1970s, aid also served Japan to rehabilitate relations with its regional neighbors. The oil shocks together with agricultural shortages caused by a US export embargo on soybeans lead to a reorientation of aid towards securing access to raw materials. For example, Japan began to undertake aid financed infrastructure projects in Arab oil producing countries and in Brazil (Lancaster, 2007, p. 116 f.). In the 1980s, Japanese aid strongly increased. It started to be directed also towards overarching Western diplomatic goals, for example in the Middle East. Despite widespread suspicion of the opposite, it appears that Japan also significantly reduced its tying practices during this time (Lancaster, 2007; Tuman et al., 2009, p. 120). Still, Japanese aid practices traditionally have put an emphasis of infrastructure and equipment purchases. This also did not change after new policy fields such as environmental aid gained prominence. Overall, the 
enduring combination of regional political goals, concerns about access to raw materials, and a mode of aid giving that at least potentially benefits Japanese industries makes the Japanese aid program the most commercially oriented of all five major Western donors.

Neither the UK nor Germany had economic or strategic interests driving their aid programs in a regionally concentrated fashion as those of the US, France or Japan. In its early days, West Germany gave aid in support of overall Western diplomatic goals, but also to benefit German export industries (Lancaster, 2007, p. 171 ff.). Special diplomatic status had German support for Israel. Despite early professionalisation of aid practices through the creation of a fully dedicated ministry of development (Bundesministerium für Wirtschaftliche Zusammenarbeit, BMZ), a focus on infrastructure projects remained an important facet of German aid policies throughout the 1970s and 80s. German aid drastically decreased during the 1990s in reaction to budgetary constraints resulting from the need to finance German unification. Beginning in the late 1990s, developmental goals moved to the center stage of German aid programming.

Similar to the French case, British aid developed out of the country's colonial experience. Unlike France though, Britain did not use these historic relationships to satisfy global political ambitions. Instead, successive governments emphasized Britain's moral obligation for the development of its former dependencies. Under Margaret Thatcher, the government announced it would change aid practices to pay more attention to Britain's commercial interests. But there was little following through in terms of policy (Cumming, 2001, p. 74 ff.). Despite the persistent development ori- 
entation, British aid retained one of the highest tying rates of the five donor countries (Cumming, 2001, p. 90), which directly benefited British industries and service providers. This changed under Tony Blair's Labour government. British aid increased manifold, as general budget support gave more flexibility to recipient governments (Seldon, 2007, p. 559), and aid tying was formally ended as a policy practice.

\subsubsection{Operationalizing Donor Preferences}

As the preceding overview has shown, we can categorize the main motives for giving aid as diplomatic, economic, and developmental. The next step is to operationalize measures that will allow us to capture those preferences for the statistical analysis. Let us look at economic interests first. The historic record shows that two areas of economic activity played a role in aid programs, export promotion and building relationships with oil producing countries.

The case for export promotion is relatively straightforward. The focus of Japanese and German aid programs on infrastructure aid, past British aid tying practices, and French insider dealings with African client countries all point towards the promotion of domestic exports. In addition, all five countries are producers and exporters of major capital goods and durable consumables, such as planes, machinery, and cars, and thus compete for export markets. Beyond this anecdotal evidence, a recent piece by Younas (2008) finds that exports of capital goods are associated with increased aid flows from donor countries, controlling for a wide variety of recipient country properties. 
We can measure exports from donor to recipient countries using the readily available Comtrade database (United Nations, 2009). What relationship should we expect between trade flows from donors to recipient countries, and the incidence of lead donorship? Donors that use aid for export promotion should compete for influence. This, in turn, will increase incentives to limit competition through collusion. We therefore should expect that higher exports are associated with an increased incidence of lead donorship.

There is some anecdotal evidence that donor countries, in particularly Japan, have used aid to improve relationships with oil producing countries, but the case is less clear-cut. It is certainly true that the economies of all five donors in our analysis were and remain dependent on foreign oil imports. However, oil is traded on an international spot market that does not discriminate against individual buyers on political grounds. It is therefore not immediately apparent why donor countries would seek to use aid to influence oil producing countries. However, there is a direct mechanism that has the potential to drive donor policy. Even though all of the six largest private oil companies are multinationals, three of them have histories as national champions of their European countries of origin (Royal Dutch Shell, BP, and Total S.A.). All oil majors, including the US based ExxonMobil (the largest global oil major), Chevron (number 4), and ConocoPhillips (number $5)$, generate massive benefits in form of taxes and employment opportunities for the countries where they have their headquarters. Since decisions about new oil concessions in producer countries are often political in nature (Yergin, 1991), donor governments that are home of multinational oil companies have incentives to provide political support for these companies. 
More anecdotal evidence for the relevance of oil for aid policy comes from the behavior of China on the international aid scene. China, a relative parvenu as donor, openly uses its bilateral aid to secure oil concessions. For example, in 2004 China secured rights to a portion of future Angolan oil output by giving the Angolan government a comprehensive loan and aid package worth $\$ 2$ billion (Hanson, 2008). Western donors do not use such open means to exert influence, but concerns for supply security will exert pressure on them to pay attention to Chinese actions on this front.

What relationship does our theory predict for oil imports and the incidence of lead donorship? As in the case of trade, donors are locked into competition with each other if they use aid to influence oil producing countries. This, in turn, will increase the incentives to collude. Higher imports from an oil producing country therefore should increase the probability that this country has a lead donor. Data on oil imports and exports is also available from the Comtrade database.

Let us now turn to diplomatic and strategic interests. With the possible exception of France, the five donors in our analysis have enjoyed closely aligned foreign policy preferences during the Cold War and beyond. However, due to its unique military strength, the US plays an exceptional role in projecting military power worldwide. In particular in the Pacific region, the permanent presence of US troops continues to produce regional strategic stability, benefiting Japan in particular. A similar effect can be attributed to the US troop presence in the Middle East in the wake of Iraq's invasion of Kuwait.

America's worldwide military engagement arguably reflects its relatively 
lower marginal costs in projecting power abroad and providing regional stability. To capture the asymmetry in the American cost-benefit calculus for providing this public good, we can look at the number of troops stationed in individual aid recipient countries. To the extent that the ability to provide military might also translates into a cost advantage for providing aid, we should expect more US troops to increase the probability of US lead donorship.

Historically, the US has claimed Central and South America as its zone of influence, albeit mostly without supporting this claim with a troop presence. There is no reason to believe that any of the other four donor countries in the analysis harbors desires to exert a similar influence in the region. ${ }^{2}$ America's preeminence therefore is an expression of asymmetric diplomatic preferences between the US and the other major donors.

In order to capture these asymmetries, I rely on a geographic definition of the American zone of influence. This is in line with historic announcements of American politicians, going all the way back to the Monroe Doctrine from 1823. In addition, there are no readily available other measures that come to mind. For the statistical analysis I narrowly limit the American zone of influence to include Mexico and the states of Central America. This seems reasonable since large states in South America such as Brazil often have defined their interests in active dissociation from American policy.

The argument with regard to the French sphere of influence in SubSaharan Africa is similar. The value of this political connection to French

\footnotetext{
${ }^{2}$ In fact, it was arguably the conscious British disengagement from the Caribbean in the late 19th century that averted military confrontation between the then declining British Empire and the rising USA.
} 
policy makers did arise from the unique history and continuing economic and security ties between France and her former colonies. No other donor could gain the same political benefits from simply increasing aid to countries in the French sphere of influence. To illustrate this, economic policy ties between France and its client states include the CFA Franc zone, which currently pegs the currencies of 14 African countries to the Euro (originally the French Franc) and is underwritten by the French treasury. This arrangement has helped reduce the costs of stationing French troops in some of these countries, which form the backbone of an ongoing security cooperation. Accordingly, the French engagement in Sub-Saharan Africa is an expression of asymmetric preferences between France and the other donors.

As measure of the French sphere of influence we include all countries that are former French colonies. An alternative would be to use membership in the CFA France zone, but this can generate problems in some statistical settings. ${ }^{3}$

Britain did not maintain a sphere of influence as clearly defined geographically and in political purpose as the French. However, we have seen that parts of the British aid program were driven by a sense of moral responsibility towards former colonies. This motive for giving aid, in conjunction with large minority groups from former colonies living in the country, arguably give Britain a higher marginal utility for helping its former colonies than other donors. We therefore include a measure in the analysis that identifies recipient countries that were former British colonies.

\footnotetext{
${ }^{3}$ When estimating lead donorship on a donor-by-donor basis, the CFA dummy variable perfectly predicts cases where France is not a lead donor. This approach was used in an earlier version of this paper.
} 
From the inception of its aid program, Japan used aid as tool to achieve political reconciliation with the countries in Asia that had suffered under its occupation. While not comparable to the relatively clear-cut spheres of influence of the US and France, Japan therefore had a unique diplomatic motivation to give aid to Asian countries. This, too, constitutes an asymmetry in donor preferences. These ties also found expression in close commercial cooperation. However, we are interested in the role of trade on lead donorship for its own sake. I therefore use another geographic dummy variable as measure of special Japanese preferences. The variable includes all countries of South-East and South Asia. ${ }^{4}$

What should we expect for the four spheres of influence with regard to the effect on lead donorship? Obviously, our assignation of areas with asymmetric donor preferences was in part made through observing donor actions. This is particularly true for France in Africa and Japan in Asia. However, in neither case did we determine what counts as sphere of influence by looking at aid alone. Still, we expect that the asymmetry in preferences makes it more likely that lead donorship arises within these spheres of interest.

\subsection{Empirical Analysis}

\subsubsection{Patterns of Lead Donorship}

In the following, I develop a scheme that categorizes aid recipient countries along the longitudinal and exclusiveness dimensions discussed above. As a measure of long-lasting donor commitments, I count the number of years

\footnotetext{
${ }^{4}$ I count Pakistan as part of the Middle East.
} 
from 1974 to 2006 that a specific donor took the top or second place position in providing aid. As measure of exclusiveness, I count the number of different top contributors a recipient country did have over the same time period.

Tables 3.1 to 3.3 report how the countries in the sample break down. In table 3.1, we have a list of countries with individual long-term top aid contributors. The donors held the top contributor position more than 50\% of the time, or 16 out of the 33 years in the sample. This group of recipient countries also fares strongly on the the exclusivity dimension. Table 3.3 lists the countries that have a large number of different top contributors $(\geq 8)$. Not surprisingly, there is no overlap between the countries in tables 3.1 and 3.3, with one exception. ${ }^{5}$ We therefore label the countries represented in table 3.1 as cases of strong lead donorship.

A quick glance at the list shows that strong lead donorship to a large extent corresponds with the spheres of diplomatic and economic influence identified in the aid literature. In the US case, the American government acts as strong lead donor mainly in Central America, and for select Southern American and Caribbean countries. This is in line with the strong historic American claim to this area as sphere of exclusive diplomatic influence. In addition, US support of Israel, Egypt, and Jordan underlines the longstanding strategic American commitments in this region. The only African country in which the US acts as strong lead donor is Liberia. This commitment speaks to the shared history of resettling freed American slaves from the US to Liberia. It is remarkable that no Asian country made the list of

\footnotetext{
${ }^{5}$ The exception is Madagascar. France acts a number one donor 19 out of 33 years, with the remaining 12 years split between 7 other donors.
} 
Table 3.1: Largest Donor, $\geq 50 \%$ of Time

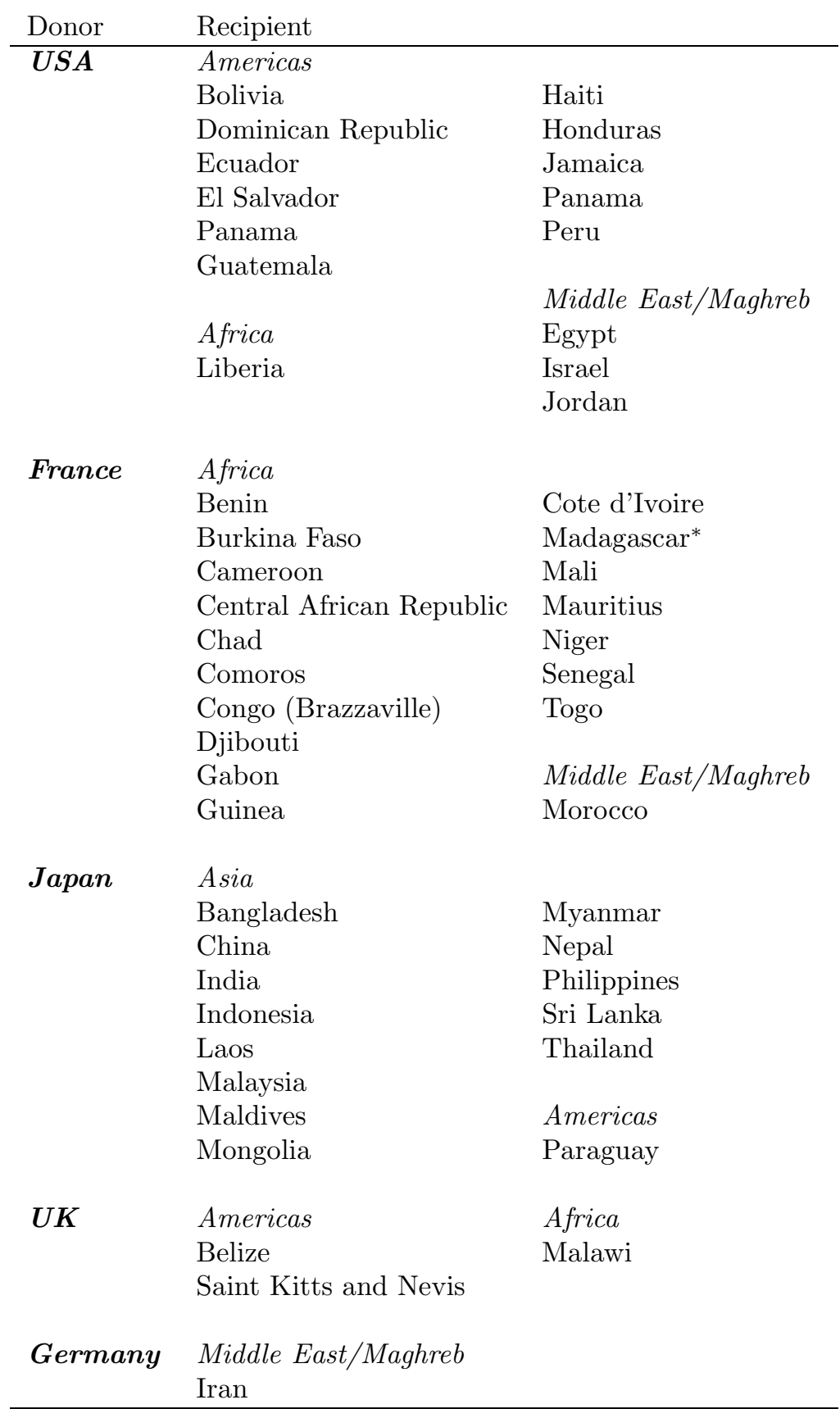

Countries marked with ${ }^{*}$ have 8 or more top aid contributors as defined in table 3.3 . 
strong American lead donorship. American strategic interests in the region do not seem to require stronger aid engagements. ${ }^{6}$

In the case of France, the list of strong lead donorship countries maps exceptionally well onto the French sphere of influence in Sub-Saharan Africa. It includes all but two current members of the CFA Franc zone, ${ }^{7}$ and covers a large number of former French colonies in West and Central Africa. The only case of strong French lead donorship outside Sub-Saharan Africa is Morocco, which also is a former French colony.

Japan is overwhelmingly engaged as strong lead donor in South Asia and South-East Asia. The list encompasses all large countries in the region, including China, India, Indonesia, and the Philippines. Japan's lead donorship behavior fits well with the description of its aid program as driven by the desire to secure regional economic influence. The only country outside Asia for which Japan plays a strong lead donor role is Paraguay. This relationship does not easily fit strategic or security interest based explanations. In addition, Japanese trade relations with Paraguay largely mirror those of the other four major donor countries. ${ }^{8}$

There is only a handful of countries for which Great Britain or Germany serve as strong lead donor. Great Britain supports three relatively small former colonies. Their size and location make it unlikely that this is due to strategic interests. Germany is engaged in Iran. Historically, Germany has enjoyed relatively good relations with Iran. Of course, Iran is also a

\footnotetext{
${ }^{6}$ The reason for this is probably that Japan, as strong American ally, substituted for American lead donorship in the region.

${ }^{7}$ The exceptions are Equatorial-Guinea and Guinea-Bissau, which joined the CFA Zone only in 1985 and 1997 respectively.

${ }^{8}$ However, a tiny Japanese minority exists in Paraguay.
} 
major producer of oil. For both countries, their restraint in taking strong lead donorship roles is in line with a lack of well-define spheres of diplomatic or economic influence.

Overall, table 3.1 gives an impression of strong lead donorship as driven by strategic and commercial interests, that center on specific regions. Important donors such as Germany and Great Britain that do not have such clearly pronounced spheres of influence do not act as strong lead donors.

How does the picture change if we slightly relax the exclusivity requirement? To answer this question, I also look at second biggest aid contributions. Maintaining the longevity criterion, table 3.2 lists the countries that have one and the same donor acting either as largest or second largest aid contributor for 17 out of 33 years under consideration (ignoring cases of strong lead donorship). A substantive number of the countries that meet this criterion failed on the wider exclusivity requirement because they attracted support from 8 or more other top donors. These countries are marked with an asterisk. I call the instances of lead donorship in table 3.2 moderate lead donorship.

The picture of moderate lead donorship emerging from table 3.2 is mixed when compared to the patterns of strong lead donorship. There is only a small number of countries that matches the diplomatic and economic spheres of influence described above.

Looking at the US, an active engagement with a number of Sub-Saharan African countries emerges. This engagement is not easily explained by economic self-interest. The affected countries are among the poorest on earth. However, they shared a role as pawns in the positioning between the su- 
Table 3.2: Largest or Second Largest Donor, $\geq 50 \%$ of Time

\begin{tabular}{|c|c|c|c|}
\hline \multirow{2}{*}{$\frac{\text { Donor }}{\boldsymbol{U S \boldsymbol { A }}}$} & \multicolumn{3}{|l|}{ Recipient } \\
\hline & $\begin{array}{l}\text { Africa } \\
\text { D.R. Congo } \\
\text { Ethiopia } \\
\text { Gambia* } \\
\text { Guinea } \\
\text { Sierra Leone } \\
\text { Somalia } \\
\text { Sudan } \\
\text { Swaziland }\end{array}$ & $\begin{array}{l}\text { Americas } \\
\text { Belize } \\
\text { Costa Rica } \\
\text { Guyana } \\
\text { Asia } \\
\text { Cambodia* } \\
\text { Philippines } \\
\text { South Korea }\end{array}$ & $\begin{array}{l}\text { Middle East/ } \\
\text { Maghreb } \\
\text { Afghanistan* } \\
\text { Lebanon* } \\
\text { Oman } \\
\text { Pakistan }\end{array}$ \\
\hline France & $\begin{array}{l}\text { Middle East/Maghreb } \\
\text { Algeria } \\
\text { Lebanon* } \\
\text { Mauritania* } \\
\text { Tunisia }\end{array}$ & $\begin{array}{l}\text { Oceania } \\
\text { Vanuatu } \\
\text { Americas } \\
\text { Mexico }\end{array}$ & $\begin{array}{l}\text { Africa } \\
\text { Burundi } \\
\text { Equatorial } \\
\text { Guinea }\end{array}$ \\
\hline Japan & $\begin{array}{l}\text { Americas } \\
\text { Brazil } \\
\text { Asia } \\
\text { Bhutan* }\end{array}$ & $\begin{array}{l}\text { Middle East/Maghreb } \\
\text { Pakistan } \\
\text { Syria* }\end{array}$ & $\begin{array}{l}\text { Oceania } \\
\text { Fiji }\end{array}$ \\
\hline$U K$ & $\begin{array}{l}\text { Africa } \\
\text { Ghana } \\
\text { Kenya* } \\
\text { Uganda } \\
\text { Zimbabwe* }\end{array}$ & $\begin{array}{l}\text { Americas } \\
\text { Dominica } \\
\text { Grenada }\end{array}$ & $\begin{array}{l}\text { Asia } \\
\text { India }\end{array}$ \\
\hline Germany & $\begin{array}{l}\text { Middle East/Maghreb } \\
\text { Egypt } \\
\text { Israel } \\
\text { Syria* } \\
\text { Jordan }\end{array}$ & $\begin{array}{l}\text { Africa } \\
\text { Togo } \\
\\
\text { Europe } \\
\text { Turkey }\end{array}$ & $\begin{array}{l}\text { Americas } \\
\text { Brazil }\end{array}$ \\
\hline
\end{tabular}

Countries marked with ${ }^{*}$ have 8 or more top aid contributors as defined in table 3.3. This table omits countries listed in table 3.1. 
perpowers during the Cold War. Thus, strategic interests did play a role for some of the sample period. Yet in most cases, the US retained top donor status after the end of the Cold War, which is not easily explained by strategic or economic self-interest. On the other hand, US engagement as moderate lead donor in Asia fits its long-standing strategic interests in the region, particular with respect to South Korea and the Philippines.

The largest group of states for which France acts as moderate lead donor consists of former colonies located in the Maghreb region. This is in line with the strategic motives of French aid provision on the African continent. French support for Mexico was particularly pronounced during the Latin American debt crisis in the 1980s and coincides with a temporary surge of French oil imports from Mexico. Growth of French exports to Mexico was relatively anemic compared to the competition from the US, Germany, and Japan, and only outdid British exports.

Only a handful of countries received moderate lead donorship support from Japan. Pakistan and Syria likely made the list because of Japanese support for Western strategic concerns in the Middle East. Brazil was and remains Japan's largest trading partner in Latin America, though its exports are less than German and American numbers.

British moderate lead donorship is completely directed towards former colonies. Again, there are no obvious commercial, economic or diplomatic interests that drive this policy.

Finally, Germany is engaged as moderate lead donor in a number of Middle Eastern countries. As in the case of Japan, this can be seen as support for general Western concerns about stability in the region. In addition, Ger- 
many's support for Israel results from the unique historic ties between the two countries. Like Japan, Germany is also a moderate lead donor to Brazil, which is Germany's largest trading partner in Latin America. Two idiosyncracies are Germany's support for Togo, which briefly was a German colony in the early 20th century, and its role in Turkey. Turks form the largest group of immigrants in Germany, suggesting motives for aid provision that go beyond strategic and regional security concerns.

It is interesting to note that a number of recipient countries have both a strong and a moderate lead donor. These countries are Israel (USA and Germany), the Philippines (Japan and the US), Belize (USA and Britain), and Togo (France and Germany). Except for perhaps Israel, all of these pairings fall into the sphere of influence of the strong lead donor, with the moderate lead donor sharing historic ties with the recipient country. The countries with moderate lead donor that fail on the exclusivity criterion are not easily categorized. They include countries in post-conflict situations such as Lebanon, former poster children of colonial independence such as Zimbabwe, but also key players for regional strategic relations such as Syria.

We now turn to the countries on the other end of the exclusivity spectrum. Table 3.3 lists those countries that during the 33 years in the sample received aid from 8 or more different top donors. Choosing a cutoff of eight is guided by the empirical distribution of the number of top contributors in the sample, and thus arbitrary to some degree. The variable is distributed approximately normal, with the median lying at 5 , and the 75 th percentile lying at 8 (the maximum is 10). Thus, we label 25 percent of recipient countries in the sample as having a large number of different top donors. 
Table 3.3: Recipient Countries with Eight or More Different Top Contributors

\begin{tabular}{lll} 
Region & Country & \\
\hline Americas & & Nicaragua \\
& Argentina & Trinidad and Tobago \\
& Barbados & Uruguay \\
& Chile & Venezuela \\
& Colombia &
\end{tabular}

Africa

$\begin{array}{ll}\text { Botswana } & \text { Nigeria } \\ \text { D.R. Congo } & \text { Rwanda } \\ \text { Gambia* } & \text { Tanzania } \\ \text { Kenya* } & \text { Zambia } \\ \text { Lesotho } & \text { Zimbabwe* } \\ \text { Madagascar* } & \end{array}$

Asia

Bhutan*

Cambodia*

Middle East/

Maghreb Afghanistan* Libya

$\begin{array}{ll}\text { Iraq } & \text { Maurit } \\ \text { Lebanon* } & \text { Syria* }\end{array}$

Europe

Former Yugoslavia / Serbia Malta

Countries marked with ${ }^{*}$ also have a lead donor as defined in . tables $3.1 \& 3.2$ 
Table 3.4: Remaining Countries with $\leq 7$ Top Contributors

\begin{tabular}{lll} 
Region & Country & \\
\hline Americas & Bahamas & Saint Lucia \\
Africa & & \\
& Guinea-Bissau & South Africa \\
Asia & & \\
& Taiwan & Singapore \\
& Vietnam & \\
Middle East & & \\
& Saudi-Arabia & Bahrain \\
& Yemen & Qatar \\
& Kuwait & United Arab Emirates
\end{tabular}

Europe

Albania Cyprus

A look at table 3.3 shows a heterogenous picture. The list contains a number of oil exporting countries, such as Venezuela, Nigeria, Iraq and Lybia. Others were of significance for strategic reasons during the Cold War (many of the African countries, but e.g. also Cambodia, Cuba, and the former Yugoslavia). Finally, the countries in the Middle East were of strategic value to all Western donors.

It remains to take a look at the residual category, countries that neither had a strong or moderate lead donor, but that also did not generate enough donor interest to have a high number of different top aid contributors. Fifteen such countries are in the sample. They are listed in table 3.4 .

The biggest homogenous group of countries in the residual category are 
the big Arab oil producers of the Middle East. While all of them received some aid at some point in the sample, neither of them enjoyed broad aid support or had a lead donor. There are not many similarities between the remaining countries. Taiwan and Singapore were already on the way to economic success during the sample period. South Africa did not receive any foreign aid before 1987. Both Albania and Vietnam were firmly lodged in the Eastern Bloc during the Cold War, even though they were not members of the Warsaw Pact. ${ }^{9}$ However, while Albania only started to receive Western aid after 1988, Vietnam received Western aid throughout the sample period.

The discussion of our categorization scheme allowed for impressionistic evaluations of the possible causes for lead donorship. The overall picture shows that strong lead donorship is an important feature of the American, French and Japanese spheres of influence. However, donor preferences are only part of the explanation for persisting lead donorship. Britain and Germany also act as strong lead donors in a few cases, and moderate lead donorship maps less well onto the spheres of influence. To understand how donors are able to persist as top contributors we need to take strategic interactions into account. We will do this in the following statistical analysis.

\subsubsection{Statistical Setup}

In this section we take a more systematic look at the sources of lead donorship. The goal is to develop a statistical setup that will allow us to test the theorized relationship between strategic donor interactions and lead donor-

\footnotetext{
${ }^{9}$ Albania formally withdrew from the Pact in 1968, having withheld support since 1961 as reaction to the Sino-Soviet split.
} 
ship. Our argument about the effects of strategic interactions on donor aid allocations points to three empirical quantities of interest. These are aid allocations, lead donor patterns, and whether aid has private or public good characteristics. Which of these variables are endogenous, which are exogenously determined? To answer this question it will be useful to revisit the logical structure of the argument.

We have argued that strategic interactions between donors have quite distinct consequences dependent on whether aid is used to secure private benefits or contributes to a public good. What both scenarios have in common is that aid allocations and resulting lead donorship patterns arise as a result of donors anticipating other donors' actions, and optimally adjusting their own aid policies. In other words, aid allocations reflect equilibrium behavior. We will maintain the assumption that the empirical record reflects equilibrium behavior throughout the empirical analysis, for three reasons.

First, this assumption allows us to gain explanatory leverage from our theory. Without this assumption, we are left without clear empirical predictions. Second, while real world political actors such as aid agencies can make mistakes, there are a multitude of mechanisms providing incentives to avoid perpetual suboptimal behavior. These incentives include resource scarcity, political oversight, and professional recognition. Thirdly, since observed aid policies and the phenomenon of lead donorship are stable over long time periods, it seems sensible to conclude that these observations are not the result of a random walk. ${ }^{10}$

\footnotetext{
${ }^{10}$ These arguments do not preclude the possibility that aid agencies act suboptimal from a welfare perspective, or that aid policies are subject to dynamic interactions. Such arguments are best dealt with in an equilibrium framework, and imply a more complicated
} 
What follows from the assumption that aid allocations are observed equilibrium behavior for the empirical analysis? While aid allocations result endogenously from the actors' best response calculus, the logic of gametheoretic deduction implies that we need to treat game type and equilibrium selection as exogenously fixed. The game type is whether aid is given to serve public or private good purposes. Equilibrium selection refers to whether donors choose to cooperate or give aid in a non-cooperative fashion.

In terms of the statistical analysis, this means that we need to model aid allocations as a function of both, the type of aid provided (public vs. private good aid), and the presence or absence of a lead donor. The exogeneity of equilibrium selection allows us to model lead donorship and the type of aid provided without accounting for allocated amounts of aid.

I incorporate these features into the following econometric setup. To differentiate between aid that goes towards public goods and aid that generates private benefits, I divide the sample into two parts. As measure of aid with private good characteristics I code all aid that is channeled through existing recipient government agencies. Codings are based on sectoral data provided by the OECD-DAC's Creditor Reporting System (CRS, OECD, 2009). Aid has private good characteristics if it allows donors to garner political favors from recipient governments. I argue that this is more likely if aid is not bound to a particular project, but is either given as general budget aid, or directed towards building administrative capacity. Since these aid moneys are under complete purview of the recipient government, accounting mechamodel of policy making. 
nisms are relatively weak, which means the money can be used as payoff for political favors. In contrast, aid that is spent on concrete projects, as well as aid that is not channeled through recipient government hands, cannot easily be diverted to pay off government officials. I therefore code public good aid as all aid that is given directly as project aid, or through NGOs.

This distinction between private and public good aid is certainly not the only possible option. Another measure of the private goods character of aid that comes to mind is the tying status of aid. I have used this measure in chapter 2. But the fact that the US stopped reporting aid tying practices in the early 1990s sharply limits the temporal domain of this measure. In addition, an imputation strategy for missing US tying data is only plausible for the early 1990s. This is because the end of the Cold War caused Western donors to reevaluate their aid policies, and those changes began to shape policy outcomes in the late 1990s.

Arguably, there are also other ways to divide the data based on the sectoral breakdown found in the CRS. However, scholars have just begun to explore the wealth of information contained in sectoral aid data (e.g. Bermeo, 2008). What is more, the small literature that explicitly deals with the private and public goods characteristics of aid looks exclusively at aggregate aid levels (Mascarenhas and Sandler, 2006). The measurement strategy employed here, while possibly imperfect, breaks conceptual ground.

I use a logit setup to model lead donorship. The logit equation generates predicted probabilities of lead donorship. I use these predicted probabilities in turn in the aid allocation equation to identify which equilibrium donors play. Because equilibrium selection comes logically prior to aid allocation 
decisions, the lead donor and aid allocation equations form a fully recursive system of equations (Greene, 2003, p. $395 \& 397$ ). This means we can estimate sequentially the probability of lead donorship, and then use the generated predicted probabilities as independent variable in the aid allocation equation. Since the sequential approach leads to incorrect standard errors in the second step, I choose to estimate both equations simultaneously in an MLE framework.

The aid allocation equation is a modified Spatial Autoregressive (SAR) model (Anselin, 1988; Franzese and Hays, 2007b). In chapter 2, I have shown the similarity between a structurally derived estimator of an impure public goods games and the SAR model. Here, I use a more general setup that does not represent any particular game structure. Instead, it allows us to statistically detect complementarities and substitution effects in simultaneous donor aid allocation decisions (Franzese and Hays, 2008). In the context of aid given for private benefit, complementarities can be interpreted as evidence of competition, while substitution effects are evidence of collusion. In the public goods scenario, substitution effects are evidence of free-riding, while complementarities show the presence of coordination between donors.

To allow for both an equilibrium with and without lead donor, I include two endogenous elements in the SAR setup. ${ }^{11}$ I interact each element with the predicted probability that the donors play this particular equilibrium. The resulting equation has the following form:

\footnotetext{
${ }^{11}$ The inclusion of two different endogenous structures does not present a problem in terms of estimation (Franzese and Hays, 2007a).
} 


$$
\boldsymbol{Y}_{i, t}=\rho_{l} E\left(Z_{i, t}\right) \boldsymbol{W}_{l} \boldsymbol{Y}_{i, t}+\rho_{d}\left(1-E\left(Z_{i, t}\right)\right) \boldsymbol{W}_{d} \boldsymbol{Y}_{i, t}+\boldsymbol{X}_{i, t} \boldsymbol{\beta}+\boldsymbol{\varepsilon},
$$

where the $\boldsymbol{Y}_{i, t}$ is a $5 \times 1$ column vector of aid allocations from the five donor countries in the analysis to recipient country $i$ in time period $t$. The endogenous element capturing the lead donorship situation is $\rho_{l} E\left(Z_{i, t}\right) \boldsymbol{W}_{l} \boldsymbol{Y}_{i, t}$, where $E\left(Z_{i, t}\right)$ is the predicted probability of lead donorship, $\boldsymbol{W}_{l}$ is a $5 \times 5$ matrix of strategic connectivity weights $w_{k, j}$ described in detail below, and $\rho_{l}$ is the estimated connectivity parameter for the lead donor situation. It takes on positive values for complementarities in aid provision and negative values for substitution effects. ${ }^{12}$ The endogenous element capturing non-lead donorship equilibrium play is $\rho_{d}\left(1-E\left(Z_{i, t}\right)\right) \boldsymbol{W}_{d} \boldsymbol{Y}_{i, t}$. The probability of no lead donor is $1-E\left(Z_{i, t}\right)$, the complement of the estimated probability of lead donorship. Parameter $\rho_{d}$ captures complementarities and substitution behavior in this equilibrium. Its interpretation is equivalent to $\rho_{l}$.

The weight matrices $\boldsymbol{W}_{l}$ and $\boldsymbol{W}_{d}$ are made up of weights $w_{k, j}$, where $j$ indexes the row donor, and $k$ indexes the column donor. The choice of connectivity weights is one of the central tasks the analyst faces in specifying an SAR model. Unless connectivity weights are explicitly derived from a strategic model as in chapter two, there is necessarily an element of arbitrariness in this decision. I follow a simple intuition. In an equilibrium with lead donor, donors pay more attention to the actions of the lead donor than to other non-lead donors. In an equilibrium without lead donor on the other hand, donors put equal weight on the actions of all other donors.

\footnotetext{
${ }^{12}$ Since I use connectivity weights that sum to 1 , and $E\left(Z_{i, t}\right)$ is bounded above at 1 (resembling a weighted average), parameter $\rho_{l}$ is naturally bounded between -1 and 1 .
} 
To justify this, consider first the public goods situation. Here, the lead donor enjoys lower marginal costs of providing the public good, ${ }^{13}$ which induces it to give more than other donors. Thinking about equation (3.1) as a system of best response functions, we can capture this difference in the marginal utility calculus by giving the lead donor greater relative connectivity weights. ${ }^{14}$ In the private goods scenario, lead donorship results from collusion. It is the substance of the collusive agreement that the lead donor enjoys privileged political access to recipient governments. It therefore seems natural that other donors pay special attention to the lead donor's actions.

The following example features the weight matrix $\boldsymbol{W}_{l}$ for the lead donor equilibrium, with donor number 3 acting as lead donor. In the statistical analysis, the matrix reflects the actual lead donor for each recipient country and year. ${ }^{15}$

$$
\boldsymbol{W}_{l}=\left[\begin{array}{ccccc}
0 & \frac{1}{6} & \frac{1}{2} & \frac{1}{6} & \frac{1}{6} \\
\frac{1}{6} & 0 & \frac{1}{2} & \frac{1}{6} & \frac{1}{6} \\
\frac{1}{4} & \frac{1}{4} & 0 & \frac{1}{4} & \frac{1}{4} \\
\frac{1}{6} & \frac{1}{6} & \frac{1}{2} & 0 & \frac{1}{6} \\
\frac{1}{6} & \frac{1}{6} & \frac{1}{2} & \frac{1}{6} & 0
\end{array}\right]
$$

Each row $j$ reports how aid allocations of donor $j$ are affected by aid allocations of column donors $k=1 \ldots 5 .{ }^{16}$ The weights $w_{k, j}$ sum to 1 across rows. The disparity between the strategic impact of the lead donor and other donors is captured in the difference between connectivity weights for

\footnotetext{
${ }^{13}$ Or, equivalently enjoys a greater marginal utility from consuming the public good.

${ }^{14}$ To see why, consider equal connectivity weights for all donors. In this situation, the best response functions of all donors would be identical, which would lead to symmetric aid allocations, and lack of lead donorship.

${ }^{15}$ For reasons of clarity of exposition, I suppress subscripts $i$ and $t$ for matrix $\boldsymbol{W}_{l}$.

${ }^{16}$ Note that $w_{j, j}=0$, i.e. aid allocations are not reflexive.
} 
the lead donor $w_{j, 3}=\frac{1}{2}, j \neq 3$, and connectivity weights for other donors $w_{j, k}=\frac{1}{6}, j \neq 3, k \neq 3$. In addition, the lead donor itself assigns equal weight to the actions of all non-lead donors, $w_{3, k}=\frac{1}{4}, k \neq 3$.

For cases without lead donor, we have no theoretical reason to give different strategic weights to different donors. Accordingly, the weight matrix reflects a symmetric arrangement:

$$
\boldsymbol{W}_{d}=\left[\begin{array}{ccccc}
0 & \frac{1}{4} & \frac{1}{4} & \frac{1}{4} & \frac{1}{4} \\
\frac{1}{4} & 0 & \frac{1}{4} & \frac{1}{4} & \frac{1}{4} \\
\frac{1}{4} & \frac{1}{4} & 0 & \frac{1}{4} & \frac{1}{4} \\
\frac{1}{4} & \frac{1}{4} & \frac{1}{4} & 0 & \frac{1}{4} \\
\frac{1}{4} & \frac{1}{4} & \frac{1}{4} & \frac{1}{4} & 0
\end{array}\right]
$$

With all elements of the statistical setup in place, we can now turn to the data.

\subsubsection{Data}

As mentioned above, all aid data is taken from the OECDs Creditor Reporting System (OECD, 2009). The raw data cover the years 1974 to 2006. However, we lose four years due to the lag structure of the dependent variable that I discuss below. The data structure are donor-recipient years. We start with a balanced panel with 19740 observations, arranged in 33 years, with 118 recipient countries and five lead donors. Due to taking lags and missing data on independent variables, the actual analysis uses 13160 observations, with 109 recipient countries. Panels are unbalanced.

The econometric setup features three different dependent variables. The first is lead donorship, a binary variable, the second and third are are aid 
allocations with private and public good characteristics. Let us start with the lead donorship variable. In the descriptive part of the analysis we utilized the entire history of aid provision in the data. We labeled a donor as strong lead donor if it provided aid to one recipient country 50 percent of the times or more. This approach is not feasible in the econometric analysis if we want to make use of the information that is contained in the temporal dimension of the data. We therefore need a modified measure of lead donorship that preserves the core characteristics of the longevity and exclusivity criteria, while not giving up too much temporal variation.

As solution, I take a sliding count of the number of years during which each donor was the largest donor to a given country over a time period of five years. Maintaining the concept that a lead donor acts as top contributor a majority of times, I code lead donors as giving most for 3 or more out of the five years. This measure does not directly tap into the exclusivity criterion, but it maps very well into the descriptive analysis. The variable correctly labels strong lead donors for most of the cases listed in table 3.1. Exceptions result from the need to drop some observations for taking lags and missing data in independent variables.

Not surprisingly the new measure assigns lead donor status to a number of recipient country-donor pairs that do not appear on the original list of strong lead donorship. In this regard, the five year sliding count is more sensitive to changes in donor-recipient country relationships than when we sum up over 33 years. For example, the new measure picks up US lead donorship in Nicaragua before the Reagan administration curbed US aid to the new Sandinista regime in 1981. 
An important issue arises from long-time character of the lead donor variable in the logit analysis. Taking a sliding count over five years uses up four years worth of data from the sample. Since we started out with 33 years in the sample, the data loss is modest, leaving us with 29 years worth of data. In cross-sectional time-series analysis it is common practice to lag independent variables to ensure the proper sequential order of events. Since in our case the dependent variable covers five years, $t=-4$ to $t=0$, we enter all independent variables with a four year lag into the logit analysis. While this ensures sequential ordering, it substantively means that our logit model is forward looking. In other words, it captures whether a donor will be a lead donor in the present and in the next four years to come.

The second and third dependent variables are allocation of aid with private and with public good characteristics. Both variables are measured as absolute aid committed by a donor to a recipient country per year, in constant (2005) US dollars. The decision to use absolute aid contributions, rather than aid scaled by recipient country GDP or population is due to our focus on donor interactions. The key point of strategic decision making is that donors make their own contributions in the light of the actions of other donors. Since our theory tells us that donors decide over actual dollar amounts, we keep this measure.

The two dependent variables are constructed using the sectoral breakdown of aid data found in the OECD Creditor Reporting System. As discussed before, I use the sectoral data to divide aid contributions into a part with private goods characteristics and a part with public good characteristics. Aid with private good characteristics is given as General Budget 
Table 3.5: Aid Channeled Through Government Agencies

\begin{tabular}{lc} 
Donor & $\begin{array}{l}\text { Percentage } \\
\text { of Total Aid }\end{array}$ \\
\hline Germany & $18.04 \%$ \\
France & $33.82 \%$ \\
Japan & $25.71 \%$ \\
UK & $21.48 \%$ \\
USA & $29.73 \%$
\end{tabular}

Support or directed to develop administrative capacity in a specific policy area. ${ }^{17}$ Public good aid, on the other hand, is under greater donor purview, thus reducing its use to serve as pay off for political favors. ${ }^{18}$

Table 3.5 reports the share of donor commitments that is classified as aid with private goods characteristics, averaged over the 32 sample years. France has the largest share (33.8 percent), followed by the US (29.7 percent) and Japan (25.71 percent). Germany (18.0 percent) and the UK (21.5 percent) have the smallest and second smallest share of this type of aid. This breakdown corresponds well with how the literature describes the aid programs of the five donors. France, the US and Japan are thought to be more prone to use aid to further bilateral goals, of a diplomatic (France, US) or commercial nature (Japan), while the British and German aid programs are deemed to be more development oriented. This correspondence lends credence to the validity of our coding scheme.

We next look at the independent variables. To capture asymmetries in donor preferences towards certain donor countries, I use a variety of mea-

\footnotetext{
${ }^{17} \mathrm{~A}$ list of included purpose codes can be found in table 3.9 in the appendix.

${ }^{18}$ I code public good aid as all CRS codes not falling into the private good category.
} 
sures. To capture US strategic interests, I take the number of US troops stationed in a recipient country. The source are the Department of Defense Personnel Statistics Online (Department of Defense, 2009). For the American sphere of interest, I code a dummy variable that captures all countries of Central America and Mexico. ${ }^{19}$ For the French sphere of influence, I originally coded a dummy variable with the members of the CFA Franc zone. However, this variable has a strong disadvantage for use in statistical analysis. In some settings, it perfectly predicts cases without French lead donorship, and therefore cannot be used in the logit analysis. As alternative measure of French strategic interests, I use a dummy variable that is coded 1 for former French colonies and 0 otherwise. I take this variable from Fearon and Laitin (2003). I rely on the same data source for the dummy variable for former British colonies. For Japan's sphere of influence, I code a dummy variable that covers all countries in Southern and South-East Asia. ${ }^{20}$

For both the lead donorship and aid allocation equations, we are interested in capturing the effects of exports from donor to recipient countries, and oil imports that flow in the opposite direction. I take export data from the Comtrade database (United Nations, 2009). ${ }^{21}$ For each donor-recipient pairing, I calculate annual total exports from the donor to the recipient country. Data on oil imports comes from the same source. The variable reflects annual oil sales from recipient to donor country, for each donor-

\footnotetext{
${ }^{19}$ The complete list includes Belize, Costa Rica, El Salvador, Panama, Former Panama Canal Zone, Guatemala, Honduras, Mexico, and Nicaragua.

${ }^{20}$ The list includes Bangladesh, Bhutan, Burma, Cambodia, China, South \& North Korea, India, Indonesia, Laos, Malaysia, Maldives, Mongolia, Nepal, Pakistan, Philippines, Singapore, Sri Lanka, Taiwan, Vietnam.

${ }^{21}$ The data accords to the SITC Revision 1 reporting standard.
} 
recipient country pairing. Both variables are measured in constant (2005) US Dollars. The variables are included in both the lead donorship and aid allocation equations.

The last substantive independent variable in the lead donorship equation accounts for changes in aid policies after the end of the Cold War. I include a dummy variable that is coded 1 for years prior to 1991, and 0 for later years. The end of the Cold War caused a shock to the aid system that forced all donors in the sample to revaluate their aid programs. Since the aid system was more stable during the Cold War years, I expect that during this time lead donorship was more likely.

The logit model includes a final set of variables that play a technical role. To model temporal dynamics of changes in lead donorship, I include a third order polynomial of the time since the last spell of lead donorship for individual donors into the analysis (Carter and Signorino, 2007). This polynomial provides the equivalent of a baseline hazard.

The aid allocation equation contains a second set of independent variables. As already mentioned, I include the oil imports and export variables. To capture effects of lead donorship on levels of aid commitment, I include the predicted probability of any of the five countries acting as lead donor as independent variable. Since the logit equation generates one predicted probability for each donor-recipient country pair, I added up those individual probabilities for all five donors. ${ }^{22}$

In addition, I chose a number of standard measures designed to capture

\footnotetext{
${ }^{22}$ In the analysis, in about 10 percent of the cases, the sum of predicted probabilities exceeded 1. I decided to keep the these imputed values in the analysis.
} 
recipient country characteristics. GDP per capita measures wealth. Many studies find that wealth plays a role in donor aid allocation decision, but the direction of the effect is contested. I also include a population variable. Larger countries should receive more aid, at least in the aggregate.

Two variables address econometric issues. To address concerns about autocorrelated errors, I include the lagged dependent variable as independent variable. In addition, aid allocation decisions are subject to an overarching budget constraint. While the actual process of inter-agency budget decision making is too complex to be modeled in statistical analysis, I include a variable that adds up total aid given by each donor to all recipient countries per year. Finally, all independent variables enter the analysis with a one year time lag. Similar to the logit equation, this ensures the proper sequential ordering of cause and effect.

Do we have to be concerned about meeting exclusion restrictions? As I have argued extensively above, lead donorship is not endogenous to aid allocation decisions. From this perspective, a weak condition on the variancecovariance matrix is met that ensures identification of the entire system of equations. ${ }^{23}$ However, our setup also contains a set of variables that can serve as credible instruments to meet exclusion restrictions. The logit equation features a third-order polynomial of time since the last lead donorship episode. This measure should be largely uncorrelated with individual private and public good aid allocations. From a theoretical perspective, we treat each year as an independent realization of a stage game. More importantly

\footnotetext{
${ }^{23} \boldsymbol{\Sigma}$ is diagonal, as disturbances do not co-vary, ensuring the entire structure is identified (Greene, 2003, p. 395)
} 
however, from an empirical perspective individual donor aid allocations do not determine lead donorship status. Changes to lead donorship status are a result of the actions of all donors in the system, over a sustained period of time (including actions of donors other than the five largest in the sample). The data bears this out. The correlation between dyadic aid commitments and the time since the least lead donor spell is low, $r=-0.133$ for the private good case, and $r=-0.140$ for the public good case.

\subsubsection{Results}

As mentioned before, the logit and SAR equations are estimated simultaneously, using MLE. Table 3.6 has results for both equations. The table shows two different models (each with one logit and one SAR equation). In the first model, aid allocations fall under private good aid given to recipient government entities. In the second model we look at public good aid, i.e. aid given directly to projects or to NGOs.

Let us consider the lead donorship equations first. The point estimates are almost identical for both models. This should come as no surprise, as the dependent and independent variables are identical across setups. A brief glance at coefficient signs and statistical significance levels shows the following. As expected, both oil exports to donor countries and imports of goods and services from donor countries increase the probability that a developing country has a lead donor. Former French colonies are more likely to have a lead donor, but the same is not true for former British colonies. Nor does the number of stationed US troops affect lead donorship. Surprisingly, the Cold War has a negative effect on lead donorship, i.e. after 
Table 3.6: Lead Donorship \& Committed Allocation

\begin{tabular}{lllll} 
& \multicolumn{2}{c}{$\begin{array}{c}\text { Aid Given to } \\
\text { Government }\end{array}$} & \multicolumn{1}{c}{$\begin{array}{c}\text { Other } \\
\text { Distribution }\end{array}$} \\
\hline Lead Donorship & & & & \\
Oil Imports & $0.188^{* *}$ & $(0.0282)$ & $0.171^{* *}$ & $(0.0287)$ \\
Exports & $0.314^{* *}$ & $(0.0855)$ & $0.320^{* *}$ & $(0.086)$ \\
US Soldiers & -0.0673 & $(0.0705)$ & -0.0472 & $(0.0697)$ \\
Cold War & $-1.17^{* *}$ & $(0.0765)$ & $-1.16^{* *}$ & $(0.0769)$ \\
French Colony & $0.576^{* *}$ & $(0.0845)$ & $0.566^{* *}$ & $(0.084)$ \\
British Colony & 0.058 & $(0.0816)$ & 0.0646 & $(0.0809)$ \\
Asia & $0.406^{* *}$ & $(0.0816)$ & $0.382^{* *}$ & $(0.0851)$ \\
Central America & $0.350^{* *}$ & $(0.128)$ & $0.323^{* *}$ & $(0.127)$ \\
Time & $-0.546^{* *}$ & $(0.0349)$ & $-0.547^{* *}$ & $(0.0347)$ \\
Time & $2.69^{* *}$ & $(0.331)$ & $2.70^{* *}$ & $(0.329)$ \\
Time & $-4.83^{* *}$ & $(0.823)$ & $-4.85^{* *}$ & $(0.817)$ \\
Constant & $0.706^{* *}$ & $(0.0992)$ & $0.703^{* *}$ & $(0.0993)$ \\
Committed Aid & & & & \\
$\rho_{d}$, No Lead Donor & 0.00155 & $(0.0242)$ & $0.122^{* *}$ & $(0.0224)$ \\
$\rho_{l}$ Lead Donor & $-0.0317^{* *}$ & $(0.0122)$ & $0.0361^{* *}$ & $(0.0113)$ \\
Pr(Lead Donor $)$ & -0.00246 & $(0.00205)$ & $0.00904^{* *}$ & $(0.00315)$ \\
Aid ${ }_{t=-1}$ & $0.032^{* *}$ & $(0.00041)$ & $0.0323^{* *}$ & $(6 \mathrm{e}-04)$ \\
Donor Total Aid & -0.000459 & $(0.000346)$ & 0.000648 & $(0.000505)$ \\
GDP Per Capita & $0.0319^{*}$ & $(0.0165)$ & $0.0778^{* *}$ & $(0.0241)$ \\
Population & $-0.0158^{* *}$ & $(0.00517)$ & $0.109^{* *}$ & $(0.00801)$ \\
Exports & -0.00201 & $(0.00267)$ & $0.0137^{* *}$ & $(0.00391)$ \\
Oil Imports & 0.000126 & $(0.000907)$ & $0.00572^{* *}$ & $(0.00133)$ \\
Constant & -0.00144 & $(0.00308)$ & $-0.0164^{* *}$ & $(0.00454)$ \\
$\mathrm{s}^{2}$ & $0.00635^{* *}$ & $(7.25 \mathrm{e}-05)$ & $0.0136^{* *}$ & $(0.000165)$
\end{tabular}


1990 a recipient country was on average more likely to have a lead donor than prior to this year.

To gauge the size of these effects, consider predicted probability plots for oil exports and imports of all goods. ${ }^{24}$ In figure 3.1, the x-axis features oil exports in million US Dollars. Because the variable is highly right-skewed, it is shown on a logarithmic scale. The y-axis shows the predicted probability that the oil importing donor acts as lead donor. The probabilities are calculated setting other continuous variables to their respective sample medians, the Cold War dummy to 1 , and all four spheres of influence variables to 0 . The graph shows a strong association between oil exports and the likelihood of lead donorship. The logarithmic scale masks that the marginal effect of oil exports does not vary much over the sample range. The probability of lead donorship increases by between 0.18 percentage points and 0.47 percentage points for each $\$ 100$ mil. in additional oil sales.

However, only a few aid recipient countries export oil at a scale that by itself is large enough to push the probability of lead donorship to substantive heights by itself. From the 109 recipient countries in the sample, 17 have absolutely no oil exports. 24 have oil exports that surpass $\$ 1$ billion to an individual donor in some years. It is for those countries that oil exports have a palpable effect on the likelihood of lead donorship. For example, doubling exports to one donor from $\$ 1$ billion to $\$ 2$ billion increases the probability that this donor will act as lead donor by about 3.5 percent. If the increase in sales occurs vis-à-vis two donors, the increase in the cumulative probability

\footnotetext{
${ }^{24}$ I report substantive effects and goodness-of-fit based on model 1, with private good aid. The numbers for model 2 , with public good aid, are nearly identical.
} 
of one of them acting as lead door is 7 percent. Increasing exports to one donor from $\$ 1$ billion to $\$ 5$ billion leads to a 15.3 percent jump in the probability that this donor acts as lead donor. In a few cases, donors even surpass the $\$ 10$ billion hurdle. This is the case for oil deliveries from Saudi Arabia to Japan, the US, and France; oil sold from Mexico, Venezuela, and Nigeria to the US; and - in one year only - oil deliveries from the United Arab Emirates to Japan.

Figure 3.1: Oil Imports, Lead Donorship

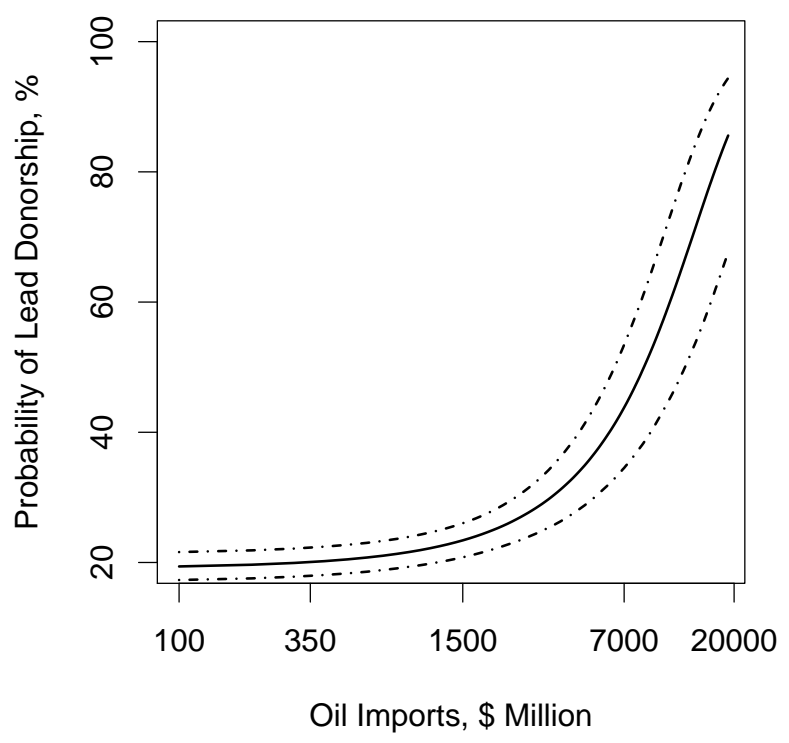

Next, in figure 3.2 we look at the substantive impact of imports of all goods and services from donor countries. Again, the x-axis features a logarithmic scale. The impressive effect that exports from the donor country at first glance have on the probability of lead donorship is misleading. Most aid recipient countries import too little to be affected at all. While exports 
topped $\$ 100$ billion in one case (Mexico and USA in 2000 and 2001), exports for the median case were less than $\$ 100$ million per year, and not more than $\$ 380$ million at the third quartile. Moving from $\$ 0$ imports to $\$ 100$ million only increases the probability of attracting a lead donor by 0.05 percentage points. For the majority of cases in the sample, lead donorship is therefore not affected by imports from donor countries. The greatest marginal effect occurs around $\$ 45$ billion, when each additional $\$ 1$ billion in imports adds about 0.8 percentage points to the probability of having the trade partner as lead donor. Only China, Mexico and South Korea import that much. ${ }^{25}$

Figure 3.2: Exports from Donor, Lead Donorship

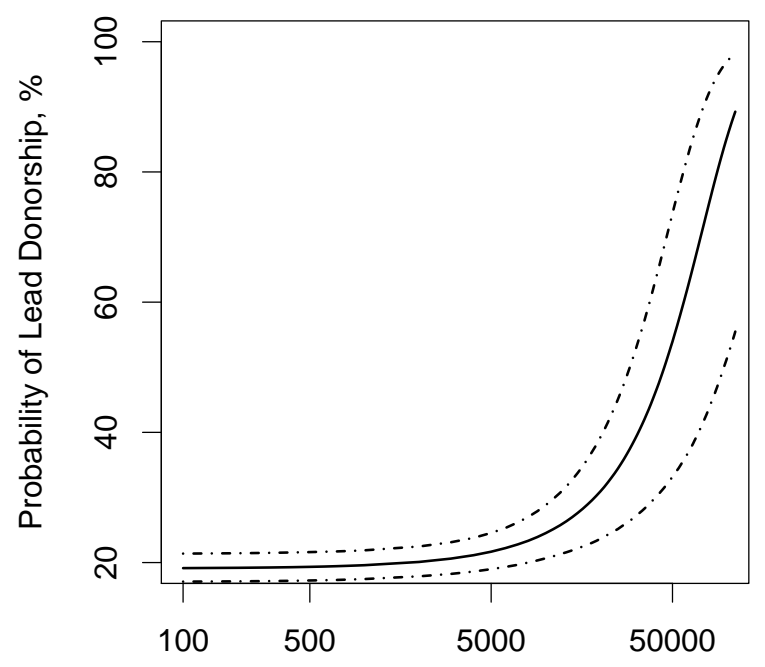

Exports From Donor, \$ Million

For the dummy variables, table 3.7 reports marginal effects holding all

\footnotetext{
${ }^{25}$ The list of countries that reaches at least $\$ 10$ billion in imports from a single donor additionally includes Brazil, Indonesia, Malaysia, Philippines, Saudi Arabia, Singapore, and Thailand.
} 
Table 3.7: Effect on Probability of Lead Donor

\begin{tabular}{llll} 
& & 3 & \multicolumn{2}{c}{ Confidence } \\
Variable & Effect & \multicolumn{2}{c}{ Bounds } \\
\hline Cold War & $-23.9 \%$ & $-27.4 \%$ & $-20.4 \%$ \\
French Colony & $14.1 \%$ & $10.0 \%$ & $18.1 \%$ \\
British Colony & $0.016 \%$ & $-0.023 \%$ & $5.41 \%$ \\
Asia & $9.49 \%$ & $5.31 \%$ & $13.6 \%$ \\
Central America & $8.02 \%$ & $1.85 \%$ & $14.1 \%$
\end{tabular}

continuous variables at their medians, and other dummies at 0 . The large negative effect (-23.9\%) of the Cold War on the probability of lead donorship comes as somewhat of a surprise. The list of strong and moderate cases of lead donorship in tables 3.1 and 3.2 show a number cases in which Western support can be attributed to Cold War concerns (e.g. the US engagement in Sub-Sahran Africa and Cambodia, broader Western support for the Middle East). Thus, our finding challenges the usual narrative that the Cold War forced Western donors into maintaining stable relationships with aid recipient countries based on strategic needs.

More in line with existing arguments is the finding that former French colonies are on average about 14.1 percent more likely to have a lead donor. Since the analysis averaged over all 5 donors in the sample, this number represent the probability that any of the five donors is a lead donor. The probability that France acted as lead donor in its former colonies is likely substantively higher. ${ }^{26}$

Former British colonies are not more likely to have a lead donor than

\footnotetext{
${ }^{26}$ Capturing this separate effect for each of the four spheres of influence would have a required a cumbersome interaction term design.
} 
Table 3.8: Lead Donorship, Accuracy of Prediction

\begin{tabular}{c|cc} 
& \multicolumn{2}{c}{ Predicted } \\
Actual & 0 & 1 \\
\hline 0 & $672(54.9 \%)$ & $552(45.1 \%)$ \\
1 & $417(29.6 \%)$ & $991(70.4 \%)$
\end{tabular}

the reference category, i.e. countries outside the four spheres of influence. Since British diplomatic interests and its aid program had the least sharply delineated geographic focus, this negative finding is not surprising. For Asia and Central America, the model shows the expected positive effects. Countries in Asia have a probability of lead donorship that is 9.49 percent greater than the reference category. For Central America, this number is 8.02 percent.

Since we use the logit equation to generate predicted probabilities of lead donorship, the question of prediction accuracy arises. To gauge this, in table 3.8 I tabulated how well the model predicts lead donorship. It does reasonably well. Using $50 \%$ probability as cut-off for a positive prediction, the model correctly predicts 70.4 percent of all instances of lead donorship. For cases of non-leadership, this number is somewhat lower at 54.9 percent.

Next, we look at the SAR equation that models aid allocation decisions. Of central interest are the strategic connectivity coefficients, $\rho_{d}$ and $\rho_{l}$. Let us begin with the private goods model that captures aid given through government channels. Our theoretical expectation was that for cases without lead donor, aid is given in complementary fashion, as donor seek to compete for political influence. In lead donor cases however, we expected a substitution effect. 
Coefficient estimates for the connectivity parameters give support to the second half of this prediction. Parameter $\rho_{l}$ is negative $\left(\rho_{l}=-.0317\right)$, and statistically significant. This means that donors substitute aid given by the lead donor for their own aid. In the case of no lead donorship, parameter $\rho_{d}$ is positive as expected, but the estimate is too small to reliably distinguish it from zero $(\rho=0.0015)$. Thus, the model fails to find evidence of competition between donors in the provision of private aid, in the absence of a lead donor.

Instead of looking at estimates for the connectivity parameters, a more intuitive way to grasp the effects of strategic donor interactions is to look at predicted aid allocations $\hat{Y}$, with and without strategic endogeneity. We can directly measure the size of substitution and complementarity effects by first calculating $\hat{Y}$ s with strategic endogeneity,

$$
\hat{\mathbf{Y}}_{i, t}=\left(\boldsymbol{I}-\hat{\rho}_{l} E\left(Z_{i, t}\right) \boldsymbol{W}_{l}-\hat{\rho}_{d}\left(1-E\left(Z_{i, t}\right)\right) \boldsymbol{W}_{d}\right)^{-1} \boldsymbol{X}_{i, t} \boldsymbol{b}
$$

where $\hat{\rho}_{l}, \hat{\rho}_{d}$ and $\boldsymbol{b}$ are coefficient estimates. We then calculate predicted values for aid allocation without strategic interactions, $\tilde{\mathbf{Y}}_{i, t}$. To this end we set $\hat{\rho}_{l}=0$ and $\hat{\rho}_{d}=0$, reducing equation (3.4) to

$$
\tilde{\mathbf{Y}}_{i, t}=\boldsymbol{X}_{i, t} \boldsymbol{b}
$$

Next, we calculate the substitution or complementarity effect for each observation by subtracting $\hat{\mathbf{Y}}_{i, t}-\tilde{\mathbf{Y}}_{i, t}$, element by element, and sum across donors to obtain the cumulative effect by country $i$ and year $t$.

Going back to private good aid, the result of this exercise shows that 
coordination between donors in countries with lead donorship on average reduced individual aid allocations between 0.4 percent and 49.7 percent, with a mean of 3.5 percent. In countries without lead donor, despite the positive (but statistically insignificant) coefficient estimate of $\rho_{d}$, we still find a substitution effect. Strategic interactions between donors account for an average reduction in aid commitments by 0.98 percent. The evidence therefore supports our theoretical argument that lead donorship dampens the provision of private good aid. However, in the absence of a lead donor the model fails to find complementarities in aid provision. These would have been indicative of competition between donors.

For project-bound aid with public good characteristics, the analysis produces the following results. Our main argument was that lead donorship arises from asymmetries in the marginal utility calculus of providing a public good. Coordination between donors should lead to lesser asymmetries, and more complementarities in the provision of aid. This is essentially what we find. While there is no evidence of actual free-riding in lead donor cases $\left(\rho_{l}=0.0361\right)$, complementarities in aid provision are much bigger if there is no lead donor $\left(\rho_{d}=0.122\right)$.

Using the method described above, the predicted complementarities in cases with lead donor amount on average to 5.8 percent of additional aid on top of what would have been allocated without coordination. For individual recipient countries, this effect ranges from 0.02 percent to 9.12 percent of additional public goods aid.

Recipient countries without lead donor experience substantively larger complementarities, with an average of 9.87 percent of additional aid resulting 
from coordination. Estimates for individual recipient countries lie between 7.95 percent and 11.6 percent. Clearly, in the absence of a lead donor, the donor community is better able to coordinate in the provision of public good aid.

Let us now turn to the independent variables. We included the expected probability of lead donorship as independent variable in the analysis. The interpretation of its coefficient estimate is not straightforward since the variable does double duty in weighing the endogenous components $\rho_{l} \boldsymbol{W}_{l} \boldsymbol{Y}$ and $\rho_{d} \boldsymbol{W}_{d} \boldsymbol{Y}$. Instead we need to look at the marginal effect that the probability of lead donorship (denoted as $E\left(Z_{i, t}\right)$ ) has on aid allocations. To this end, we differentiate equation (3.1) with respect the $E\left(Z_{i, t}\right)$ :

$$
\frac{\partial Y}{\partial E\left(Z_{i, t}\right)}=\rho_{l} \boldsymbol{W}_{l} \boldsymbol{Y}_{i, t}-\rho_{d} \boldsymbol{W}_{d} \boldsymbol{Y}_{i, t}+\beta
$$

where $\beta$ is the coefficient for the probability of lead donorship. Note that the marginal effect of the probability of lead donorship is conditioned on the parameter estimates $\rho_{l}$ and $\rho_{d}$, as well as aid allocations by other players $\boldsymbol{Y}_{i, t}$, weighed by the connectivity matrices $\boldsymbol{W}_{l}$ and $\boldsymbol{W}_{d}$. When calculating estimated marginal effects, we therefore have to make assumptions about aid allocations $\boldsymbol{Y}$. Instead of counterfactual values for $\boldsymbol{Y}$, I use the actual data on aid allocations.

In the case of private good aid, the coefficient estimate is negative but not statistically significant. However, the marginal effect of lead donorship is statistically significant. Moving from no lead donorship $\left(E\left(Z_{i, t}\right)=0\right)$ to 
certain lead donorship $\left(\operatorname{Pr}\left(E\left(Z_{i, t}\right)=1\right)\right.$, aid allocations by individual donors on average decrease by $\$ 807,000$ on an annual basis, with a 95 percent confidence interval of $[-\$ 1,411,000,-\$ 217,000] .{ }^{27}$ For individual recipient countries, extreme cases range between a zero reduction of aid and a decrease by $\$ 48.6$ million. This provides strong evidence that lead donorship leads to substitution effects in the provision of private good aid and thus limits competition in aid allocations.

For aid with public good characteristics, the average effect of moving from no lead donorship to lead donorship is associated with an average increase of aid allocations by $\$ 1.72$ million annually (with a 95 percent confidence interval of [ $\$ 0.648$ million, $\$ 2.79$ million]). For individual cases, the largest estimated effect is an increase by $\$ 138$ million, and the smallest is a zero increase.

Our theory suggests that, in a public goods scenario, lead donorship helps to overcome free-riding problems. A corollary is that, ceteris paribus, donors should give less aid under lead donorship compared to when coordination succeeds. In contrast, we find that lead donorship has a positive marginal effect on aid provisions. How can this be squared with our evidence that greater complementarities in aid provision exist in situations without a lead donor? The two findings indicate that the direct positive effect of lead donorship on aid allocations, as captured in the coefficient $\beta$, is stronger than the negative strategic effect of lead donorship. There are at least two possible explanations for this result. First, it is possible that our measure of

\footnotetext{
${ }^{27}$ Confidence intervals are based on simulations using the estimated variance-covariance matrix.
} 
public good aid is contaminated by aid used for other purposes. If some of the strong lead donors in our sample give aid for idiosyncratic reasons that do not fit the public goods category, these allocations could outweigh any possible gains from coordination on public good aid.

Second, our theoretical and statistical analysis potentially fails to account for the relationship between how much aid a recipient country needs, and how easy it is for donors to coordinate. If donors find it more difficult to coordinate when facing countries with greater aid needs, and easier if needs are smaller, we would end up with an empirical pattern similar to what we observe. This is because successful coordination would produce relatively small complementarities in aid provision (due to low need), while countries with big aid needs would see coordination failure, lead donorship, and relatively high aid allocations (because of their big needs). A more detailed look at this relationship needs to await future research.

We next turn towards the substantive effects of the other independent variables in the aid allocation equation. Only two variables behave identically for both, the private and public goods models. Recipient countries with higher GDP per capita on average attract more of both aid types. The literature generally reports mixed findings with regard to GDP per capita. In our setup, we control for the predicted probability of lead donorship and strategic interactions, but running the analysis without those controls does not substantively change results for this or the other independent variables. The second variable that behaves similar in both models is the lag of the dependent variable, indicating that both dependent variables have an autoregressive component. 
An interesting contrast exists between the effect of recipient country population size on the different types of aid. Aid going towards government agencies decreases with population size, but public good aid increases. While the literature usually identifies a negative relationship between population size and aid, these findings are typically built on the analysis of aggregate data. What could account for the discrepancy? Possibly it is more difficult to pay off leaders for political favors through aid the larger a recipient country is. This could either be the case because larger countries have inherently larger winning coalitions, making public goods provision more desirable from the perspective of incumbents (Bueno de Mesquita et al., 2003). Or, it could be a function of larger countries having a more decentralized bureaucracy. Arguably, with more autonomous institutions, the political gains from channeling money through them decreases. The discrepancies in the effects of the population variable highlight the relevance of looking at aid allocations from a sectoral perspective.

The variables that capture oil imports and exports of all goods and services have no effect on private good aid, but are statistically significant and positive for public good aid. We included these variables into the analysis to capture donor motivations for gaining private advantage through aid. Our expectation was that these measures would affect private good aid more heavily than public good aid. This is not the case. The finding does not change if we run the analysis without the probability of lead donorship as independent variable and without the SAR setup. Our private goods model of lead donorship fails to find support on this account.

Overall, the empirical analysis produces some successes, and some mixed 
results. Preference asymmetries and commercial interests appear as good predictors of lead donorship. Big oil producing countries and important trading partners of donors states are more likely to have a lead donor. Lead donorship is also more likely to occur in the spheres of influence of France (Sub-Saharan Africa), the US (Central America), and Japan (Asia), but not in former British colonies, and not as a function of US troops being stationed in a country.

The test of the role of strategic interactions between donors for lead donorship produces mixed results. For private good aid, we are able to identify a strong relationship between lead donorship and substitution effects in aid provision, as predicted by our theory. In addition, we find that lead donorship has a strong overall negative effect on aid allocations. This confirms our hypothesis that collusion serves to reduce competition in aid allocations. However, the statistical analysis fails to uncover evidence of actual competitive behavior in the absence of a lead donor. Our measures for private interests, oil imports and exports of goods and services, also fail to register as drivers of aid allocations with private good character. We therefore conclude that collusion as driver of lead donorship in the private goods realm receives moderate support in the data.

The evidence in the case of aid with public goods characteristics is similarly mixed. Confirming the central tenets of our theory, we find that donors give aid in a more complementary fashion the less likely a recipient country is to have a lead donor. However, we also find that lead donorship increases aid allocations. This unexpected finding points to the role of recipient country needs in the ability of donors to coordinate. Further research is needed 
to clarify this relationship. In addition, we find that richer countries and larger countries receive more public good aid, which is in line with existing research. Also, oil imports and exports of goods and services are associated with higher public goods aid.

\subsection{Conclusion}

This paper presented an analysis of the understudied phenomenon of lead donorship. It introduces a theory that innovates on several accounts. International aid serves many purposes, some of which have public good properties, and some of which generate private benefits to donors. The theory is one of the first to systematically integrate this distinction into the analysis of aid allocations. It also breaks ground by explicitly tying lead donorship to strategic interactions between donors. While there has been some recognition of the importance of these interactions, its role in shaping aid policies remains understudied.

On the empirical side, this paper contributes to our knowledge by developing and applying a new conceptualization of what constitutes lead donorship. The resulting overview of the five biggest providers of bilateral aid (France, Germany, Japan, UK, and USA) since the 1970s shows that diplomatic, commercial, and developmental goals are an important driver of lead donorship.

Going beyond description, the statistical analysis uses a novel setup to test for strategic interactions in the provision of aid with public and private good characteristics, with and without lead donorship. It finds strong evi- 
dence that in the provision of public good aid, lead donorship is associated with a lower degree of coordination between donors than in more symmetric arrangements. This is in line with the theoretical premise that preference asymmetries and a lack of coordination drive lead donorship in the provision of public good aid.

For aid that generates private benefits to donors, the analysis finds that lead donorship leads to increased substitution effects. This provides support for the theoretical claim that in private goods scenarios lead donorship serves to suppress competition between donors. However, the analysis was not able to recover reliable evidence for competitive behavior in the absence of a lead donor.

These findings open up a number of exciting venues for future research. First, we need to come to a more systematic understanding how to measure the different purposes that aid is serving. While the paper introduces a novel distinction of aid with and without public good properties based on sectoral aid allocations, this and related measures should be subjected to systematic evaluation in a variety of settings. The results would greatly benefit the future study of strategic interactions between donors, including those giving rise to lead donorship.

Second, the finding that strategic interactions play an important role in producing lead donorship raises the question which channels, institutional and otherwise, allow donors to coordinate aid provision. To answer this, we need to know more about variation in strategic outcomes. Why is it that donors succeed to coordinate in some cases, but not in others? In the same vein, what role do private benefits play for lead donors who also care 
about development and other public goods? These and other questions have important implications for how aid is given and ultimately whether aid is an effective foreign policy tool. Lead donorship is just one of many facets of contemporary aid practice that is affected by strategic interactions between donors. Looking deeper into the role of strategic interactions promises to improve our understanding of foreign aid policy as a whole. 


\section{Bibliography}

Acemoglu, D., S. Johnson, and J. A. Robinson. 2001. "The Colonial Origins of Comparative Development: An Empirical Investigation." American Economic Review 91:1369-1401.

Acemoglu, D., S. Johnson, and J. A. Robinson. 2002. "Reversal of Fortune: Geography and INstitutions in the Making of the Modern World." Quarterly Journal of Economics 117:1231-1294.

Acemoglu, Daron, and James A. Robinson. 2000. "Why Did The West Extend The Franchise? Democracy, Inequality, and Growth in Historical Perspective." Quarterly Journal of Economics :1167-1199.

Acemoglu, Daron, and James A. Robinson. 2005. Economic Origins of Dictatorship and Democracy. Cambridge: Cambridge University Press.

Aldasoro, Iñaki, Peter Nunnenkamp, and Rainer Thiele. 2009. "Less Aid Proliferation and More Donor Coordination? The Wide Gap between Words and Deeds." Kiel Institute for the World Economy Working Paper 1516. 
Alesina, Alberto, and David Dollar. 2000. "Who Gives Foreign Aid To Whom And Why?" Journal of Economic Growth 5:33-63.

Alesina, Alberto, and Beatrice Weder. 2002. "Do Corrupt Governments Receive Less Foreign Aid?" The American Economic Review 92:11261137.

Alt, James E., Gary King, and Curtis S. Signorino. 2001. "Aggregation Among Binary, Count, and Duration Models: Estimating the Same Quantities from Different Levels of Data." Political Analysis :21-44.

Anselin, Luc. 1988. Spatial Econometrics: Methods and Models. Studies in Operational Regional Science, Springer.

Anselin, Luc. 2002. "Under the Hood: Issues in the Specification and Interpretation of Spatial Regression Models." Agricultural Economics 27:247267.

Anselin, Luc, Julie Le Gallo, and Hubert Jayet. 2008. "Spatial Panel Econometrics." In The Econometrics of Panel Data: Fundamentals and Recent Developments in Theory and Practice, eds. Patrick Sevestre and László Mátyás. New York, NY: Springer, 625-660.

Arcand, Jean-Louis, and Lisa Chauvet. 2001. "Foreign Aid, Rent-Seeking Behavior and Civil War." Working Paper.

Balla, Eliana, and Gina Yannitell Reinhardt. 2008. "Giving and Receiving Foreign Aid: Does Conflict Count?" World Development 36:2566-2585. 
Special Section: Social Movements and the Dynamics of Rural Development in Latin America (pp. 2874-2952).

Bandyopadhyay, Subhayu, and Howard J. Wall. 2007. "The Determinants of Aid in the Post-Cold War Era." Federal Reserve Bank of St. Louis Review 89:533-547.

Beck, Nathaniel, Kristian Skrede Gleditsch, and Kyle Beardsley. 2006. "Space Is More than Geography: Using Spatial Econometrics in the Study of Political Economy." International Studies Quarterly 50:27-44.

Bermeo, Sarah Blodgett. 2008. "Aid Strategies of Bilateral Donors." Paper presented at 2008 Annual Meeting of the International Political Economy Society, Philadelphia.

Besag, Julian. 1975. "Statistical Analysis of Non-Lattice Data." The Statistician 24:179-195.

Bräutigam, Deborah, and Stephen Knack. 2004. "Foreign Aid, Institutions, and Governance in Sub-Saharan Africa." Economic Development and Cultural Change 52:255-285.

Brown, Kaysie, and Stewart Patrick. 2007. Center for Global Development Working Paper 131.

Brueckner, Jan K. 2003. "Strategic Interaction Among Governments: An Overview of Empirical Studies." International Regional Science Review $26: 175-188$. 
Bueno de Mesquita, Bruce, and Alastair Smith. 2007. "Political Development and the Threat of Revolution." Working Paper, New York University.

Bueno de Mesquita, Bruce, Alastair Smith, Randolph H. Siverson, and James D. Morrow. 2003. The Logic of Political Survival. Cambridge, MA: MIT Press.

Buhaug, Halvard, and Jan Ketil Rød. 2006. "Local Determinants of African Civil Wars, 1970-2001." Political Geography 25:315-335.

Burnside, Craig, and David Dollar. 2000. "Aid, Policies, and Growth." American Economic Review 90:847-868.

Carter, David, and Curtis S. Signorino. 2007. "Back to the Future: Modeling Time Dependence in Binary Data." Peace Science Society 2007 North American Meeting.

Clarke, Kevin A., and Randall W. Stone. forthcoming 2008. "Democracy and the Logic of Political Survival." American Political Science Review .

Collier, Paul. 2001. "Economic Causes of Civil Conflict and their Implications for Policy." In Turbulent Peace: The Challenges of Managing International Conflict, eds. Chester A. Crocker, Fen Osler Hampson, and Pamela Aall. Washington, D.C.: U.S. Institute of Peace Press.

Collier, Paul, V. L. Elliott, Håvard Hegre, Anke Hoeffler, Marta ReynalQuerol, and Nicholas Sambanis. 2003. Breaking the Conflict Trap: Civil War and Development Policy. Washington, DC: The World Bank. 
Collier, Paul, and Anke Hoeffler. 1998. "On the Economic Causes of Civil War." Oxford Economic Papers 50:563-573.

Collier, Paul, and Anke Hoeffler. 2000. "Greed and Grievance in Civil War." Policy Research Working Paper 2355.

Collier, Paul, and Anke Hoeffler. 2002. "Aid, Policy and Peace: Reducing the Risks of Civil Conflict." World Bank Working Paper 28125.

Collier, Paul, Anke Hoeffler, and Måns Öderbom. 2004. "On the Duration of Civil War." Journal of Peace Research 41:253-273.

Conley, Timothy, and Francesca Molinari. 2007. "Spatial Correlation Robust Inference with Errors in Location or Distance." Journal of Econometrics 140:76-96.

Conley, Timothy G., and Ethan Ligon. 2002. "Economic Distance and CrossCountry Spillovers." Journal of Economic Growth 7:157-187.

Cumming, Gordon. 2001. Aid to Africa: French and British Policies from the Cold War to the New Millennium. Aldershot: Ashgate.

Department of Defense. 2009. "Personnel \& Procurements Statistics Online." http://siadapp.dmdc.osd.mil/index.html, accessed 10/2/2009.

Doucouliagos, Hristos, and Martin Paldam. 2008. "Aid Effectiveness on Growth: A Meta Study." European Journal of Political Economy 24:124 . 
Dreher, Axel, Peter Nunnenkamp, and Rainer Thiele. 2008. "Does US Aid Buy UN General Assembly Votes? A Disaggregated Analysis." Public Choice 136:139-164.

Easterly, William, Ross Levine, and David Roodman. 2004. "New Data, New Doubts: A Comment on Burnside and Dollar's "Aid, Policies, and Growth"." American Economic Review 94:774-780.

Fearon, James. D. 1995. "Rationalist Explanations for War." International Organization 49(3):379-414.

Fearon, James D., and David D. Laitin. 2003. "Ethnicity, Insurgency, and Civil War." American Political Science Review 97:75-90.

Franzese, Robert J., and Jude C. Hays. 2007a. "Empirical Models of Spatial Interdependence." Working Paper. University of Michigan. Accessed online on 2/2/2010 at https://netfiles.uiuc.edu/jchays/www/ FranzeseHays_OxfordHandbook.pdf.

Franzese, Robert J., and Jude C. Hays. 2007b. "Spatial Econometric Models of Cross-Sectional Interdependence in Political Science Panel and TimeSeries-Cross-Section Data." Political Analysis 15:140-164.

Franzese, Robert J., and Jude C. Hays. 2008. "Interdependence in Comparative Politics: Substance, Theory Empirics, Substance." Comparative Political Studies 41:742-780.

Fudenberg, Drew, and Jean Tirole. 1991. Game Theory. Cambridge, MA: MIT Press. 
Gabas, Jean-Jacques. 2005. "French Development Co-operation Policy." In Perspectives on European Development Co-operation: Policy and Performance of Individual Donor Countries and the EU, eds. Paul Hoebink and Olav Stokke. London: Routledge, 242-267.

Giacomini, Raffaella, and Clive W.J. Granger. 2004. "Aggregation of SpaceTime Processes." Journal of Econometrics 118:7-26.

Gibson, Clark C., Krister Andersson, Elinor Ostrom, and Sujai Shivakumar. 2005. The Samaritan's Dilemma: The Political Economy of Development Aid. Oxford: Oxford University Press.

Gleditsch, Kristian Skrede. 2002. All International Politics is Local: The Diffusion of Conflict, Integration, and Democratization. Ann Arbor: University of Michigan Press.

Gleditsch, N.P., P. Wallensteen, P. Eriksson, M. Sollenberg, and H. Strand. 2002. "Armed Conflict 1946-2001: A New Dataset." Journal of Peace Research 39:615-637.

Greene, William H. 2003. Econometric Analysis. Fifth ed. Upper Saddle River: Prentice Hall.

Grossman, Gene M., and Elhanan Helpman. 1994. "Protection for Sale." American Economic Review 84:833-850.

Grossman, H.I. 1991. "A General Equilibrium Theory Model of Insurrections." American Economic Review 81:912-921. 
Grossman, H.I. 1992. "Foreign Aid and Insurrection." Defence Economics $3: 275-288$.

Grossman, H.I. 1999. "Kleptocracy and Revolutions." Oxford Economic Papers 51:267-283.

Hanson, Stephanie. 2008. "China, Africa, and Oil." Council on Foreign Relations Backgrounder. http://www.cfr.org/publication/9557, accessed $10 / 20 / 2009$.

Hjertholm, Peter, and Howard White. 2000. "Foreign Aid In Historical Perspective: Background and Trends." In Foreign Aid and Development: Lessons Learnt and Directions for the Future, ed. Finn Tarp. London: Routledge, 80-102.

Hoebink, Paul, and Olav Stokke. 2007. Perspectives on European Development Co-operation: Policy and Performance of Individual Donor Countries and the EU. London: Routledge.

Hook, Steven W., and Guang Zhang. 1998. "Japan's Aid Policy since the Cold War: Rhetoric and Reality." Asian Survey 38:1051-1066.

Huffer, Fred W., and Hulin Wu. 1998. "Markov Chain Monte Carlo for Autologistic Regression Models with Application to the Distribution of Plant Species." Biometrics 54:509-524.

Jaeger, William K. 1992. "The Effects of Economic Policies on African Agriculture." World Bank Discussion Paper 147. 
Jepma, Catrinus J. 1991. The Tying of Aid. Paris: OECD Development Centre.

Kasara, Kimuli. 2007. "Tax Me If You Can: Ethnic Geography, Democracy and the Taxation of Agriculture in Africa." American Political Science Review 101:159-172.

Kelly, Sean. 1993. America's Tyrant: The CIA and Mobutu of Zaire. Washington, D.C.: American University Press.

King, Gary, Michael Tomz, and Jason Wittenberg. 2000. "Making the Most of Statistical Analysis: Improving Interpretation and Presentation." American Journal of Political Science 44:341-355.

Knack, Stephen, and Phillip Keefer. 1995. "Institutions and Economic Performance: Cross-Country Tests Using Alternative Institutional Measures." Economics and Politics 7:942-963.

Knack, Stephen, and Aminur Rahman. 2007. "Donor fragmentation and bureaucratic quality in aid recipients." Journal of Development Economics $83: 176-197$.

Lancaster, Carol. 2000. "Redesigning Foreign Aid." Foreign Affairs 79:7488.

Lancaster, Carol. 2007. Foreign Aid: Diplomacy, Development, Domestic Politics. Chicago: University of Chicago Press.

Lebovic, James H. 2005. "Donor Positioning: Development Assistance from 
the U.S., Japan, France, Germany, and Britain." Political Research Quarterly :119-126.

Lewis, Jeffrey B., and Kenneth A. Schultz. 2003. "Revealing Preferences: Empirical Estimation of a Crisis Bargaining Game with Incomplete Information." Political Analysis 11:345-367.

Martens, Bertin. 2005. "Why Do Aid Agencies Exist?" Development Policy Review 23:643-663.

Mascarenhas, Raechelle, and Todd Sandler. 2006. "Do Donors Cooperatively Fund Foreign Aid?" Review of International Organizations 1:337-357.

Mount, Graeme Stewart, and Mark Gauthier. 2006. 895 Days that Changed the World: The Presidency of Gerald R. Ford. Black Rose Books.

Murdoch, James C., Todd Sandler, and Keith Sargent. 1997. "A Tale of Two Collectives: Sulphur versus Nitrogen Oxides Emisssion Reduction in Europe." Economica 64:281-301.

Murdoch, James C., Todd Sandler, and Wim P. M. Vijverberg. 2003. "The Participation Decision Versus the Level of Participation in an Environmental Treaty: A Spatial Probit Analysis." Journal of Public Economics $87: 337-362$.

Neumayer, Eric. 2003. "Do Human Rights Matter in Bilateral Aid Allocation? A Quantitative Analysis of 21 Donor Countries." Social Science Quarterly 84:650-666. 
OECD. 2006. International Development Statistics on CD ROM. Paris: OECD Publishing.

OECD. 2008a. Country Statistical Profiles. http://webnet.oecd.org/wbos/ index.aspx.

OECD. 2008b. Creditor Reporting System Online. http://www.oecd.org/document/0/0,2340,en_2649_34447_37679488_1_1_1 _1,00.html.

OECD. 2009. International Development Statistics on CD ROM. Paris: OECD Publishing.

OECD DAC. 2007a. Aid at a Glance. http://www.oecd.org/countrylist/ 0,3349,en_2649_33721_25602317_1_1_1_1,00.html\#G.

OECD DAC. 2007b. International Development Statistics. http://stats.oecd.org/wbos/default.aspx?DatasetCode=TABLE\%202A.

Olson, Jr., Mancur, and Richard Zeckhauser. 1966. "An Economic Theory of Alliances." The Review of Economics and Statistics 48:266-279.

Ostrom, Elinor, Larry Schroeder, and Susan Wynne. 1993. Institutional Incentives and Sustainable Development: Infrastructure Policies in Perspective. Boulder, CO: Westview Press.

Páez, Antonio, and Darren M. Scott. 2004. "Spatial Statistics for Urban Analysis: A Review of Techniques With Examples." GeoJournal 61:5367. 
Pezzullo, Ralph. 2006. Plunging into Haiti: Clinton, Aristide, and the Defeat of Diplomacy. University Press of Mississippi.

Przeworski, Adam, Michael E. Alvarez, José Antonio Cheibub, and Fernando Limongi. 2000. Democracy and Development: Political Institutions and Well-Being in the World, 1950-1990. Cambridge: Cambridge University Press.

Quinn, John James, and David J. Simon. 2006. "Plus ca change,...: The Allocation of French ODA to Africa during and After the Cold War." International Interactions 32:295-318.

Sachs, Jeffrey D., and Andrew Warner. 1995. "Economic Reform and the Process of Global Integration.” .

Sambanis, Nicholas. 2001. "Do Ethnic and Nonethnic Civil Wars Have the Same Causes? A Theoretical and Empirical Inquiry (Part 1)." Journal of Conflict Resolution 45:259-282.

Seldon, Anthony. 2007. Blair's Britain: 1997 - 2007. Cambridge: Cambridge University Press.

Signorino, Curtis. 1999. "Strategic Interaction and the Statistical Analysis of International Conflict." American Political Science Review 93:279-298.

Signorino, Curtis S. 2003. "Structure and Uncertainty in Discrete Choice Models." Political Analysis 11:316-344.

Stone, Randall W. 2006. "Buying Favors: The Political Economy of Bilat- 
eral Development Assistance." presented at Annual International Studies Association Convention, San Diego, CA.

The World Bank Group. 2009. World Development Indicators Online. Washington, DC: The World Bank Group. http://go.worldbank.org/6HAYAHG8H0.

Thorbecke, Erik. 2000. "The Development Doctrine and Foreign Aid, 19502000." In Foreign Aid and Development: Lessons Learnt and Directions for the Future, ed. Finn Tarp. London: Routledge, 17-47.

Tuman, John P., Jonathan R. Strand, and Craig F. Emmert. 2009. "The Disbursement Pattern of Japanese Foreign Aid: A Reappraisal." Journal of East Asian Studies 9:219-248.

United Nations. 2009. United Nations Commodity Trade Statistics Database. hhttp://comtrade.un.org/db/default.aspx. Accessed on 20 July 2009.

Varian, Hal R. 1992. Microeconomic Analysis. 3rd ed. New York: Norton.

Vaubel, Roland. 1986. "A Public Choice Approach to International Organization." Public Choice 51:39-57.

Ward, Michael D., and Kristian Skrede Gleditsch. 2002. "Location, Location, Location: An MCMC Approach to Modeling the Spatial Context of War and Peace." Political Analysis 10:244-260.

World Bank. 1998. Assessing Aid: What Works, What Doesn't, and Why. Washington, DC: The World Bank. 
Yergin, Daniel. 1991. The Prize: The Epic Quest for Oil, Money and Power. New York: Free Press.

Younas, Javed. 2008. "Motivation for Bilateral Aid Allocation: Altruism or Trade Benefits." European Journal of Political Economy 24:661-674. 


\section{Appendices}

\section{Appendix to Chapter 1}

Theorem: There exists a unique Perfect Bayesian Equilibrium

$\left(t^{*}, a^{*}(t), m^{*}(t, a), r^{*}(t, a, m)\right)$, which for all configurations of parameters takes on one of the following forms: deterministic war $(1,0,0, f)$ if $p(\tilde{m}(t)) t+$ $\tilde{m}(t)<\underline{m}(t)$; deterministic peace $(\underline{t}, 0,0, \sim f)$ if $\bar{t}<\underline{t}$; probabilistic war if $\phi<\underline{m}(t)$ with equilibrium strategies $(\hat{t}, 0,0, f)$ if $\bar{t} \geq \underline{t}, \hat{t}<1$ and $\hat{t} \leq \bar{t}$; $(\bar{t}, 0,0, f)$ if $\bar{t} \geq \underline{t}, \bar{t}<1$ and $\bar{t} \leq \hat{t}$; or $(1,0,0, f)$ if $\bar{t} \geq \underline{t}$, and $\hat{t}, \bar{t} \geq 1$; probabilistic peace if $\phi \geq \underline{m}(t)$ with equilibrium strategies $(\hat{t}, \underline{m}(\hat{t}), \underline{m}(\hat{t}), \sim f)$, $(\bar{t}, \underline{m}(\bar{t}), \underline{m}(\bar{t}), \sim f)$, or $(1, \underline{m}(1), \underline{m}(1), \sim f)$, conditioned as in probabilistic war.

Proof: I will establish uniqueness and the exhaustiveness of the equilibrium characteristics through backwards induction.

$R$ won't fight if peace is at least as good as fighting:

$$
\begin{gathered}
U_{R}(\sim f) \geq U_{R}(f), \\
p(m) t \leq c,
\end{gathered}
$$


where $p \in[0,1], p^{\prime}(m)<0$, and $p^{\prime \prime}(m) \geq 0$. Thus $r^{*}(t, a, m)=\sim f$ if and only if (3.8) holds, and $r^{*}(t, a, m)=f$ otherwise.

$G$ 's optimal choice $m^{*}$ satisfies

$$
\begin{gathered}
m^{*}(t, a)=\arg \max \begin{cases}{[1-p(m)] t+a-m} & \text { if } m<\underline{m}(t), \\
t+a-m & \text { if } m \geq \underline{m}(t),\end{cases} \\
\text { s.t. } 0 \leq m \leq a,
\end{gathered}
$$

where $\underline{m}(t)=p^{-1}(c / t)$, i.e. $\underline{m}(t)$ satisfies (3.8) with equality.

$G$ 's faces the budget constraint $m \leq a$. We need to consider three cases. First let $a \geq \underline{m}(t)$. In the upper range of $m$, where $m \geq \underline{m}(t)$, utility is maximized at $\underline{m}(t)$. For the lower range, $m<\underline{m}(t)$, the maximum, call it $\tilde{m}(t)$, lies either at an interior point, call it $\hat{m}(t)$, or on the constraint 0 , i.e. $\tilde{m}(t)=\max [0, \hat{m}(t)]$. The interior solution $\hat{m}$ is given by $\hat{m}=(D p)^{-1}(-1 / t)$. $G$ chooses optimally between the maximizers of both ranges. On this path of play, $G$ 's peace condition therefore is

$$
\begin{array}{r}
U_{G}(\underline{m}(t)) \geq U_{G}(\tilde{m}), \\
p(\tilde{m}(t)) t+\tilde{m}(t) \geq \underline{m}(t) .
\end{array}
$$

Second, let $\tilde{m}(t) \leq a<\underline{m}(t)$. G's choice is now constrained to the lower range of $m$. The maximum is either at the interior solution $\tilde{m}$ or at 0 . On this path of play there is always war.

Finally, let $a<\tilde{m}$. The maximum now lies on either the upper constraint 
$a$, or the lower constraint 0 . This path of play also always leads to war.

$D$ 's optimal choice $a^{*}(t)$ satisfies

$$
\begin{aligned}
& a^{*}(t)=\arg \max \begin{cases}-a & \text { if } m^{*}(t, a)<\underline{m}(t), \\
\phi-a & \text { if } m^{*}(t, a) \geq \underline{m}(t),\end{cases} \\
& \text { s.t. } 0 \leq a .
\end{aligned}
$$

In the range $m^{*}(t, a) \geq \underline{m}(t)$, we always have $m^{*}(t, a)=\underline{m}(t)$ since the government will not spend more than necessary to keep the peace. Thus the maximum lies on the constraint $\underline{m}(t)$, as the donor won't give any aid that is not spend on deterrence. This is on the paths of play that lead to peace (both deterministic and probabilistic) . For $m^{*}(t, a)<\underline{m}(t)$, the maximum again is the corner solution, $a^{*}=0$. Similarly, this is on the paths of play that lead to war (both deterministic and probabilistic). This gives us the first part of D's aid condition (the two parts are necessary and jointly sufficient):

$$
\begin{aligned}
U_{D}(\underline{m}(t)) & \geq U_{D}(0) \\
\phi & \geq \underline{m}(t) .
\end{aligned}
$$

The second part of the aid condition is identical to (3.12), G's peace condition. $D$ will only provide aid if $G$ uses it to preserve stability. 
In it's first move, $G$ chooses $t^{*}$, satisfying

$$
t^{*}=\arg \max \left\{\begin{array}{rr}
q\left(\left[1-p\left(m_{\text {war }}^{*}(t, a)\right)\right] t+a_{\text {war }}^{*}(t)-m_{\text {war }}^{*}(t, a)\right) & \\
+(1-q)\left(t+a_{\text {peace }}^{*}(t)-m_{\text {peace }}^{*}(t, a)\right), & \text { if } t \leq \bar{t} \\
{\left[1-p\left(m_{\text {war }}^{*}(t, a)\right)\right] t+a_{\text {war }}^{*}(t)-m_{\text {war }}^{*}(t, a),} & \text { if } t>\bar{t}
\end{array}\right.
$$

$$
\text { s.t. } t \in[0,1], q \in[0,1] \text {, }
$$

where $q=\operatorname{Pr}(\phi<\underline{m}(t))=F_{x}(\underline{m}(t))$ is the probability of war, and the subscripts war and peace indicate the players' optimal strategies in the respective subgames. The value $\bar{t}$ represents the highest value of $t$ for which the second part of $D$ 's aid condition still holds. It thus is the value of $t$ that solves (3.12) with equality. For $t>\bar{t}$ the path of play leads to deterministic war.

We need to show that $\bar{t}$ properly partitions the intervals of the maximization problem. Recall the second part of $D$ 's aid condition this is given by (3.12):

$$
p(\tilde{m}(t)) t+\tilde{m}(t) \geq \underline{m}(t) .
$$

Take any $t$ that satisfies (3.19), call it $\tau$. It is sufficient to show that the left-hand side (LHS) and right-hand side (RHS) of (3.19) cross at most once for all $t>\tau$. Recall that $\underline{m}(t)=p^{-1}(c / t)$. Since $p$ is strictly decreasing and convex, we know that $\underline{m}(t)$ is strictly increasing in $t$. Whether $\underline{m}(t)$ is convex or concave depends on the functional form of $p(m)$. Now recall 
$\tilde{m}=\max \left[0,(D p)^{-1}(-1 / t)\right] . \quad \tilde{m}$ is thus increasing and concave in $t$. Since $p(\tilde{m}(t)) t$ is strictly concave, we know that the entire LHS of (3.19) is strictly concave in $t$, albeit possibly decreasing. Since LHS $>$ RHS at $\tau$, the RHS is strictly increasing, and the LHS is strictly concave, LHS and RHS cross at most once for all $t>\tau$.

The Government's optimization problem breaks down into two ranges of $t$ that lead to three different paths of play: For the lower range of $t$, the corner solution at $q=0$ leads to deterministic peace. Probabilistic war/peace $(q \in(0,1))$ results from either the interior solution, call it $\hat{t}$, the corner solution at $t=1$, or the corner solution at $t=\bar{t}$. Finally, for $t>\bar{t}$ the path of play leads to deterministic war.

The tax rate associated with the corner solution $q=0$ is given by

$$
\begin{array}{r}
\underline{m}(\underline{t})=p^{-1}(c / \underline{t})=0, \\
\underline{t}=c / p(0) .
\end{array}
$$

We need to distinguish two more cases. First, if (3.19) does not bind, i.e. $1<\bar{t}$, the maximum is either the interior solution $\hat{t}$ or the upper corner solution 1. Second, if $\bar{t}<1$, the maximum lies either at $\hat{t}$, or at $\bar{t}$.

Let us turn to the upper range of $t$, where $t>\bar{t}$, on the deterministic war path of play. $G$ 's optimal choice lies at the constraint, 1.

It depends on the parametric forms of $p(m)$ and $f_{x}(x)$ which paths of play can be attained within the natural bounds of $t$. $G$ compares the maximum expected payoffs generated for each feasible path of play. Equilibrium strategies for deterministic peace are $(\underline{t}, 0,0, \sim f)$, equilibrium strategies 
for probabilistic peace are either $(\hat{t}, m(\hat{t}), m(\hat{t}), \sim f),(\bar{t}, m(\bar{t}), m(\bar{t}), \sim f)$, or $(1, m(1), m(1), \sim f)$. Equilibrium strategies for probabilistic war are $(\hat{t}, 0,0, f),(\bar{t}, 0,0, f)$, or $(1,0,0, f)$. Equilibrium strategies for deterministic war are $(1,0,0, f)$. 


\section{Appendix to Chapter 3}

Table 3.9: List of CRS Codes, Private Good Aid

Code Description

11110 Education policy and administrative management

12110 Health policy and administrative management

13010 Population policy and administrative management

14010 Water resources policy and administrative management

15110 Economic and development policy/planning

15140 Government administration

160 Other social infrastructure and services, all sub-codes

21010 Transport policy and administrative management

22010 Communications policy and administrative management

23010 Energy policy and administrative management

24010 Financial policy and administrative management

25010 Business support services and institutions

25020 Privatisation

31110 Agricultural policy and administrative management

31210 Forestry policy and administrative management

31310 Fishing policy and administrative management

32110 Industrial policy and administrative management

322 Mineral resources and mining, all sub-categories

32310 Construction policy and administrative management

33110 Trade policy and administrative management

33181 Tourism policy and administrative management

41010 Environmental policy and administrative management

43030 Urban development and management

43040 Rural development

51010 General budget support

53030 Import support (capital goods)

53040 Import support (commodities) 